\title{
Water Quality Modeling in the Systems Impact Assessment Model for the Klamath River Basin - Keno, Oregon to Seiad Valley, California
}

Open File Report 99-113

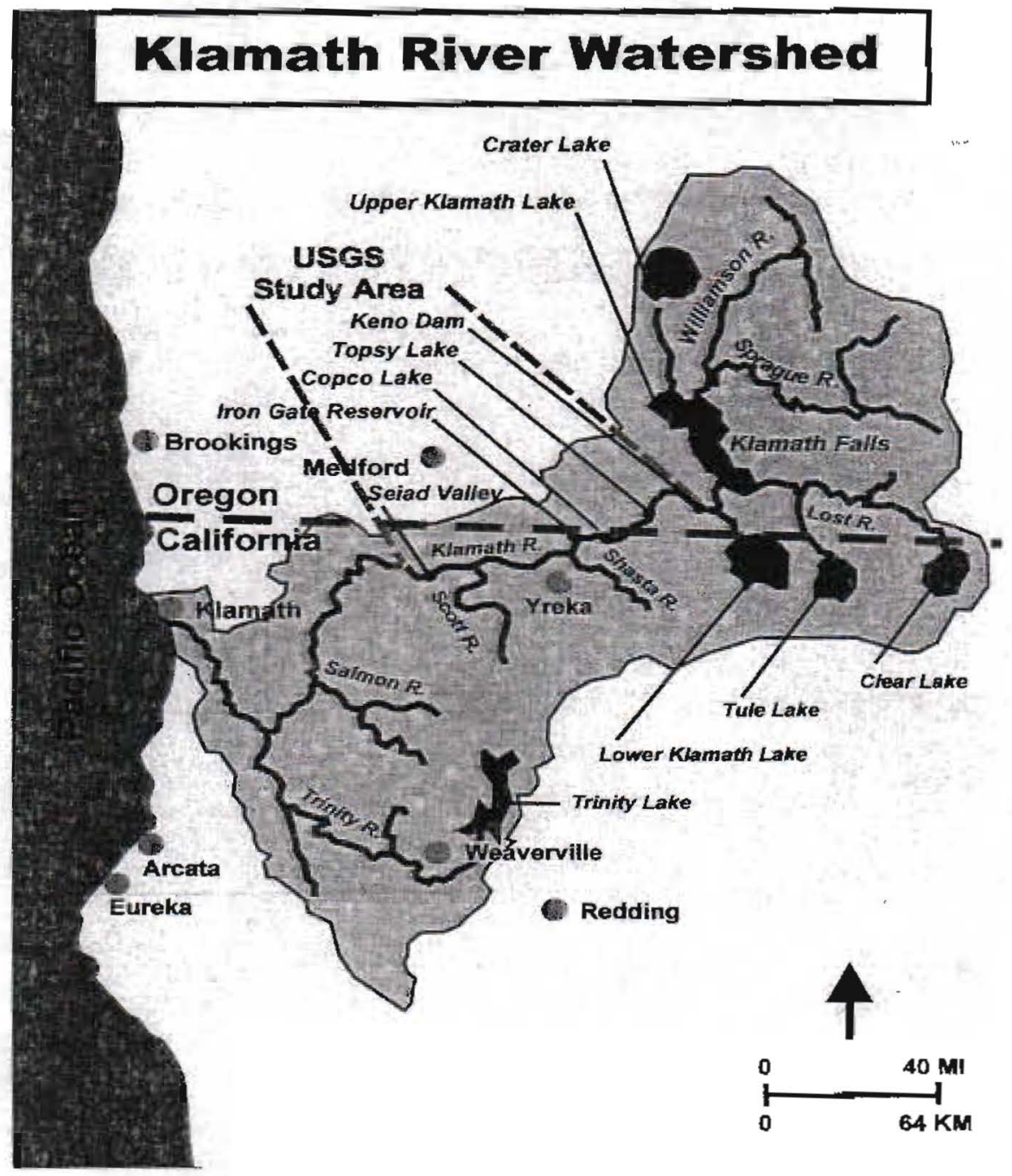

U.S. Department of the Interior U.S. Geological Survey

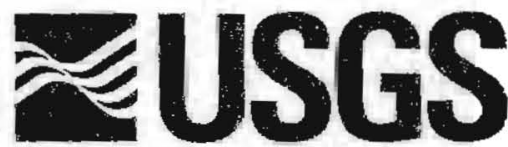

science for a changing world
Prepared in Cooperation with U.S. Bureau of Reclamation North Coast Regional Water Quality Control Board University of California at Davis and Pacificorp 


\title{
U.S. DEPARTMENT OF THE INTERIOR
}

\author{
U.S. GEOLOGICAL SURVEY
}

\begin{abstract}
Water Quality Modeling in the Systems Impact Assessment Model for the Klamath River Basin - Keno, Oregon to Seiad Valley, California.
\end{abstract}

By

R. Blair Hanna ${ }^{1}$ and Sharon G. Campbell ${ }^{2}$

May 2000

Open-File Report 99-113

${ }^{1}$ Johnson Controls World Services, 4512 McMurry Avenue, Fort Collins, CO 80525

${ }^{2}$ USGS/BRD, 4512 McMurry Avenue, Fort Collins, CO 80525

This report is preliminary and has not been reviewed for conformity with U.S. Geological Survey editorial standards (or with the North American Stratigraphic Code). Any use of trade, product, or firm names is for descriptive purposes only and does not imply endorsement by the U.S. Government.

Midcontinent Ecological Science Center

4512 McMurry Avenue

Ft. Collins, CO 80525-3400 


\section{Table of Contents}

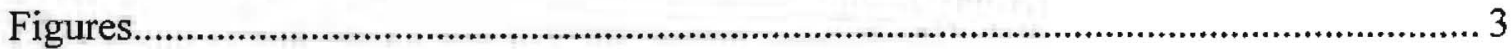

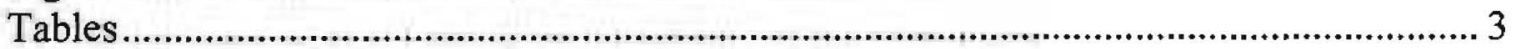

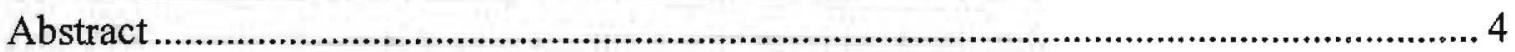

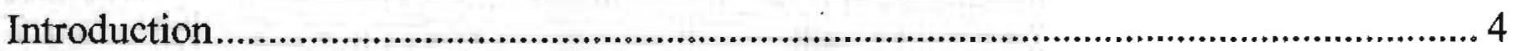

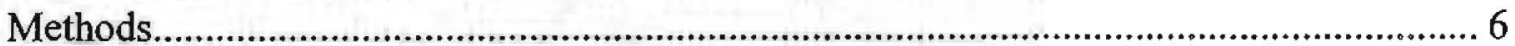

Overview of Water Quality Modeling Methods......................................................... 6

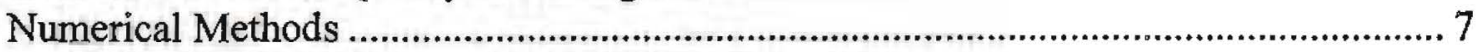

Modeling River and Reservoir Systems .............................................................. 8

Development of the Water Quality Model for the Klamath Basin................................ 10

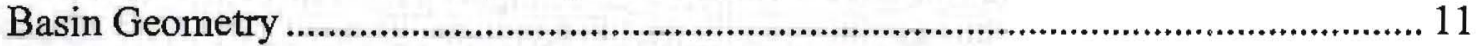

Basin Hydrology Used by the Water Quality Model .............................................. 12

Additional Water Quality Model Input Data.............................................................. 13

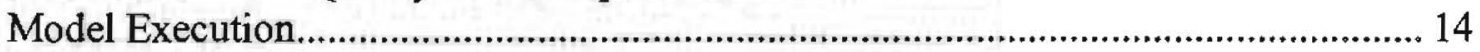

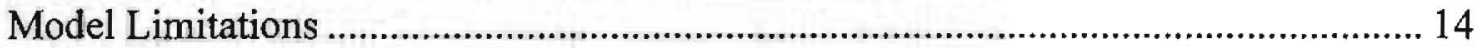

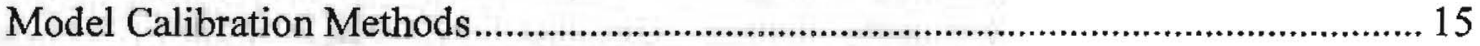

Model Calibration-Calendar Year 1996 .................................................................. 19

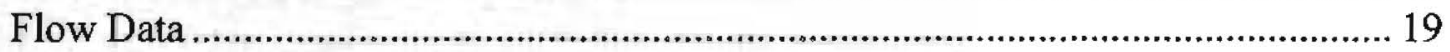

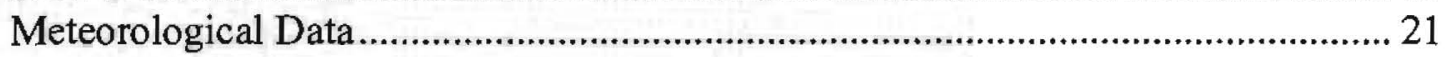

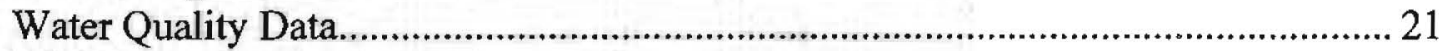

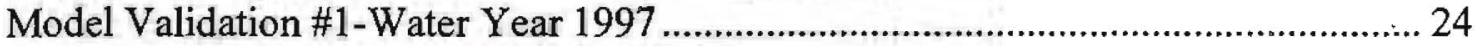

Model Validation \#2- Calendar Year 1998 .................................................................. 27

Measures of Goodness of Fit of Model Predictions to Measured Data ......................... 29

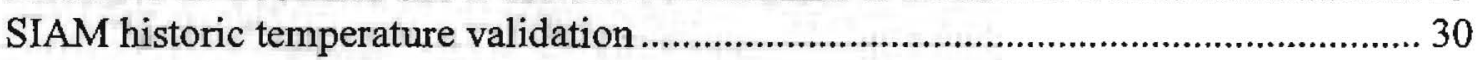

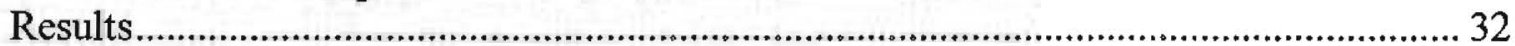

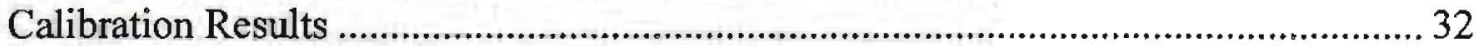

Model Validation \#1 Goodness of Fit ..................................................................... 33

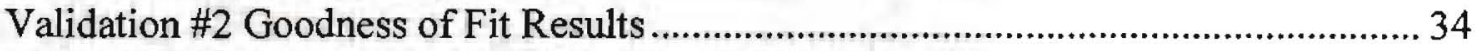

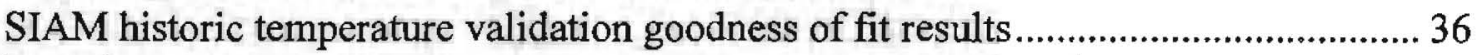

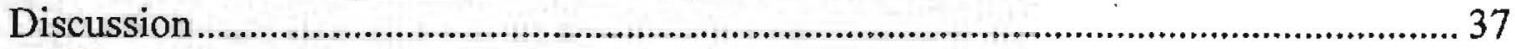

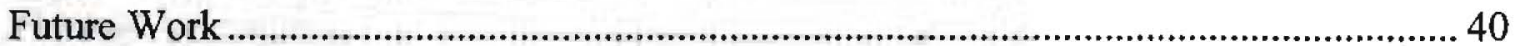

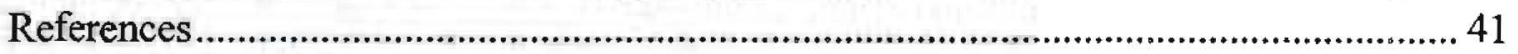

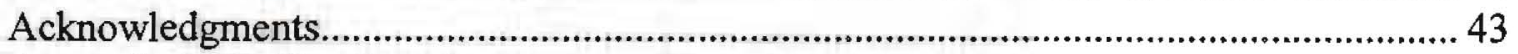

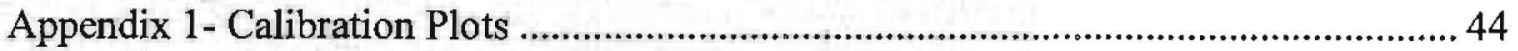

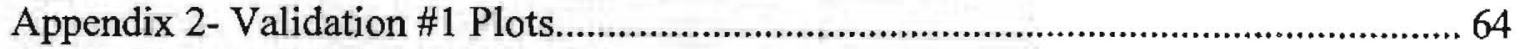

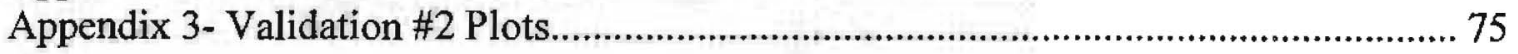




\section{Figures}

Figure 1. Klamath Basin watershed map

Figure 2. Computational elements within a one-dimensional river and reservoir water quality model

Figure 3. The Klamath Basin water quality model domain .......................................... 11

Figure 4. Creation of trapezoidal cross sections from measured data ............................ 12

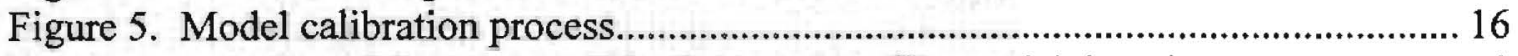

Figure 6. Location of flow data within the water quality model domain .......................20

Figure 7. Location of water quality data used for 1996 calibration.................................22

Figure 8. Estimated Keno water quality data for water year 1997 ................................ 27

Figure 9. Comparison of Keno datasonde data with data from Shasta and Scott Rivers for calendar year 1998

Figure 10. Representative output for Iron Gate and Seiad from the SIAM historical validation

\section{Tables}

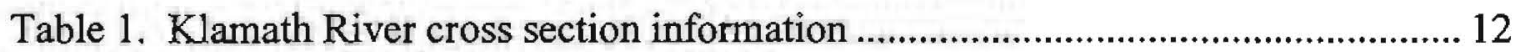

Table 2. USGS river gages used for flow data............................................................. 19

Table 3. Reservoir temperature and transport tuning parameter values .......................... 23

Table 4. Seasonal BOD calibration values for inflow waters to the Klamath River ....... 23

Table 5. Adjustment factors for Medford meteorological data for use in HEC5Q......... 30

Table 6. Days of months used for computation of daily flow in cubic feet per second used by HEC5Q ......................................................................................... 31

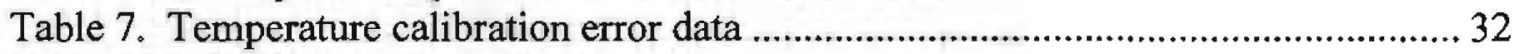

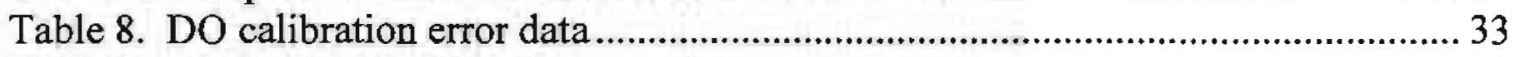

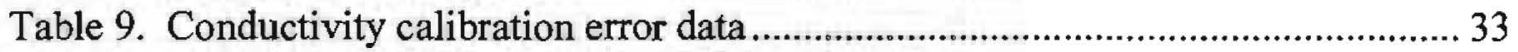

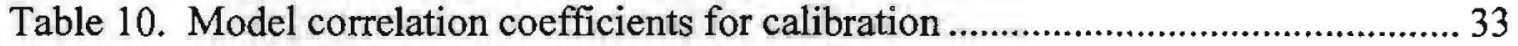

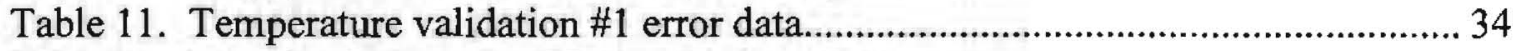

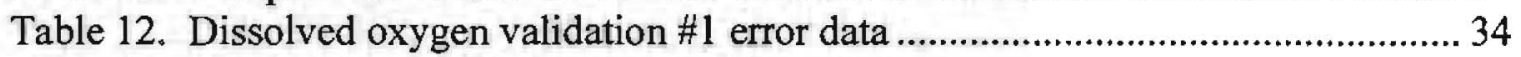

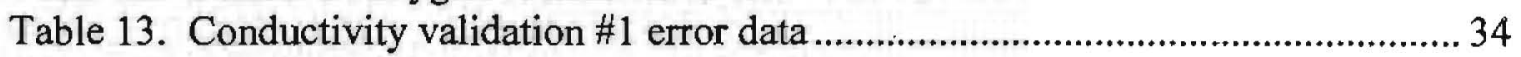

Table 14. Model correlation coefficients for validation \#1 ............................................ 34

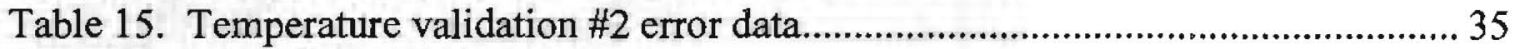

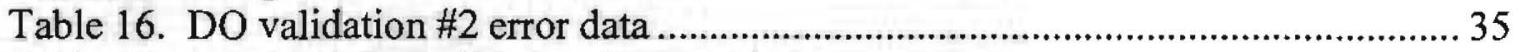

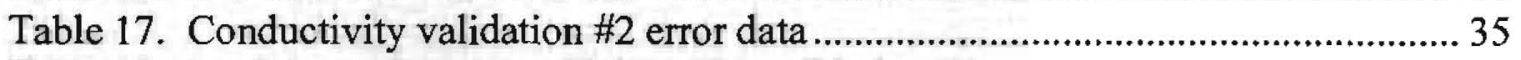

Table 18. Model correlation coefficients for validation $\# 2$.......................................... 35

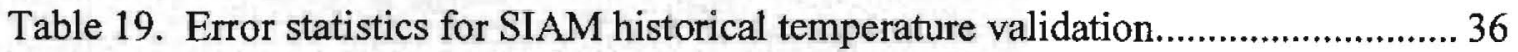

Table 20. Water quality model predictive estimates.................................................... 38

Table 21. Model predictive ability for each constituent ............................................... 38 


\begin{abstract}
This report describes the water quality model developed for the Klamath River System Impact Assessment Model (SIAM). The Klamath River SIAM is a decision support system developed by the authors and other US Geological Survey (USGS), Midcontinent Ecological Science Center staff to study the effects of basin-wide water management decisions on anadromous fish in the Klamath River. The Army Corps of Engineers' HEC5Q water quality modeling software was used to simulate water temperature, dissolved oxygen and conductivity in 100 miles of the Klamath River Basin in Oregon and California. The water quality model simulated three reservoirs and the mainstem Klamath River influenced by the Shasta and Scott River tributaries. Model development, calibration and two validation exercises are described as well as the integration of the water quality model into the SIAM decision support system software. Within SIAM, data are exchanged between the water quantity model (MODSIM), the water quality model (HEC5Q), the salmon population model (SALMOD) and methods for evaluating the ecosystem health. The overall predictive ability of the water quality model is described in the context of calibration and validation error statistics. Applications of SIAM and the water quality model are described.
\end{abstract}

\title{
Introduction
}

The Klamath River, originating in southern Oregon and its main tributary the Trinity River, both flow in northern California and west to the Pacific Ocean (Figure 1). These rivers were placed under the California and National Wild and Scenic Rivers Systems to protect their outstanding anadromous fishery values. In addition, Congress established the Klamath River Basin Fishery Resources Restoration Act of 1986 (16 U.S.C. 460ss), to provide fishery resources necessary for Indian subsistence and ceremonial purposes, ocean commercial harvest, recreational fishing, and the economic health of many local communities. In further support of this Act, Public Law 99-552 was created on October 1, 1986 (100 Stat. 3080.). This Law authorized a twenty year long Federal-State cooperative Klamath River Basin Conservation Area Restoration Program to rebuild the river's fish resources. In the Act, Congress recognized that flooding, land use, and river basin development significantly reduced anadromous fish habitat in the Klamath-Trinity River System. Land use changes include mining, timber harvest, and road building, while river basin development encompasses the construction and operation of dams, diversions, and hydroelectric projects. These changes have contributed to sedimentation, altered flows, and degraded water quality (particularly water temperature) throughout much of the Klamath Basin. 


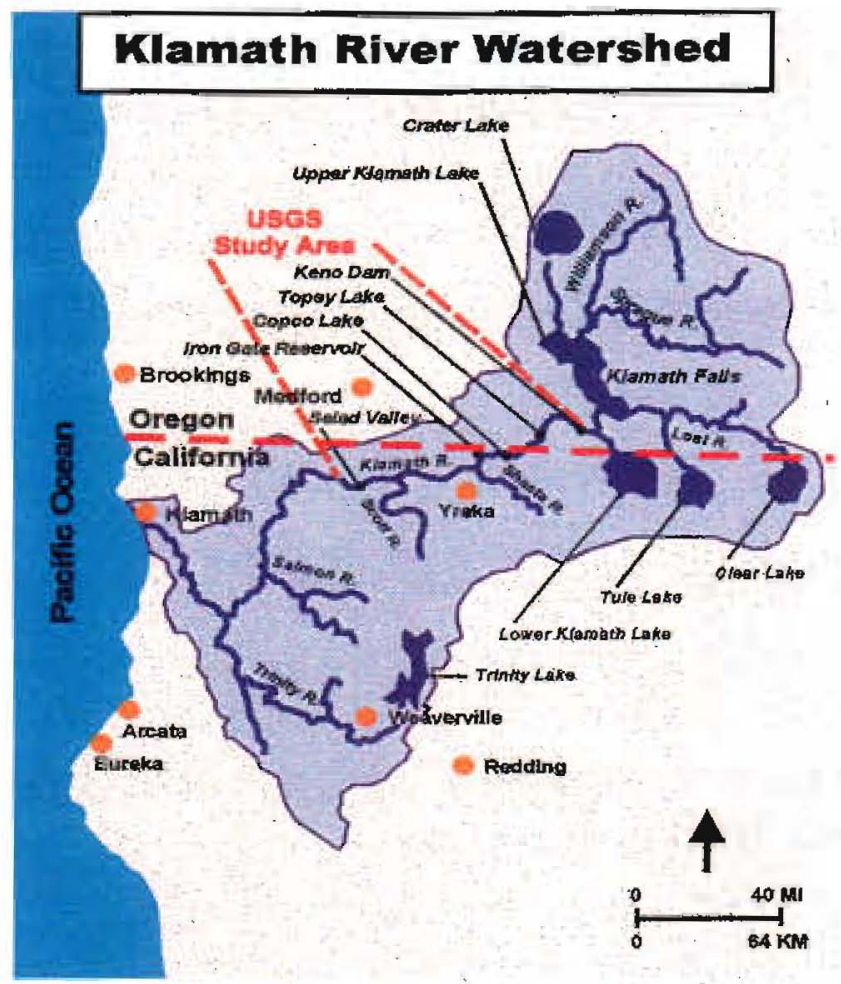

Figure 1. Klamath Basin watershed map

Historically, Upper Klamath Lake was naturally composed of extensive marsh and wetlands. It is located in the Pacific Flyway and had the reputation as the largest North American habitat for migrating waterfowl. Much of the marsh and wetlands have been drained and converted to cultivatable agricultural lands. The US Bureau of Reclamation (BOR) manages the Klamath Reclamation Project that supplies $493 \mathrm{Mm}^{3}$ of water annually to 73,000 ha of cultivated land in the upper basin.

PacifiCorp operates 4 hydroelectric projects within the study reach: Link River (circa 1895), J.C. Boyle (1958), Copco (1917) and Iron Gate Dam (1962). Copco is a peaking release power plant with minimal ability to ramp releases through the turbines either upward to operating level or downward for shut down. In 1962, Iron Gate Dam was built as a re-regulating reservoir for Copco's peaking power releases and a FERC (Federal Energy Regulatory Commission) minimum flow release schedule was imposed. The FERC flow schedule has been modified several times by variances such as the US Fish and Wildlife Service (FWS) Biological Opinions of 1992 and 1996, and continues to be re-evaluated as more scientific studies and data analysis become available. Water use issues in the Klamath Basin are further complicated by unresolved interstate, intrastate, and Native American reserved water rights. Flug and Scott (1998) provide a more detailed history of water development in the Klamath Basin.

Since 1994, the authors and other US Geological Survey (USGS), Midcontinent Ecological Science Center staff, have partnered with the Klamath River Basin Fishery Task Force (TF) and its Technical Work Group (TWG) to develop a better scientific understanding of the water quantity and quality problems limiting anadromous fish restoration. USGS-MESC bas developed a Systems Impact Assessment Model that integrates water quantity, water quality, habitat, and fish production components to 
quantify the biological, physical, chemical and economic consequences of changes in water management operations in the Klamath Basin. The fundamental use for individual models and SIAM is the evaluation of alternative water management operational schemes put forth for the conservation, protection, and restoration of anadromous fish.

The SIAM software is a decision support system which includes: a water quantity model, MODSIM (Labadie, 1988); the water quality model, HEC5Q (USACOE, 1986); a salmon population model, SALMOD (Bartholow and others, 1997); and an evaluation of ecosystem health based on water quantity and quality (SIAM 'red flags'). Within SIAM, the MODSIM water allocation model provides all hydrologic data. The SIAM software provides all supporting data for the water quality model. SALMOD and the ecosystem health component use output from the water quantity and water quality models. For more information on the SIAM system, see Bartholow (1998).

This report provides a complete description of the development of the water quality model used within SIAM. Two previous reports created during the development process: Hanna (1997) and Hanna (1998) provide details of work-in-progress and include some additional information.

\section{Methods}

\section{Overview of Water Quality Modeling Methods}

A water quality model is a mathematical representation of the physical and chemical processes that affect water quality. By representing the processes that effect changes in water quality as a mathematical expression, computer programs implementing numerical methods can be used to predict values of water quality constituents through time.

The basic equation generally used to describe changes in water quality is called the advection-diffusion-reaction equation. This is a partial differential equation commonly used in water quality modeling as well as groundwater transport and air pollution models. A general form of the one-dimensional advection-diffusion-reaction equation is presented in equation 1.

Where:

$$
\frac{\partial C}{\partial}=-v \frac{\partial C}{\partial x}+D \frac{\partial^{2} C}{\partial x^{2}} \pm f(C)
$$

$\mathrm{C}$ is concentration of a water quality constituent

$t$ is time dimension

$\mathrm{x}$ is the physical dimension

$v$ is the water velocity

$\mathrm{D}$ is the coefficient of diffusion

$f(C)$ is a generalized 'reaction' expression for the increase or decrease

in concentration based on outside influences 
The terms of the equation can also be described in words, as follows:

The change in concentration over time $=$ change in concentration due to water movement or advection, change in concentration due to diffusion and mixing of water, gain and loss of concentration due to generalized 'reactions' and/or interactions with the atmosphere. This reaction is usually a function of the current concentration.

The above expression is presented in a very general form that can be used to quantify the concentration of one water quality constituent. Note that water temperature is also considered to be a water quality constituent and is modeled by the advectiondiffusion-reaction equation. Due to the different 'reaction' terms for different constituents, specific equations are required for each constituent modeled.

\section{Numerical Methods}

The advection-diffusion-reaction equation describes the change in water quality in space and time (i.e., along the river or vertically within the reservoir and throughout the course of the year). This equation is a complex partial differential equation that is best solved using numerical methods. Although the equation is a representation of the change in water quality over continuous time and continuous space, numerical methods require that this equation be solved by dividing both time and space into increments. The numerical methods used to solve this partial differential equation use finite difference approximations for the derivative terms, where the derivatives exist in both time and space.

The basic premise of the finite difference approximation used in computational water quality modeling is the division of the water body (i.e., river or reservoir) into computational elements. A computational element is a section of the river or reservoir where it is assumed that the water is of constant quality. The computational element is a division of space. This water quality is also assumed constant for a time period. Given this assumption, the advection-diffusion-reaction equation can be written to describe the change in water quality within a computational element. A mass balance approach is used, whereby all inflows and outflows of mass to/from all interconnected computational elements are defined. This results in a set of equations and a set of unknown concentrations that are solved using numerical methods. Water quality modeling software therefore builds the set of equations based on input data and simultaneously solves the set of equations repeatedly as a simulation is performed.

Since the advection-diffusion-reaction equation expresses changes in concentration throughout time, the solution method also requires that time be broken up into increments or timesteps. A timestep can be hours, days or months. The solution method used in water quality modeling solves for the set of concentrations for all computational elements at each timestep. 


\section{Modeling River and Reservoir Systems}

Water quality models such as the HEC5Q model are used to describe river and reservoir systems; computational elements are connected in one dimension, in the direction of change in water quality and water transport. This direction is vertically in reservoirs, where water moves vertically due to density differences. In river reaches, computational elements are connected longitudinally in the flow direction. The interconnected elements in a river and reservoir system are presented in Figure 2. The set of computational elements is called the model domain. Movement of water and concentrations of water quality constituents between elements is indicated by arrows in Figure 2.

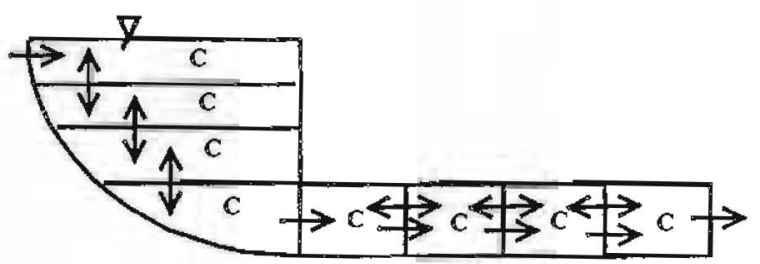

Figure 2. Computational elements within a one-dimensional river and reservoir water quality model

The influence of inflow water from upstream and from tributary inflows is also simulated in the model. The interaction of inflowing water with water in the model domain is an outside influence on water quality and is called a boundary condition or forcing function for the model. The water quality model also describes the interactions between water and the atmosphere and water and the sediments; these are additional boundary conditions. Heat exchange between the atmosphere and the reservoirs and river reaches is computed at the water surface. Equations used within the model express the change in water temperature as a function of meteorological conditions. The atmosphere and the sediment influence other water quality constituents in the river and reservoirs. Additional equations describing some of these influences are included in the water quality model. The level of detail of these equations used in a given model is often limited, usually well documented, and used to express the level of reality included in the water quality model software used.

The one-dimensional model representation is obviously a simplification of a complex three-dimensional system. The one-dimensional representation of reservoir and river water systems simulates the dominant processes that change water quality and has been proven to be quite accurate and useful (e.g., USACE, 1993). 
The data requirements for a water quality model such as HEC5Q are usually quite substantial for the simulation of a multi-reservoir system. A large set of measured data is required to allow for the computation of the set of concentrations. Since concentrations are being computed throughout space and time, the data required are also defined in both space and time, i.e., throughout the model domain and throughout the simulation period.

The basin geometry must be defined; this consists of the sizes, shapes and storage of all reservoirs and the size, shape and slope of the river reaches. The location and sizes of all reservoir outlets must also be defined. This basin geometry is assumed to remain constant throughout the simulation.

Water quality model equations express the change in concentration over time, therefore an initial set of conditions throughout the system must be provided. The set of initial conditions includes the reservoir storage values and the values for water quality constituents throughout the reservoirs at the start of the simulation. Values describing initial river water quality are not required as input parameters for $\mathrm{HEC5Q}$, the reservoir outfall water quality is instead the upstream boundary condition for the river reach below.

The driving forces that change water quality throughout the system during the simulation must be described. These driving forces include: the description of the water flow throughout the basin, the meteorological conditions that occur throughout the simulation and the water quality of any water that enters the model domain.

The water flow throughout the basin is the set of discharge values for all reservoir inflows and outlets, tributary inflow discharges and discharge values along the river reaches. Horizontal arrows in Figure 2 indicate these flow values. Since discharge throughout the system changes over time, this set of discharge values has to be defined for all locations in the basin for the entire simulation time period. Water quality modeling software packages either compute these discharge values or accept data from outside sources, such as other modeling software.

The meteorological conditions are assumed to be the same throughout the basin. However, conditions change throughout time, so these data are required for each timestep in the simulation. The meteorological conditions are used to calculate the heat exchange between the atmosphere and the water surfaces. Required parameters usually include: air temperature, dew point temperature, wind speed and parameters for the amount of solar radiation.

Water that flows into the model domain should also be characterized. This water is an outside influence on water quality within the model domain. The quality of the inflow water also changes throughout time, therefore the quantity and water quality of all tributary inflows has to be provided for each timestep in the simulation.

The model computations are performed for a simulation time period (usually one year) with individual computations performed on a time step (usually one day). Initial condition values are used only at the start of the computations. Driving force values are used throughout the simulation. Data that are required for use during the simulation must be defined for all time steps for the entire simulation time. Therefore, increasing the length of the simulation period or decreasing the size of the timestep increases the size of the required data set dramatically. 
Output from the water quality model is the entire set of computed concentrations for all the computational elements in the model domain for each time step of the simulation. When concentration values are viewed in the physical dimension, profiles of reservoir water quality and profiles of river water quality can be created. When these concentrations are viewed throughout time, time-series of water quality at one location can be created. The output dataset is often very large, requiring tools for organization, manipulation and graphical display.

This general overview was presented to demonstrate the basic mathematical methods, data requirements, and computational methods used in water quality modeling. The methods described in this section are standard computational methods used in many areas of environmental modeling. All of the methods described above are consistent with the methods employed by the HEC5Q model.

\section{Development of the Water Quality Model for the Klamath Basin}

The US Army Corps of Engineers, Hydrologic Engineering Center (HEC) modeling software HEC5Q was chosen for this project. This software was designed to simulate interconnected river and reservoir systems within one model, a capacity that fit well with the Klamath River study. This software also allows for the simulation of the main water quality constituents required for this study. The one-dimensional solution to the advection-diffusion-reaction equation using finite difference approximations (described previously) is the computational method implemented by HEC5Q. The onedimensional modeling software was chosen to predict water temperature and quality in the Klamath basin because vertical temperature gradients dominate the reservoirs and longitudinal temperature gradients occur throughout the river reaches, therefore a onedimensional model would capture the changes in water quality of interest. This software was originally created in the 1970's. The documentation provided is USACOE (1986). The version of the program used in SIAM is dated August 1991. The HEC provides support for HEC5 but no longer provides support for the water quality portion of the model.

The water quality model domain is defined on the Klamath River in California and Oregon between Keno reservoir and the Seiad river gage. Therefore Keno Reservoir, JC Boyle Reservoir, Copco Reservoir and Iron Gate Reservoir are modeled as well as the interconnecting river reaches and the river reach from Iron Gate dam to Seiad. Upper Klamath Lake is not included in the water quality model domain. The water quality model application for the Klamath Basin was developed for integration into SIAM. SIAM allows for the integration of a number of models that describe water quantity, water quality and are used to describe ecosystem health. For consistency within SIAM, the reservoirs and river reaches simulated are equivalent in both the water quality model and the MODSIM model between Keno and Seiad.

Water temperature, dissolved oxygen and conductivity are simulated by the Klamath Basin water quality model. This small set is of specific interest for the projected SIAM users, provides required data for other models currently in SIAM and provides a strong basis for demonstration of the capabilities of the water quality model with SIAM. 
The water quality model currently simulates one 360 -day year using a timestep of one day. The resulting model output is the predicted daily average water quality throughout the basin during this one-year simulation.

Figure 3 describes the water quality model domain. Reservoirs are indicated as solid triangles and circles, water inflows are indicated by arrows, water inflows and outflows to maintain water balance are indicated by double-headed arrows, small circles indicate model control points delineating river reaches.

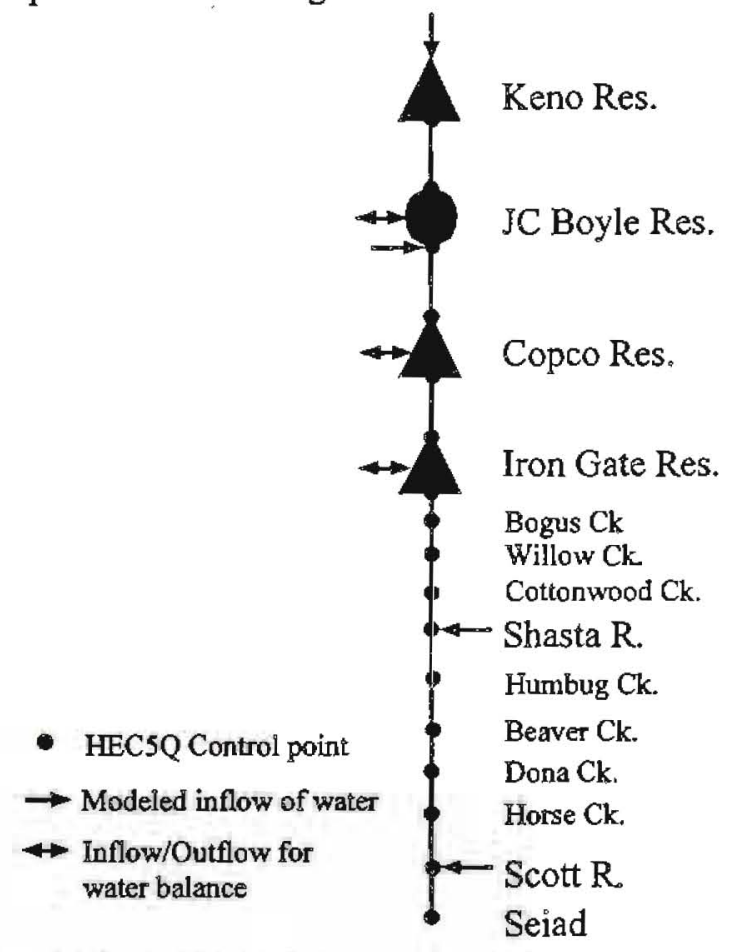

Figure 3. The Klamath Basin water quality model domain

\section{Basin Geometry}

The reservoir geometries were defined using the area-storage-elevation tables provided by PacifiCorp (1995). PacifiCorp (1995) also provided the reservoir outlet characteristics. All outlets were modeled for Copco and Iron Gate reservoirs. These included the turbine outlets, uncontrolled spillways and Iron Gate hatchery outlets.

The river reaches within the HEC5Q model were defined by reach length, elevation of endpoints and cross sectional shape of the endpoints of the reach. The length and elevation data were obtained by USGS gage location information, microhabitat study area information (Henriksen and Shaw, unpublished data) and USGS topographic maps. Channel cross sections were estimated as trapezoidal sections based on data from the mesohabitat study segments (Henriksen and Shaw, unpublished data). These data provided a river water surface width, depth pair (B and y indicated in Figure 4). From this information, a trapezoidal cross section with bottom width $B_{0}$ and $3: 1$ side slope was constructed (for each 1- $\mathrm{m}$ increase in depth, the river width increases by $6 \mathrm{~m}$ ). 
B

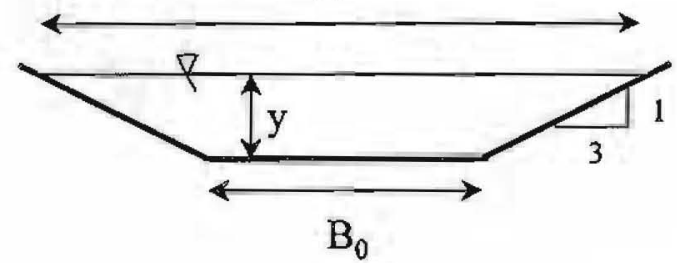

Figure 4. Creation of trapezoidal cross sections from measured data

The measured data and values for bottom width used within the HEC5Q model to delineate reach boundaries are presented in Table 1. Additional values required for each cross section in HEC5Q include: elevation, cross sectional area, hydraulic radius ${ }^{2 / 3}$ (where hydraulic radius is the river cross sectional area divided by the wetted perimeter), surface width and the Manning roughness coefficient (Manning $n$ ). These values are required by the Manning equation for uniform flow used by $\mathrm{HEC} 5 \mathrm{Q}$, which relates discharge to flow depth and velocity in an open channel. The value for Manning $\mathrm{n}$ used for all reaches is $n=0.05$. Values of $0.04<n<0.05$ are commonly used for natural river channels (Chaudry, 1993). The value of the Manning $n$ must be estimated for the Klamath River because discharge-depth relationships at known transects did not exist at the time of model development. In the future, data from the geomorphology study currently underway could be used to represent more of the natural channel shape variations.

Table 1. Klamath River cross section information

\begin{tabular}{|l|c|c|c|c|c|}
\hline $\begin{array}{c}\text { Cross Section } \\
\text { Name }\end{array}$ & $\begin{array}{c}\text { River } \\
\text { Mile }\end{array}$ & $\begin{array}{c}\text { Measured } \\
\text { Width (m) }\end{array}$ & $\begin{array}{c}\text { Measured } \\
\text { Depth (m) }\end{array}$ & $\begin{array}{c}\text { Computed } \\
\text { Bed Elevation } \\
\text { (ft) }\end{array}$ & $\begin{array}{c}\text { Computed } \\
\text { Bottom Width } \\
\text { (m) }\end{array}$ \\
\hline Keno Outfall & 230.0 & NA & NA & 3472 & 23.8 \\
\hline JC Boyle Inflow & 228.0 & NA & NA & 3329 & 23.8 \\
\hline JC Boyle Outflow & 225.0 & NA & NA & 3326 & 23.8 \\
\hline Copco Inflow & 203.0 & NA & NA & 2605 & 23.8 \\
\hline Copco Outfall & 198.3 & NA & NA & 2334 & 23.8 \\
\hline Iron Gate Inflow & 197.0 & NA & NA & 2327 & 23.8 \\
\hline Iron Gate Outfall & 190.0 & NA & NA & 2161 & 23.8 \\
\hline Bogus Creek & 189.8 & 37.2 & 1.2 & 2159 & 29.9 \\
\hline Willow Creek & 188.0 & 48.5 & 0.9 & 2132 & 43.0 \\
\hline Cottonwood Creek & 182.0 & 46.6 & 1.2 & 2049 & 39.3 \\
\hline Shasta River & 176.6 & 34.7 & 1.2 & 1973 & 27.4 \\
\hline Humbug Creek & 172.6 & 27.4 & 0.7 & 1917 & 23.8 \\
\hline Beaver Creek & 160.6 & 49.7 & 0.9 & 1749 & 44.2 \\
\hline Dona Creek & 152.6 & 35.1 & 0.9 & 1636 & 29.6 \\
\hline Horse Creek & 147.8 & 34.7 & 1.2 & 1569 & 27.4 \\
\hline Scott River & 143.0 & 39.3 & 2.1 & 1497 & 26.5 \\
\hline Seiad Valley & 130.0 & 38.4 & 1.2 & 1319 & 31.1 \\
\hline
\end{tabular}

\section{Basin Hydrology Used by the Water Quality Model}

Within the SIAM package, all hydrologic data is provided by the MODSIM water quantity model (Labadie, 1988). MODSIM is the hydrologic planning and water 
allocation model developed by the USGS for use within the basin (Flug and Scott, 1996). MODSIM calculates flow on a monthly timestep, providing reservoir storage and river flow values for each month of the simulation. Monthly values are used to compute daily flows used by the HEC5Q model. Monthly flow volumes are divided into 30 days of daily average flows. Therefore the hydrodynamics and daily variations of flow in the river have been simplified dramatically and steady uniform flow over the course of each month is assumed. No routing of flow through reservoirs or down river reaches is performed by HEC5Q in SIAM.

Within the water quality model, all natural water inflows into the Klamath Basin are modeled as specific point inflows into the domain. Losses of water, required to meet water balances are also simulated as diversions at specific locations. The following inflows and diversions are simulated: the upstream inflow point at Keno, accretions or diversions at JC Boyle reservoir, "Big Springs" below JC Boyle reservoir (indicated by a single inflow arrow below JC Boyle in Figure 3), accretions or diversions at Copco and Iron Gate reservoirs and the Shasta and Scott tributaries. All inflows and diversions are indicated with arrows in Figure 3. The inflows modeled are the dominant inflow sources and are designated also within the MODSIM model. Other accretions and baseflow sources (differences in measured flows down the mainstem) are modeled ungaged local flows in HEC5Q. The MODSIM inodel provides a correct water balance for reservoirs; all water throughout the basin is accounted for. MODSIM accretion flows are unregulated inflows to all reservoirs. Losses are a result of net evaporative loss computed by MODSIM. Therefore, unregulated inflows and net evaporative loss values are used for accretion and diversion flows, respectively within HEC5Q.

\section{Additional Water Quality Model Input Data}

Reservoir storage and water quality conditions are required as initial conditions by HEC5Q. This data set consists of an initial storage value for each reservoir and an initial profile of each modeled constituent concentration (including temperature) for each reservoir. Initial storage values are obtained directly from MODSIM. Initial profile values are assumed. For calendar year simulations, which begin in January, isothermal well-mixed conditions are assumed. For water year simulations, well-mixed conditions, which assume recent turnover, are also used.

Inflow water into the Klamath River and its reservoirs is a driving force for changes in water quality. The daily average water quality must be known for all inflow water. Often there is no data for these inflow waters. Measured data from the Keno site has been used as a representative data set to characterize the inflow accretion water quality. Seasonal values for the water quality of "Big Springs" below JC Boyle reservoir are based on the point measurements of Klamath River water quality in the canyon below JC Boyle (the KRCANYON monitoring site).

One basin-wide set of meteorological conditions is used for the Klamath Basin model. This data set consists of daily average values of air temperature, dew point temperature, wind speed and cloud cover. These raw data are input to the HEC HEATX model and the output from that model used within the HEC5Q input data file. Use of the HEATX model is a data pre-processing step that is required by the HEC5Q model. See USACOE (1986) for details of the HEATX model. The HEATX model takes the above 
data and basin latitude, longitude, elevation and reflectivity parameters and uses empirical relationships by Edinger and Geyer, (documented in USACOE, 1986) to compute specially formatted values of equilibrium temperature, coefficient of surface heat exchange and short wave solar radation at the air-water interface.

\section{Model Execution}

The HEC5Q model is a DOS-based console application. This application requires one formatted input file containing all the above data. Preprocessing software within SIAM is used to combine data sets and build the formatted file for the water quality model. The output from the HEC5Q model is a large formatted output file which contains a reiteration of all the input data and the sequenced daily average water quality in all reservoirs and throughout the river reaches. Post-processing software within SIAM is used to read this initial output file and generate specific output files that are used to create graphical output.

\section{Model Limitations}

During the course of model development, certain software limitations were found that impacted the HEC5Q simulations in the Klamath Basin. For the correct characterization of changes in reservoir water quality, the water retention time within the reservoir must be greater than the simulation timestep. After analysis of the usual river discharge during the high runoff portion of the year (February - April) it was apparent that the retention time of water within JC Boyle reservoir during that time was much less than one day. The retention time is estimated by: reservoir volume/Q, where reservoir discharge, $\mathrm{Q}=\mathrm{Q}_{\text {in }}=\mathrm{Q}_{\text {out }}$.

Example: JC Boyle active storage: 3377 acre ft, maximum flows roughly 10,000 cfs, JC Boyle retention time: 0.17 days. A I day retention time in JC Boyle, would require inflow $=$ outflow $\sim 1700 \mathrm{cfs}$.

Therefore, JC Boyle could not be modeled as a reservoir. The Klamath River between the upstream portion of JC Boyle reservoir (river mile 228) and JC Boyle dam (river mile 225 ) was modeled as a river reach with a trapezoidal cross section, bottom width 80 feet, 3:1 side slope and zero bed slope. This replacement of JC Boyle as a river reach is valid during high flow periods. However, because JC Boyle does stratify during summer months this replacement may be problematic. JC Boyle could be modeled as a reservoir if seasonal simulations were to be performed or a timestep of less than a day were used. Following this limitation for JC Boyle, the small Copco 2 reservoir (with capacity 74 acre $\mathrm{ft}$ ) is also modeled as a river reach below Copco Dam.

The HEC5Q model allows for the simulation of a large set of constituents: ammonia, nitrate, phosphorus, DO, algae and BOD, known as the phytoplankton option. This option simulates plant growth and decay, which more completely simulates the chemical system. Implementation of this option has not been performed, mainly due to time limitations and the difficulties of calibration. Plant growth and decay has an impact on water quality, and is a known problem in the Klamath Basin reservoirs. A simplified 
DO system, also provided by HEC5Q, was used to estimate DO in the Klamath. The model prediction represents changes in DO as a function of water temperature and longitudinal changes along river reaches as a function of reaeration, and is therefore a good starting point for DO simulation for SIAM. The limitations of this prediction should be kept in mind when interpreting the simulation results. This simplified DO system, includes reaeration at the water surface and inflow water as the only sources of DO and biochemical oxygen demand (BOD) as the only sink of DO. Reaeration within HEC5Q is characterized using the common expressions developed by Kanwisher for reservoir water surface reaeration and O'Connor-Dobbins for the stream reaeration rate (documented in USACOE, 1986). The variety of organic materials present in the river are not explicitly simulated in $\mathrm{HEC} 5 \mathrm{Q}$. Instead, their influence on the dissolved oxygen level in the river water is simulated. The generalized BOD parameter, a constituent in HEC5Q, is used to characterize the resultant oxidation required for the decay of all organic compounds currently decomposing in the river. The concept of BOD has been used for many years, mainly in the characterization of the impact of wastewater outfalls on river water quality (Chapra, 1997). BOD is expressed in oxygen units (commonly in $\mathrm{mg} / \mathrm{l}$ ) and is equivalent to the dissolved oxygen removed from the water by the decay of organic materials. A similar DO sink, sediment oxygen demand (SOD), which accounts for additional organic decay in the sediments, is also used within reservoirs in HEC5Q. SOD is modeled in HEC5Q as a sink of DO in $\mathrm{mg} / 1$ per unit area of sediment in contact with reservoir water. Both $B O D$ and $S O D$ will be categorized as $B O D$ for this report.

Another limitation resulting from MODSIM and HEC5Q integration is the characterization of monthly flows for use as daily flows in HEC5Q. The monthly timestep output from the MODSIM model is essentially unchanged as it is passed to HEC5Q. Thirty days of daily average values are created from each MODSIM monthly flow value. These monthly hydrographs are the flows used by HEC5Q (See discharge plots in Appendices I - III). Large discontinuities are common between month boundaries, where reservoir outflows and flows in the river change drastically in one day. For some model simulations, these flow discontinuities manifest themselves as discontinuities in predicted water quality constituents. A month-to-month flow interpolation method is described in Hanna (1998) that decreases discontinuities in flow has been shown to decrease discontinuities in corresponding water quality. This method is scheduled to be included in SIAM in a future release.

\section{Model Calibration Methods}

Following creation of the model domain for the basin being studied, the next step in model development is calibration. Model calibration is the process where, starting with a generalized model, a specific model is created for the basin under consideration. The water quality model is more than just the basin geometry and input data. The effects of physical and chemical processes are unique to specific basins. The modeling software through the use of model tuning parameters can simulate these basin-specific process characteristics. One iteration of the model calibration process is demonstrated in Figure 5. 


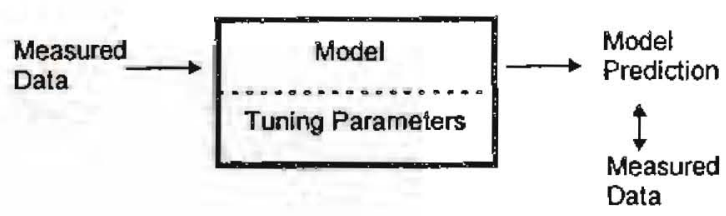

Figure 5. Model calibration process

A set of measured water quality data is obtained and used to test the model's predictions for the basin. Part of the measured data is supplied as input data to the model. The model is run and model predictions are compared to another set of measured data. Tuning parameters are adjusted that control water quality computations. These parameters include empirical constants and rates used by model equations, that have specific ranges of acceptable values. Model tuning can also be performed by the estimation of unavailable data that is required by the model. Through an iterative process, tuning parameters are adjusted until model predictions match the measured data.

Within river and reservoir systems, water released from reservoirs moves down the river reaches below. Similarly, the water quality within the reservoir is reflected in the river reaches below reservoirs. The tuning parameters available within HEC SQ allow for the adjustment of the reservoir water quality computations. This direct adjustment of the reservoir water quality indirectly adjusts the river water quality. The values of tuning parameters provided in HEC5Q are set for the entire annual simulation. The ability to use multiple tuning parameter values to account for seasonal variations in modeled water quality processes is not provided by HEC5Q in SLAM.

The vertical movement of water within reservoirs is due mainly to density differences. Less dense water moves upward, more dense water moves downward. The direct relationship between water temperature and water density dictates that if the water temperatures throughout the reservoir are well represented, so is the relative water movement. This movement of water vertically, and thus the movement of water quality constituents within the reservoirs, is computed by the model. Parameters for water stability and diffusion that control vertical movement of water and the movement of constituents, respectively, within the water are user-adjustable via a set of tuning parameters. The adjustment of tuning parameters allows regulation of water temperatures, reservoir stratification prediction and constituent transport based on each individual reservoirs' characteristics.

\section{Calibration for Water Temperature}

The effect of reservoir heating due to atmospheric effects can also be adjusted by model tuning parameters. Tuning can account for atmospheric effects that are not specifically modeled by the one-dimensional idealization. For example, it is assumed that the sun heats the water surface uniformly; the effects of sun shading are not considered in HEC5Q. Any localized heating or cooling are not specifically modeled; for the Klamath Basin model, one meteorological station was used to characterize the entire basin. Specialized effects such as these can be accounted for by tuning the available reservoir heating model parameters. The two available parameters within HEC5Q include: a fraction of solar radiation that is absorbed and the depth at which that fraction 
is absorbed in the reservoir, (variables XQPCT and XQDEP, respectively). The secchi depth, EDMAX in HEC5Q, is also provided as a reservoir physical constant. The sensitivity of the model prediction to these three parameters is fairly high, therefore reservoir water temperature can easily be adjusted up or down. Standard heat exchange empirical relationships are used within HEC5Q. These relationships are fully described in USACOE (1986). There are no other tuning parameters for the heat exchange relationships for river reaches or reservoirs other than the three described above.

One method in HEC5Q for computing the vertical movement of water by density differences is called the stability method. This method is commonly used for deep, wellstratified reservoirs. The tuning parameters associated with this method include a water column critical stability value (in $\mathrm{kg} / \mathrm{m}^{3} / \mathrm{m}$ ), the GSWH variable in HEC5Q. The critical stability value is the point where the water column becomes unstable and water moves vertically due to density differences. The diffusion coefficient (in $\mathrm{m}^{2} / \mathrm{s}$ ), the variable A1 in HEC5Q and the variable D in the advection-diffusion-reaction equation (1) determines the movement of water and constituents by concentration gradients alone. The stability method computes an effective diffusion coefficient when the water column stability is greater than the critical stability value and uses the given diffusion coefficient when the stability is less than the critical value. The method for the computation of the effective diffusion coefficient and the range of appropriate values is fully described in the USACOE (1986) in section 2.2.4.

For calibration, the stability and diffusion coefficients and the heating parameters were adjusted so that the model-predicted water temperature profiles within the reservoirs matched the measured temperature profile values. By successfully predicting the water temperature profile throughout the simulation, the temperature of the release water and the vertical transport of water are also correctly simulated. Other water quality constituents may or may not be successfully predicted when transport is well predicted in the reservoir.

The tuning parameters were adjusted to correctly predict water temperature in the hypolimnion, the location and temperatures of the thermocline and the temperature near the reservoir outlets. The tuning parameters for heating were used to adjust the temperature of the bulk reservoir temperature. The values of the diffusion and critical stability coefficients were used to adjust the magnitude of temperature gradient at the thermocline. By decreasing the diffusion coefficient, a larger temperature gradient could be obtained. By changing the critical stability value, the default diffusion coefficient would be used more or less during the course of the year. By lowering the critical stability value, more mixing (and thus less temperature gradient) would occur.

The tuning parameters are values used for the entire simulation. The parameter values used in the calibrated model are values that provided the best fit of the temperature and constituent profiles for the entire calibration period.

A simplified dissolved oxygen simulation is used for the Klamath Basin water quality model consists of sources and sinks of DO. Sources of DO include the inflow water and reaeration at the water surface. Sinks of DO are only due to the BOD (described as the 5-day carbonaceous BOD) of the water. The computation of DO due to reaeration and $\mathrm{BOD}$ is computed using standard methods within $\mathrm{HEC} 5 \mathrm{Q}$. 


\section{Calibration for Dissolved Oxygen}

Empirical methods are used for the computation of reaeration within HEC5Q, therefore there are no tuning parameters available for adjusting the reaeration rates. The $\mathrm{DO}$ and $\mathrm{BOD}$ of the inflow and accretion water acts to change the DO within the reservoirs and river reaches. $\mathrm{HEC} 5 \mathrm{Q}$ requires that the $\mathrm{DO}$ and $\mathrm{BOD}$ of all inflow waters are specified. Where no DO data existed for inflow waters, the DO of the inflow water was adjusted and used as tuning parameters. There were no BOD data available for the Klamath Basin, therefore the specification of BOD values for inflow waters were used also as tuning parameters for $\mathrm{DO}$.

The DO for all reservoir accretion waters and Shasta and Scott Rivers was based on the available Keno water quality data. The DO values for Keno are in Appendix I as calibration input data.

During the course of calibration, it was noted that some useful tuning parameters were not available within HEC5Q. Changes in water quality influenced by the reservoir outlets and turbines were not explicitly modeled, and therefore no tuning parameters existed for adjusting the effects of the outlets. More specifically: any reaeration or heat exchange that occurs at the turbine outlets, stilling basins or spillways was not modeled by HEC5Q. Some empirical equations for reaeration and heat exchange at dams based on the head drop do exist (See Chapra, 1997). Tuning parameters for these generalized equations for changes in water quality due to the outlets are not available in HEC5Q and would have been valuable for fine-tuned calibration. There is no method available to add these types of equations or adjust the water quality at the outlets in any way. This represents a model limitation within $\mathrm{HEC} 5 \mathrm{Q}$.

\section{Calibration for Conductivity}

Conductivity is the measure of the ability of water to conduct electrical current. Conductivity is measured in mho $(1 / \mathrm{ohm})$ or $\mu \mathrm{S}$ per $\mathrm{cm}$, which is a measure of conductivity of water between two electrodes a known distance apart. It is also an indirect measure of the total dissolved solids within water. In HEC5Q conductivity is a conservative parameter. That is, there are no chemical reactions that cause conductivity to increase or decrease. Only mixing and dilution via inflow waters cause changes in conductivity. Conservative constituents, such as conductivity, are commonly used as calibration checks within water quality models. If calibration for a conservative tracer is performed, it is a good check that all water (and the conductivity of all water) is accounted for correctly.

As with DO, some conductivity data were unavailable. Values for conductivity of accretion waters at reservoirs and inflows at the Shasta and Scott Rivers were unavailable and assumed to be similar to Keno. Therefore, daily average values for conductivity at Keno (which were available and of good quality) were used to represent all inflow water into the Klamath. Unlike the DO system, there are no tuning parameters available to adjust conductivity. The "goodness of fit" for conductivity calibration, i.e., predicted conductivity values matching measured conductivity values, indicates the appropriateness of any assumed data. 
Model Calibration-Calendar Year 1996

Calendar year 1996 was the time period selected for model calibration. A fairly large and nearly complete dataset was available for this time period. The data required for calibration consisted of basin-wide flow values, basin-wide water quality data (for both input to the model and comparison with model predictions) and meteorological data. Using these data, model runs and comparisons were performed to determine the final set of tuning parameters.

In some cases, the data needed for calibration were not complete. Some estimated values were used where data were not available. The reader should remember that the model requires a large and complete set of data and estimated values were used to allow model creation to proceed. These estimated values may or may not be adequate for complete model calibration,

\section{$\underline{\text { Flow Data }}$}

MODSIM simulation runs for 1996 were not available during the calibration exercise. Therefore, data were compiled from other sources. Daily average measured discharges were available for portions of the model domain from USGS river gage data (Table 2). The spatial distribution of the total ungaged Iron Gate to Seiad reach accretion volume was computed based on watershed area as defined in the Phase I Scoping Report, USGS/BRD (1995), pages 29 and 30 . This method realistically accounts for the ungaged accretion in the Scott River between the USGS gage at Fort Jones and the confluence with the Klamath River. This computation is hydrologically correct for the Klamath Basin and consistent with the MODSIM model.

Table 2. USGS river gages used for flow data

\begin{tabular}{|l|c|}
\hline \multicolumn{1}{|c|}{ USGS Gage Name } & USGS Gage $\overline{\text { Number }}$ \\
\hline Klamath River at Keno, OR & 11509500 \\
\hline $\begin{array}{l}\text { Klamath River below John C. Boyle } \\
\text { Powerplant, near Keno, OR }\end{array}$ & 11510700 \\
\hline Klamath River below Iron Gate Dam, CA & 11516530 \\
\hline Shasta River near Yreka, CA & 11517500 \\
\hline Scott River near Fort Jones, CA & 11519500 \\
\hline Klamath River near Seiad Valley, CA & 11520500 \\
\hline
\end{tabular}

A complete set of flows into and out of all reservoirs was also required for calibration. PacifiCorp power company provided daily operations data for Copco and Iron Gate reservoirs. These data consisted of daily reservoir releases through all outlet structures and daily changes in reservoir storage. From these data and the USGS gage data, all Klamath River inflows into Copco and Iron Gate, all net gain/loss of water to/from Copco and Iron Gate and a complete set of reservoir releases for Copco and Iron Gate were computed. For Iron Gate dam outflow, data from the USGS gage below the dam were used instead of the PacifiCorp data because the USGS data were considered to 
be more accurate. Locations of all flow data within the model domain are presented in Figure 6.

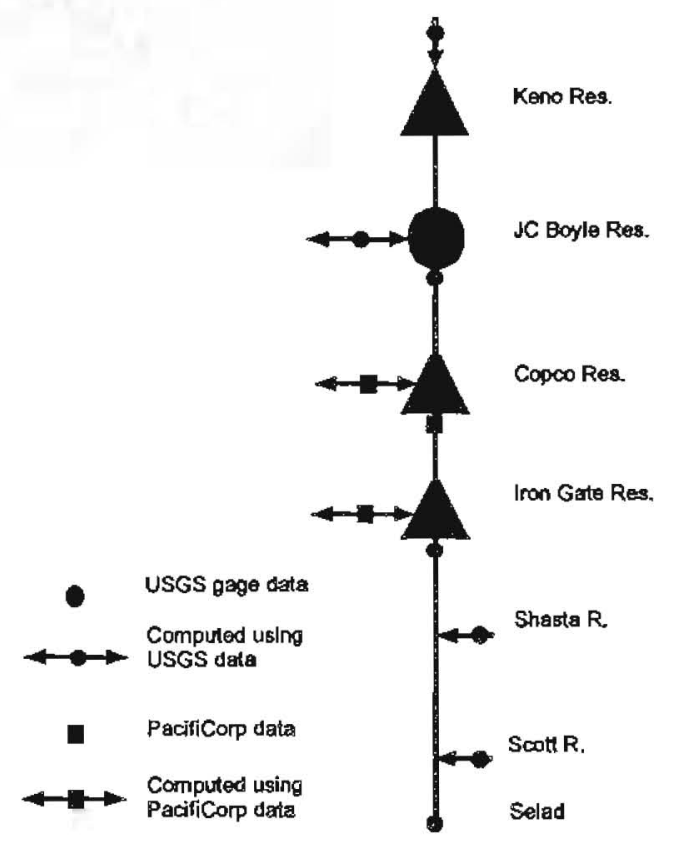

Figure 6. Location of flow data within the water quality model domain

The water quality model is intended to be used within SIAM; calibration was performed with data similar to the data that will be available from MODSIM. MODSIM provides monthly flow values throughout the basin; calibration of the water quality model was therefore performed using sets of 30 days of daily average flow values, computed from the monthly average data.

All water within the basin had to be accounted for and described by the data provided to the water quality model. Water balances have been performed for each reservoir to compute the net ungaged flows on a daily basis into each reservoir. The water balance for JC Boyle reservoir (which is represented as a river reach within the model and assumed to have zero storage) was computed based on the Keno and JC Boyle gage data, for inflow and outflow, respectively. The flow attributed to the "Big Springs" below JC Boyle has been set to a constant inflow of $100 \mathrm{cfs}$.

For a given reservoir, the daily total inflow and the total outflow must equal the daily change in reservoir storage, as expressed in Equation (2). Given the upstream gage data, the change in storage and the reservoir release, any water balance discrepancy can be resolved by the addition or subtraction of water. These daily volumes were computed and modeled as reservoir inflows, at the upstream end of the reservoir or reservoir diversion flows for each reservoir. On a daily basis, either an inflow or a diversion could occur. This method assumes that all measured data are correct and accounts for all the water that moves through the reservoirs and aggregates all the unknown water volume into one term. 


$$
\text { Total Inflow }- \text { Total Outflow }=\text { Change in Storage }
$$

The water balances at Copco and Iron Gate were computed using upstream inflow, change in reservoir storage and dam release. The flow data were a combination of PacifiCorp-measured data and USGS gage data. For Iron Gate discharge, both sources provided data; the USGS data were used and the PacifiCorp data was used for quality control. For calendar year 1996, the daily reservoir storage values were estimated by linear interpolation from USGS month-end storage data.

\section{Meteorological Data}

A set of meteorological data for the Klamath Basin was obtained from the NOAA World Wide Web site. The Montague/Siskiyou, California airport meteorological data, was used for both the 1996 calibration and 1997 validation. The web interface to meteorological data has changed often. As of the date of this report, these data were available through the CLIMVIS - Global Summary of the Day pages (http://www.ncdc.noaa.gov/onlineprod/gsod/climvis/gsod.html, the station ID for the data used was 725955). Data were available for mean daily wind speed, mean daily dew point, mean daily air temperature, mean daily visibility and mean daily precipitation. These data sets were downloaded in text format through the web interface. The cloud cover parameter was not available for this meteorological station. Therefore, the cloud cover parameter was estimated based on the relationship between weather systems and cloud cover in the Klamath Basin. Mean daily visibility data (in miles) and precipitation data (inches) were used to estimate relative cloud cover as a proportion (in tenths). For days where precipitation occurred, the cloud cover was set to $10 / 10$, i.e., during days with any rain it was assumed to be fully overcast (M. Deas, personal communication, 1997). For days when precipitation did not occur, cloud cover in tenths was computed as the ratio of the visibility on that day to the maximum visibility that occurred throughout the year and converted into tenths. For days with high visibility, a low cloud cover also occurred and vice versa. This method for estimating cloud cover is based on the premise that cloud cover and visibility at the airport are linearly and inversely related. There were no other data available for the Montague/Siskiyou Airport that could have been used to test this cloud cover estimation method.

\section{Water Quality Data}

The water quality data obtained for 1996 consisted of daily average data provided by in-stream data loggers placed throughout the basin by USGS/BRD, the Bureau of Reclamation (BOR) and University of California, Davis (UCD). North Coast Regional Water Quality Control Board (NCRWQCB) obtained other point water quality measurements. The data loggers provided hourly measurements of water temperature, DO and conductivity as well as other water quality parameters. From the hourly data, daily average values were computed. Some gaps in the data did exist and where required, values were estimated by linear interpolation. For comparison with the model daily average water quality, daily average input data are most appropriate. Point measurements 
are used mostly for comparison with model predictions and show annual trends and size of the diurnal range.

The locations of the most complete daily average data (provided by USGS/BRD and BOR) were: in Keno Reservoir, below JC Boyle outfall, below Shovel Creek (at the KRBORDER site) and below Iron Gate outfall. Other daily average data, capturing the peak annual temperature period, provided by UCD, were also available above Cottonwood Creek, below the Shasta River, Beaver Creek (at Walker Road bridge), below the Scott River and at Seiad. In-stream daily average data were available for the Shasta and Scott Rivers. Point measurements of water quality (provided by NCRWQCB) used for model calibration were available at locations: above JC Boyle outfall (KRCANYON site), below Copco outfall, $\mathrm{u} / \mathrm{s}$ of Cottonwood Creek, $\mathrm{d} / \mathrm{s}$ of Shasta River, $\mathrm{d} / \mathrm{s}$ of Beaver Creek and $\mathrm{d} / \mathrm{s}$ of Scott River. Six monthly water constituent profiles (provided by NCRWQCB, PacifiCorp and BOR) were available for all modeled reservoirs for June, July, August, September, October and November. In some reservoirs, multiple profiles were available for different locations. The profile measured closest to the dam in each case was used for calibration. The locations of all water quality data used for calibration are presented in Figure 7.

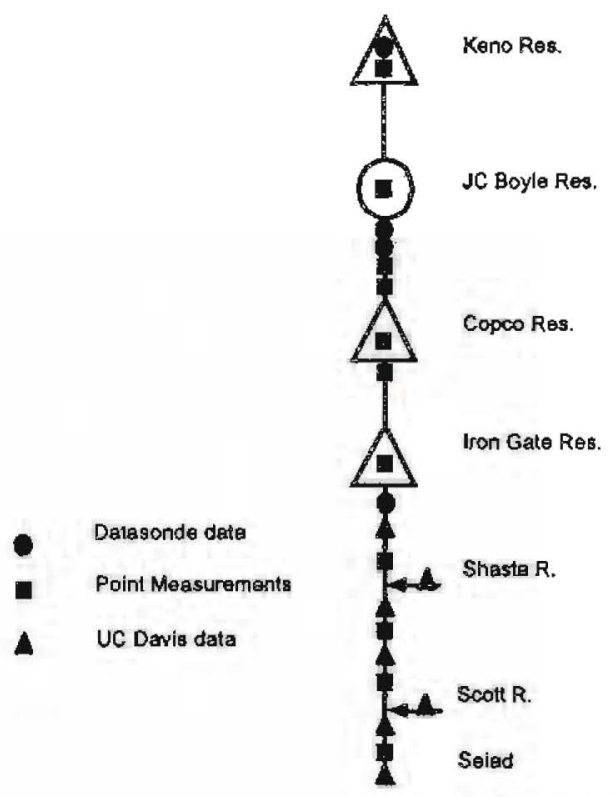

Figure 7. Location of water quality data used for 1996 calibration

For the 1996 calibration, no consistent daily average water quality data existed for the Shasta and Scott River tributaries. Temperature data were obtained from M. Deas of UC Davis for a portion of the summer months, (days 171-279 for Shasta R. and days 199297 for Scott R.). When no other temperature data were available, Keno data (both measured and estimated) were used. No DO and conductivity data were available for the Scott and Shasta Rivers for calibration. Therefore, Keno data (both measured and estimated) were used. The water quality of all the computed reservoir accretion water volumes was also represented using Keno water quality data. The inflow water quality was based on Keno data and adjusted slightly for calibration. Therefore the unknown 
quality of accretion waters was used as a tuning parameter for calibration. The HEC5Q model was not very sensitive to changes in this inflow water quality, but adjustment of concentrations of DO for example could account for some reaeration at the reservoir outlet, which was not simulated in HEC5Q.

Through the iterative calibration process, the values of the tuning parameters were adjusted and a final set of values was chosen (Table 3). Note that Keno Reservoir is considered a boundary condition and not explicitly modeled. JC Boyle and Copco 2 reservoirs are also not modeled as reservoirs in the HEC5Q model.

Table 3. Reservoir temperature and transport tuning parameter values

\begin{tabular}{|l|c|c|}
\hline & Copco Reservoir & Iron Gate Reservoir \\
\hline Secchi Depth & $3 \mathrm{~m}$ & $2.4 \mathrm{~m}$ \\
\hline $\begin{array}{l}\text { Fraction of Solar } \\
\text { Radiation Absorbed }\end{array}$ & $99 \%$ & $70 \%$ \\
\hline Depth Absorbed & $6 \mathrm{~m}$ & $1.5 \mathrm{~m}$ \\
\hline Critical Stability Value & $1.0 \times 10^{-5} \mathrm{~kg} / \mathrm{m}^{3} \mathrm{~m}$ & $5.0 \times 10^{-5} \mathrm{~kg} / \mathrm{m}^{3} \mathrm{~m}$ \\
\hline Diffusion Coefficient & $5.0 \times 10^{-5} \mathrm{~m}^{2} / \mathrm{s}$ & $1.5 \times 10^{-5} \mathrm{~m}^{2} / \mathrm{s}$ \\
\hline
\end{tabular}

Measured data for secchi depth were used as a starting point for the secchi depth tuning parameter; Copco and Iron Gate Reservoir values averaged $8 \mathrm{ft}$ (10 $\mathrm{ft}$ used for Copco). The critical stability values and diffusion coefficients are within the upper and lower envelope values suggested in Figure 3 of USACOE (1986). USACOE (1986) suggests a relationship between secchi depth, the fraction of radiation absorbed, and the depth at which it is absorbed. These relationships were used as a starting point for the tuning parameters. However, to provide the best overall match with all the measured temperature profiles using one value for the entire annual simulation, the final values used for these tuning parameters were higher than the "usual" values indicated in USACOE (1986). The BOD for accretion waters was set to four seasonal values (Table 4).

Table 4. Seasonal BOD calibration values for inflow waters to the Klamath River

\begin{tabular}{|l|c|c|c|c|}
\hline & Jan & Apr & Aug & Dec \\
\hline Keno & $14 \mathrm{mg} / 1$ & $14 \mathrm{mg} / 1$ & $15 \mathrm{mg} / 1$ & $15 \mathrm{mg} / 1$ \\
\hline JC Boyle & $3 \mathrm{mg} / 1$ & $3 \mathrm{mg} / 1$ & $4 \mathrm{mg} / 1$ & $4 \mathrm{mg} / 1$ \\
\hline Copco & $1 \mathrm{mg} / 1$ & $1 \mathrm{mg} / 1$ & $2 \mathrm{mg} / 1$ & $2 \mathrm{mg} / 1$ \\
\hline Iron Gate & $1 \mathrm{mg} / 1$ & $1 \mathrm{mg} / 1$ & $2 \mathrm{mg} / 1$ & $2 \mathrm{mg} / 1$ \\
\hline Shasta R. & $0 \mathrm{mg} / 1$ & $0 \mathrm{mg} / 1$ & $0 \mathrm{mg} / 1$ & $0 \mathrm{mg} / 1$ \\
\hline Scott R. & $0 \mathrm{mg} / 1$ & $0 \mathrm{mg} / 1$ & $0 \mathrm{mg} / 1$ & $0 \mathrm{mg} / 1$ \\
\hline
\end{tabular}

A representative range of $\mathrm{BOD}$ values throughout the Klamath basin was not available at the time of calibration, therefore estimated values were used. The BOD of inflow waters at the upstream portion of the domain (at Keno) is fairly high with lower values used downstream. The high values used at Keno have been used as calibration parameters to decrease DO levels to match measured values at downstream locations. The impact of the upstream BOD inflow acts as a persistent DO sink in the water and moderates DO values throughout the river downstream. As oxidation occurs and the DO is utilized, the 
excessive value of BOD introduced at Keno is tempered as well as diluted by the upstream reservoirs in the system. The resulting BOD downstream is in the $0-3 \mathrm{mg} / \mathrm{l}$ range during the simulation. In reality, some $\mathrm{BOD}$ will exist in all inflow waters, no additional BOD was required to be added at the Shasta and Scott River inflows for reasonable calibration for DO in HEC5Q.

Following calibration and validation, a representative value for June - September BOD of $5.4 \mathrm{mg} / 1$ exiting Fremont Bridge in the upper basin was found in the literature (OSSA, 1964, Jacob Kahn Personal Communication, 2000). The values of BOD throughout the river of $0-3 \mathrm{mg} / \mathrm{l}$ match fairly well with the reported value of $5.4 \mathrm{mg} / \mathrm{l}$.

\section{Model Validation \#1-Water Year 1997}

The process of model validation is generally considered a required second step, following calibration, in the application of a mathematical model. Model validation is very similar to model calibration in that measured data is provided to the model and the model prediction is compared with a corresponding set of measured data. In model validation, the calibration tuning parameters are kept constant and are set to the values determined by the calibration process. Model validation is performed using a different set of data than was used during calibration. Water year 1997 (October 1, 1996 September 30,1997 ) was chosen as one of the independent periods for model validation. The ability of the calibrated model to predict water quality for an independent set of input data is one measure of the validity and accuracy of the model. However, water year 1997 data is not entirely independent of the calendar year 1996 calibration data. October 1 December 31, 1996 are included in both the calibration and validation time periods but data for the summer and fall (the period of interest for salmonids) is unique for this validation. The same data sources were used for both calibration and validation. The same methods for converting raw data to model input data were employed for both calibration and validation.

MODSIM model output was again not available during this validation exercise. The basin-wide flow data set was compiled using a combination of USGS gage and storage data and operations data obtained from the PacifiCorp Power Company. The USGS gage data for water year 1997 was not available via the USGS web site. Provisional daily average flow data were obtained from state offices in Portland, OR and Redding, CA. USGS month-end storage data for Copco and Iron Gate were available from the USGS California Hydrologic Data Report for water year 1997. These data were also used in the MODSIM model for the Klamath Basin. The water balances for Copco and Iron Gate were computed using the calibration methodology.

As in calibration, daily measured water quality data serve as input to the model at all boundaries of the model domain: Keno Reservoir, all reservoir accretions, and the Shasta and Scott Rivers. Some daily data were unavailable for water year 1997 . The water year 1997 model validation period spans two calendar years and two water quality sampling seasons. The water quality sampling season is roughly the beginning of April through the end of November. The winter river flows are usually too high to allow for inriver deployment of sampling devices. Data were lacking for the high-flow winter season, from the end of November through April (roughly days $60-185$ of the water year, 125 days of missing data). 
The model boundary condition data are major driving factors for water quality. The quality of water entering the model domain must be known with relative confidence for all days in the simulation. A physically reasonable method had to be used to fill in the missing data record for the winter months.

For water temperature, a 10-day running average of air temperature was used to characterize fluctuations in winter water temperature. During the 1996 calibration, this 10-day running average of air temperature was compared to measured water temperature data. The shape and magnitude of the fluctuations in predicted water temperature vary closely with the measured data. This average most closely describes the measured water temperature for the winter months, when the flow rate is high. Later in the season, the timing of the fluctuations does not correlate as well. Since the missing data coincides with the winter high flow period, this method was used to fill the missing water temperature data for the 1997 model validation.

The corresponding missing dissolved oxygen data were created based on the assumption that during the winter, the water is saturated with DO. Using this assumption, the DO at saturation can be computed as a function of water temperature and elevation using known expressions. DO at saturation as a function of water temperature only is computed using the following expression (APHA 1992, from Chapra, 1997) and compared with tabular data in Hydrolab (1995):

$\ln O_{s}=-139.34411+\frac{1.575701 \times 10^{5}}{T_{a}}-\frac{6.642308 \times 10^{7}}{T_{a}^{2}}+\frac{1.243800 \times 10^{10}}{T_{a}^{3}}-\frac{8.621949 \times 10^{11}}{T_{a}^{4}}$

Where:

$\mathrm{O}_{\mathrm{s}}$ is the saturation concentration of fresh water at $1 \mathrm{~atm}[\mathrm{mg} / \mathrm{L}]$

$T_{a}$ is the absolute temperature $[K], T_{a}=T$ (in Celsius) +273.15

DO at saturation as a function of elevation and temperature is computed using the value of $\mathrm{O}_{s}$ as a function of temperature and using the following expression (Zison et al., 1978, found in Chapra, 1997):

$$
O_{s p}=O_{s}[1-0.000035(\mathrm{elev})]
$$

Where:

$\mathrm{O}_{\mathrm{sp}}$ is the saturation concentration including the effect of atmospheric pressure

$\mathrm{O}_{\mathrm{s}}$ is the saturation concentration of fresh water at $1 \mathrm{~atm}[\mathrm{mg} / \mathrm{L}]$

elev is elevation above mean sea level [ft], Keno elevation: $3961 \mathrm{ft}$.

Using the computed water temperature data, the DO for Keno is computed using the expressions above to simulate the water at the elevation of Keno, saturated with DO. This technique creates realistic DO values that were used where data were missing for winter months.

For conductivity, a simple linear interpolation technique was used to fill in the missing winter data because conductivity is not influenced by other water quality parameters, such as temperature. The interpolated values for the missing data fall within the annual average for Keno conductivity. Plots of these estimated boundary water quality data are presented in Figure 8. 

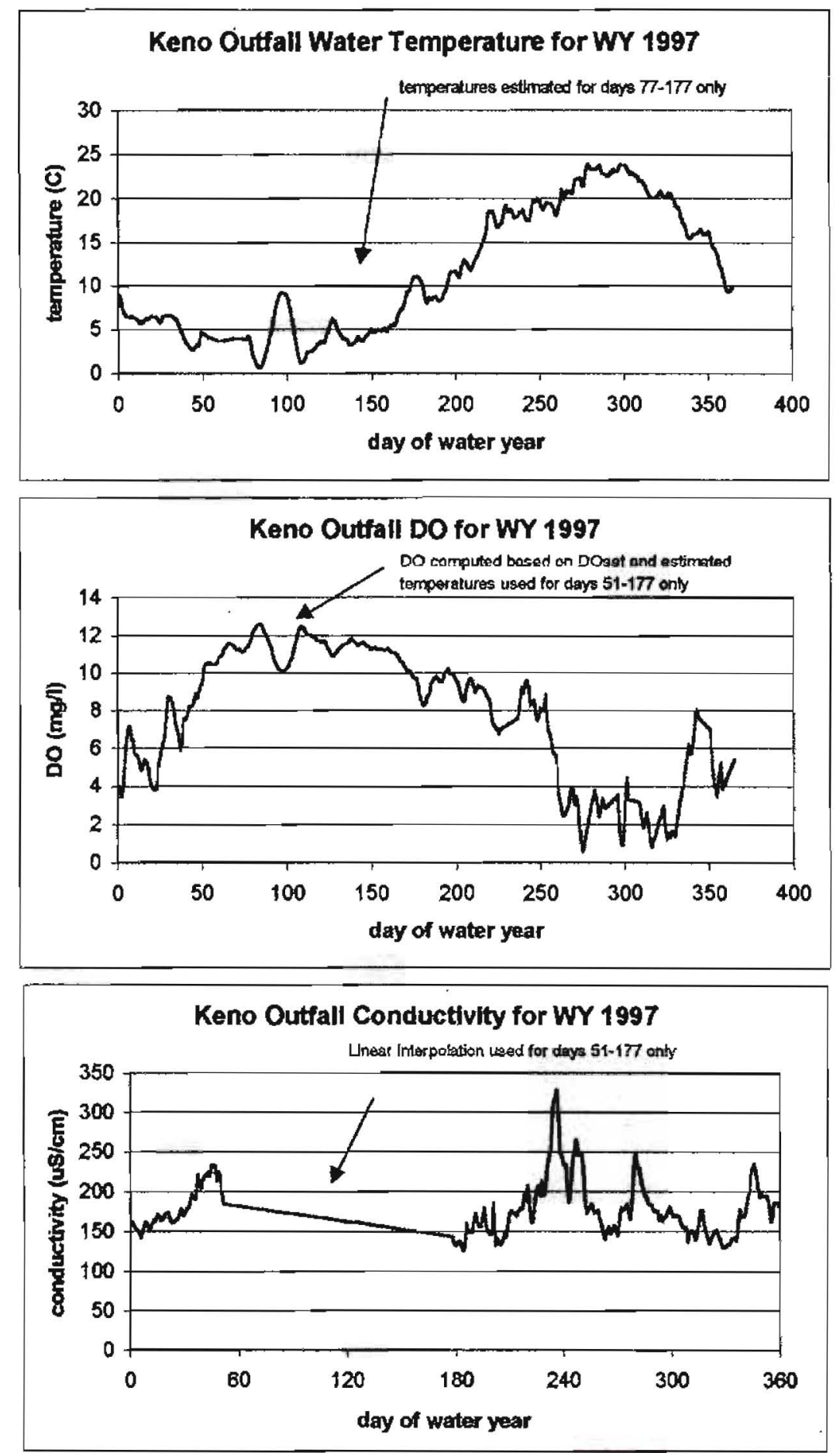

Figure 8. Estimated Keno water quality data for water year 1997

For the water year 1997 validation, no consistent daily average water quality data existed for the two tributaries: Shasta and Scott Rivers. Temperature data were obtained from M. Deas of UC Davis for two portions water year 1997, (days 1-5 and days 229-365 of water year 1997). When no other temperature data were available, Keno data (both 
measured and estimated) were used for the Shasta and Scott Rivers. No DO and conductivity data were available for the Scott and Shasta Rivers for water year 1997. Therefore, Keno data (both measured and estimated) were used. This method for the creation of Shasta and Scott River values using both site-specific data and representative data from Keno was used for both the 1996 calibration and 1997 validation. Because measured data for various accretion waters were unavailable, Keno water quality was used for all accretion waters.

\section{Model Validation \#2-Calendar Year 1998}

Another dataset was used for further validation of the water quality model. A very complete set of continuous data was available for calendar year 1998. For this year, datasonde samplers were relocated to provide data for model input and comparison at the boundaries of the model domain. Water quality data were available at many USGS gage locations, including in the Shasta River at the Yreka gage and the Scott River at the Fort Jones gage. Datasonde data were also available at the downstream end of the model domain at Seiad Valley. These new sets of data allowed for a more complete characterization of the tributary inflow water quality and provided a new continuous data set for comparison with model predictions in the mainstem.

The new datasonde data provided a check for the validity of the Keno data usage as representative tributary inflow water quality. Comparisons of Keno datasonde data for 1998 with Shasta and Scott River data are presented in Figure 9. Differences between the Keno data and the tributary data are very apparent. With the exception of Shasta River temperature data, the use of Keno data as representative inflow water quality for the tributaries may not be a good assumption. For 1998, water temperatures in the Scott River are up to $5^{\circ} \mathrm{C}$ cooler, compared to Keno. DO values in the tributaries in midsummer are up to $5 \mathrm{mg} / \mathrm{l}$ higher than at Keno. Conductivity values are also much higher in the tributaries. The discrepancies between the tributary datasonde and Keno datasonde are greatest in mid-summer. Datasonde data correspond more closely in the spring and fall. The tributary datasonde data were used as the inflow water quality for each tributary when the data were available. For the rest of the days in the simulation, Keno datasonde data were used as representative data.

The discrepancy between the water quality of the major tributaries and the Keno data source, illustrated in Figure 9, demonstrate that the use of Keno as representative data for all tributaries may not be a valid assumption. The use of Keno data has been used to fill the data record for the Shasta and Scott Rivers only out of necessity. Tributary water quality data will be used exclusively as that data becomes available. 

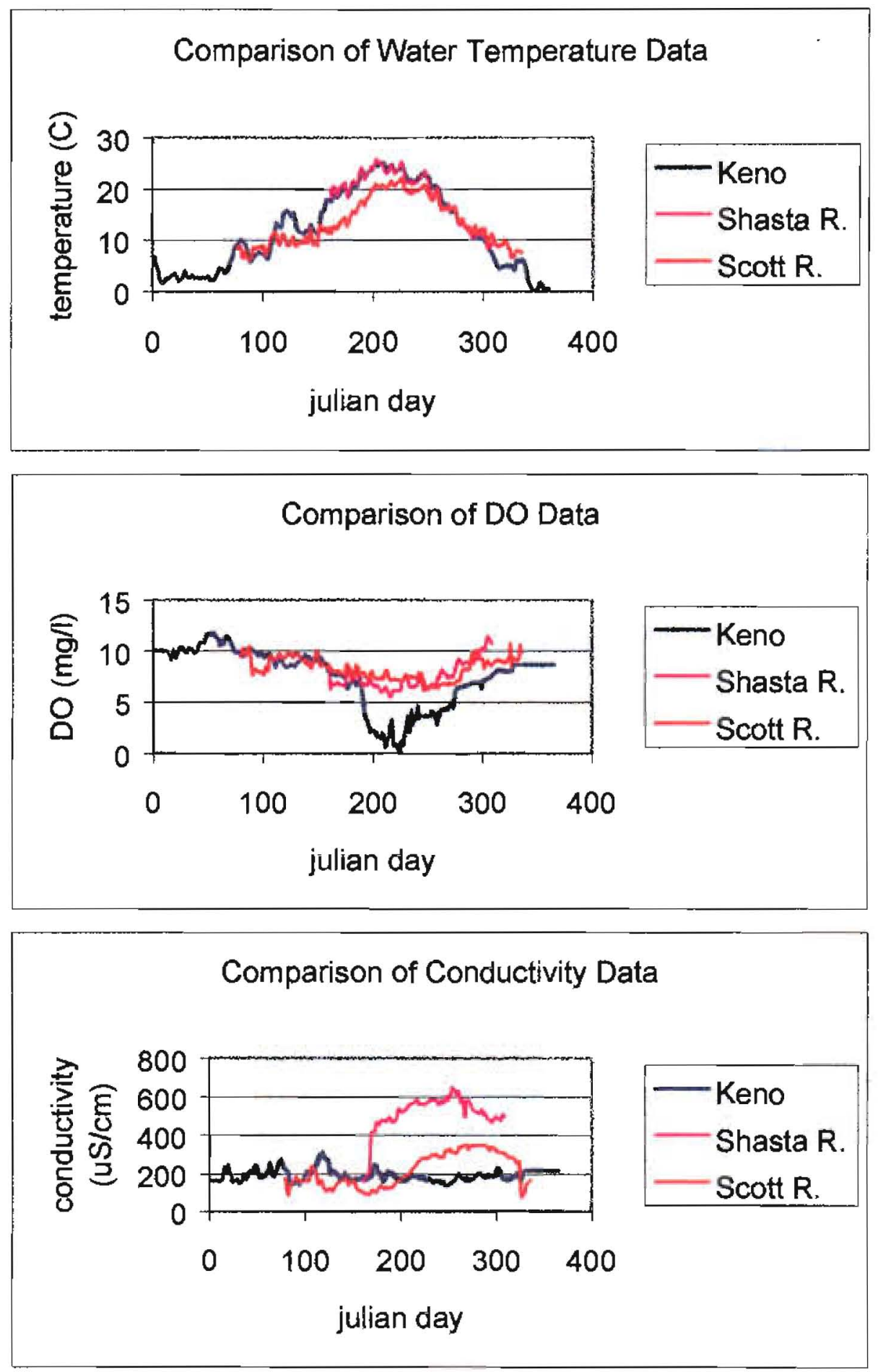

Figure 9. Comparison of Keno datasonde data with data from Shasta and Scott Rivers for calendar year 1998

This validation simulation, like the original calibration exercise, is a calendar year simulation. With the exception of use of new tributary datasonde data for the summer months, the methods used to create model input data from raw data sources was 
consistent with calibration and the water year validation. As in the previous validation exercise, no tuning parameters were adjusted for this simulation. The new datasonde data were used only for comparison with model predictions. This approach provides a straight comparison of measured daily average conditions with daily average model predictions.

\section{Measures of Goodness of Fit of Model Predictions to Measured Data}

The statistical error measurements, Root Mean Squared Error (RMSE) (alternatively referred to the standard error of the estimate), Absolute Mean Error (ABSE), Mean Error (ME), Maximum error (MAXE) and $\mathrm{R}^{2}$ (the square of the Pearson product moment correlation coefficient) were used to compare the model prediction to the measured data (Haber and Runyon, 1969). These error values will be in the units of the constituent measured (i.e., degrees $\mathrm{C}$ ) and are defined in equations $5-9$ below.

$$
\begin{gathered}
R M S E=\sqrt{\frac{\sum_{i=1}^{n}\left(X p_{1}-X m_{1}\right)^{2}}{n}}(5) \\
A B S E=\frac{\sum_{i=1}^{n}\left|X p_{i}-X m_{i}\right|}{n}(6) \\
M E=\frac{\sum_{i=1}^{n}\left(X p_{i}-X m_{i}\right)}{n} \\
\left.R^{2}=\left[\frac{M A X E}{\sqrt{\left[n \sum_{i=1}^{n} X p_{i}^{2}-\left(\sum_{i=1}^{n} X m_{i}\right)^{2}\right]\left[n \sum_{i=1}^{n} X m_{i}^{2}-\left(\sum_{i=1}^{n} X p_{i}\right)^{2}\right]}}\right]^{2}\right]^{2}
\end{gathered}
$$

Where:

$\mathrm{Xp} \mathrm{p}_{\mathrm{i}}$ is model-predicted water quality at one location and time

$\mathrm{Xm}_{\mathrm{i}}$ is measured water quality at one location and time $\mathrm{n}$ is the number of data comparisons

The Root Mean Squared error and Absolute Mean Error are measures of the deviation of the model prediction from the measured data. Overpredictions and underpredictions are accounted for as errors in these measures. The Mean Error describes the overall bias of the model to overpredict or underpredict compared to the measured data. In this error measurement, overpredictions and underpredictions are averaged out, and the overall ability to match the data is described. This error measurement is very valuable when viewed at different geographic portions of the model domain, and is used to determine if the model overpredicts in some areas while 
underpredicting in others. The Maximum error describes the largest point of deviation of the model prediction compared to the measured data. This value, along with the Mean error describes the range of deviations.

The $\mathrm{R}^{2}$ value is a dimensionless metric used to describe the overall variation in the data that is described by the model. A perfect match of the model prediction with measured data results in $\mathrm{R}^{2}=1.0$, where $100 \%$ of the variation in the data is described by the model.

\section{$\underline{\text { SIAM historic temperature validation }}$}

After the water quality model was calibrated and validated apart from SIAM, the predictive accuracy of SIAM as a whole was validated. A large historic input and comparison dataset was generated to allow for a validation of water temperature predictions below Iron Gate dam and at Seiad.

The source for meteorology data for the period water years 1961-1994 was the Earthinfo CD database (Earthinfo, Inc., 1996a, 1996b). Meteorological data from 199497 was obtained on the National Oceanic and Atmospheric Administration (NOAA) web site at http://www.noaa.gov. Although there are several weather site locations throughout the basin, such as Klamath Falls, OR, Medford Jackson County, OR and MontagueSiskiyou, CA airports, the Medford Jackson County, Oregon record was the most complete for the period of record desired for model simulations. However, there were significant differences between the Medford weather data and the Montague-Siskiyou data. Weather data and estimate of cloud cover based on precipitation and visibility from Montague-Siskiyou airport had been used for calibration and validation of the water quality model. Therefore, the Medford Jackson County airport, OR data set was adjusted to more closely emulate the Montague-Siskiyou data set by comparing data for both weather stations from January, 1994 - December, 1998. The annual average air temperature, dew point, wind speed, and cloud cover for both locations were computed. An adjustment factor was applied (Table 5) to the Medford data to create an annual average value for each of these parameters identical to the Montague-Siskiyou values. This adjustment method is similar to applying a dataset at a different elevation by adjusting for elevation using an adiabatic lapse rate. The resulting meteorological database was used as input data for the historical period validation simulation.

Table 5. Adjustment factors for Medford meteorological data for use in HEC5Q

\begin{tabular}{|l|c|}
\hline \multicolumn{1}{|c|}{ Meteorological Parameter } & Adjustment \\
\hline Medford Jackson County air temperature & Decrease by $3.4^{\circ} \mathrm{F}$ \\
\hline Medford Jackson County dew point & Decrease by $7.7^{\circ} \mathrm{F}$ \\
\hline Medford Jackson County wind speed & Increase by $0.36 \mathrm{mi} / \mathrm{hr}$ \\
\hline Medford Jackson County cloud cover & Increase by 1.3 tenths. \\
\hline
\end{tabular}

HEC5Q does not have the capability to perform multiple year simulations. Within SIAM, flow and meteorology are provided to HEC5Q in sequence with the previous year's ending simulation results forming the next year's initial conditions. Therefore, for multiple year simulations, the initial water quality for each reservoir at the start of each year is a single value equal to the reservoir discharge water quality for the 
last day of the previous year's simulation. Each reservoir is assumed to be completely mixed at this point resulting in homogeneous water quality throughout the water column. Since the reservoirs, based on measured data for 1996-98, are at or near fall turnover (isothermal) around the first of October this seems to be an acceptable method. The output from the HEC5Q model within SIAM is a 360 -day simulation, twelve 30 -day months. The computation of daily flows for HEC5Q in cubic feet per second from the MODSIM model output in acre $\mathrm{ft}$ per month does, however, use the traditional calendar for the number of days per month. The number of days for each month of the simulation used for the units conversion is presented in Table 6. These calculated flows are simulated for 30-day months by HEC5Q. There is no provision for leap years in the period of record for the SIAM simulation results. SIAM formats the output data file to insert five blank days at the end of each year simulated, i.e., days 1-360 are model output, days 361-365 not predicted, day 366 is the first day of the following year. Thus, all years in the formatted output file are 365 days in length.

Table 6. Days of months used for computation of daily flow in cubic feet per second used by HEC5Q

\begin{tabular}{|ll|c|}
\hline \multicolumn{2}{|l|}{ Month of water year } & Number of days \\
\hline 1 & October & 31 \\
\hline 2 & November & 30 \\
\hline 3 & December & 31 \\
\hline 4 & January & 31 \\
\hline 5 & February & 28 \\
\hline 6 & March & 31 \\
\hline 7 & April & 30 \\
\hline 8 & May & 31 \\
\hline 9 & June & 30 \\
\hline 10 & July & 31 \\
\hline 11 & August & 31 \\
\hline 12 & September & 30 \\
\hline
\end{tabular}

The calibrated and validated MODSIM model was used to provide flows for this simulation (kla97_6c.xy MODSIM file available in SIAM). This model predicts monthly KIamath River historical flows within 1\% error on an annual basis (Flug and Scott, 1998, Flug and Scott, 1996 - 1997 Task 8 Report).

A set of maximum and minimum water temperature data for Iron Gate Dam and Seiad USGS gages were obtained from the Earthinfo CD (Earthinfo, Inc, 1996c). The maximum and minimum water temperatures were averaged to obtain a measure of average daily water temperature. The period of record was from $10 / 1 / 62-4 / 6 / 80$ at the Iron Gate Dam (USGS gage 11416530) location and from $10 / 1 / 62-3 / 18 / 78$ at the Seiad (USGS gage 11520500) location. In addition to the datasonde records below Iron Gate in 1996-97, Hobotemp data at both locations was available from U.C. Davis studies in the Klamath River. A total of 11815 temperature values were available for the Iron Gate and Seiad locations for error analysis. An historic dataset for inflow water quality was not available. Therefore Inflow water quality was characterized using the Keno, 1996 data 
for each year in the historic simulation. For more information concerning the SIAM historical validation see Hanna, Campbell and Bartholow, 2000.

\section{Results}

Calibration Results

A complete set of plots that describe the comparison between model prediction and measured data is presented in Appendix I. All input data to the water quality model for the calibration process are also included in Appendix I of this report.

Visually, the overall fit of the model prediction to measured data is quite good. Statistical measures of error can help quantify the model's ability to predict water quality. Different types of discrepancy errors describe the ability of the model to match the measured data in a variety of ways.

The statistical methods described above were applied to the 1996 calibration data and model prediction output. Error computations were made for each constituent in the water quality model. Additional error computations have been made for distinct in-river locations along the mainstem Klamath and summarized for the entire domain and the more crucial site below Iron Gate dam. These statistical measures are summarized in Table 7 - Table 10 below.

The summary statistics have been computed based on only the sites indicated. This ensured that the model predictions for the entire length of the model domain were compared with the measured data. Note that the model predicts daily average water quality values. In some cases daily average predictions were compared against grab sample measurements when only grab sample data were available. The grab sample data values are measurements of the water quality at one point during the day. Comparison of these values to the daily average predicted by the model is inconsistent, but the only available comparison for some locations.

Table 7. Temperature calibration error data

\begin{tabular}{|c|c|c|c|c|c|}
\hline Location & RMSE $\left({ }^{\circ} \mathbf{C}\right)$ & ABSE $\left({ }^{\circ} \mathbf{C}\right)$ & $\begin{array}{c}\text { ME } \\
\left({ }^{\circ} \mathbf{C}\right)\end{array}$ & $\begin{array}{c}\text { MAXE } \\
\left({ }^{\circ} \mathbf{C}\right)\end{array}$ & $\mathbf{n}$ \\
\hline d/s of JC Boyle & 1.96 & 1.47 & 1.13 & 6.50 & 188 \\
\hline d/s of Copco & 2.04 & 1.53 & 0.68 & 5.30 & 19 \\
\hline $\mathrm{d} / \mathrm{s}$ of Iron Gate & 0.93 & 0.59 & -0.12 & 6.20 & 218 \\
\hline $\mathrm{d} / \mathrm{s}$ of Shasta confluence & 1.06 & 0.69 & -0.15 & 5.10 & 123 \\
\hline $\mathrm{d} / \mathrm{s}$ of Scott confluence & 1.07 & 0.69 & -0.08 & 2.41 & 122 \\
\hline Entire domain & 1.41 & 0.99 & 0.29 & 6.50 & 670 \\
\hline Domain d/s of Iron Gate & 1.65 & 1.20 & 0.56 & 6.20 & 463 \\
\hline
\end{tabular}


Table 8. DO calibration error data

\begin{tabular}{|c|c|c|c|c|c|}
\hline Location & $\begin{array}{c}\text { RMSE } \\
(\mathbf{m g} / \mathbf{l})\end{array}$ & $\begin{array}{c}\text { ABSE } \\
(\mathbf{m g} / \mathbf{l})\end{array}$ & ME (mg/l) & $\begin{array}{c}\text { MAXE } \\
(\mathbf{m g} / \mathbf{)})\end{array}$ & $\mathbf{n}$ \\
\hline $\mathrm{d} / \mathrm{s}$ of JC Boyle & 1.73 & 1.41 & -1.10 & -5.06 & 198 \\
\hline $\mathrm{d} / \mathrm{s}$ of Copco & 1.66 & 1.46 & -0.51 & -3.9 & 20 \\
\hline $\mathrm{d} / \mathrm{s}$ of Iron Gate & 1.22 & 0.94 & -0.85 & -3.77 & 213 \\
\hline $\mathrm{d} / \mathrm{s}$ of Shasta confluence & 0.84 & 0.71 & 0.15 & 1.70 & 19 \\
\hline $\mathrm{d} / \mathrm{s}$ of Scott confluence & 0.79 & 0.69 & -0.46 & 1.60 & 17 \\
\hline Entire domain & 1.25 & 1.04 & -0.55 & -5.06 & 462 \\
\hline Domain d/s of Iron Gate & 1.54 & 1.27 & -0.82 & 1.70 & 249 \\
\hline
\end{tabular}

Table 9. Conductivity calibration error data

\begin{tabular}{|c|c|c|c|c|c|}
\hline Location & $\begin{array}{c}\text { RMSE } \\
(\mu \mathrm{S} / \mathbf{c m})\end{array}$ & $\begin{array}{c}\text { ABSE } \\
(\mu \mathrm{S} / \mathbf{c m})\end{array}$ & $\begin{array}{c}\text { ME } \\
(\mu \mathrm{S} / \mathrm{cm})\end{array}$ & $\begin{array}{c}\text { MAXE } \\
(\mu \mathrm{S} / \mathbf{c m})\end{array}$ & $\mathbf{n}$ \\
\hline $\mathrm{d} / \mathrm{s}$ of JC Boyle & 34.33 & 23.05 & 15.37 & 107.76 & 186 \\
\hline $\mathrm{d} / \mathrm{s}$ of Copco & 28.36 & 20.37 & 12.78 & 76.6 & 19 \\
\hline $\mathrm{d} / \mathrm{s}$ of Iron Gate & 19.66 & 13.48 & 7.95 & 70.52 & 187 \\
\hline $\mathrm{d} / \mathrm{s}$ of Shasta confluence & 24.30 & 19.08 & 3.52 & 48.00 & 19 \\
\hline $\mathrm{d} / \mathrm{s}$ of Scott confluence & 24.25 & 18.42 & 7.03 & 93.20 & 17 \\
\hline Entire domain & 26.18 & 18.88 & 9.33 & 107.76 & 428 \\
\hline Domain d/s of Iron Gate & 27.45 & 18.96 & 12.03 & 93.20 & 223 \\
\hline
\end{tabular}
comparisons

Table 10. Model correlation coefficients for calibration

\begin{tabular}{|c|c|}
\hline Constituent & $\mathbf{R}^{\mathbf{2}}$ \\
\hline Temperature & 0.898 \\
\hline DO & 0.346 \\
\hline Conductivity & 0.177 \\
\hline
\end{tabular}

\section{Model Validation \#1 Goodness of Fit}

Statistical methods, identical to the methods used to evaluate calibration results, were also used to compare the water year 1997 validation data and model output. The summary statistics appear in Table 11- Table 14 below. A complete set of plots that describe the comparison between model prediction and measured data can be seen in Appendix II. A table indicating corresponding dates for calendar year simulations and water years simulations has been provided in Appendix II. All input data to the water quality model for the validation process can also be found in the Appendix $\Pi$ of this report. 
Table 11. Temperature validation \#1 error data

\begin{tabular}{|c|c|c|c|c|c|}
\hline Location & $\begin{array}{c}\text { RMSE } \\
\left({ }^{\circ} \mathbf{C}\right)\end{array}$ & $\begin{array}{c}\text { ABSE } \\
\left({ }^{\circ} \mathbf{C}\right)\end{array}$ & $\begin{array}{c}\text { ME } \\
\left({ }^{\circ} \mathbf{C}\right)\end{array}$ & $\begin{array}{c}\text { MAXE } \\
\left({ }^{\circ} \mathbf{C}\right)\end{array}$ & $\mathbf{n}$ \\
\hline $\mathrm{d} /$ s of JC Boyle & 2.59 & 2.29 & 1.89 & 5.69 & 184 \\
\hline $\mathrm{d} /$ s of Copco & 1.09 & 0.77 & -0.37 & -2.80 & 15 \\
\hline $\mathrm{d} / \mathrm{s}$ of Iron Gate & 0.58 & 0.50 & -0.42 & -2.17 & 200 \\
\hline $\mathrm{d} / \mathrm{s}$ of Shasta confluence & 0.61 & 0.62 & -0.44 & -2.00 & 200 \\
\hline $\mathrm{d} / \mathrm{s}$ of Scott confluence & 1.18 & 1.28 & -0.72 & 4.00 & 200 \\
\hline Entire domain & 1.29 & 1.02 & -0.01 & 5.69 & 1094 \\
\hline Domain d/s of Iron Gate & 0.80 & 0.76 & -0.52 & 4.00 & 895 \\
\hline
\end{tabular}

Table 12. Dissolved oxygen validation \#1 error data

\begin{tabular}{|c|c|c|c|c|c|}
\hline Location & $\begin{array}{c}\text { RMSE } \\
(\mathbf{m g} / \mathbf{l})\end{array}$ & $\begin{array}{c}\text { ABSE } \\
(\mathbf{m g} / \mathbf{l})\end{array}$ & $\begin{array}{c}\text { ME } \\
(\mathbf{m g} / \mathbf{)})\end{array}$ & $\begin{array}{c}\text { MAXE } \\
(\mathbf{m g} / \mathbf{)}\end{array}$ & $\mathbf{n}$ \\
\hline $\mathrm{d} / \mathrm{s}$ of JC Boyle & 1.19 & 0.90 & -0.67 & -2.83 & 175 \\
\hline $\mathrm{d} / \mathrm{s}$ of Copco & 1.46 & 1.27 & 1.24 & 2.90 & 15 \\
\hline $\mathrm{d} / \mathrm{s}$ of Iron Gate & 1.41 & 1.16 & 0.66 & -3.50 & 251 \\
\hline $\mathrm{d} / \mathrm{s}$ of Shasta confluence & 1.05 & 0.93 & 0.69 & 1.80 & 14 \\
\hline $\mathrm{d} / \mathrm{s}$ of Scott confluence & 0.73 & 0.53 & -0.31 & -2.1 & 14 \\
\hline Entire domain & 1.31 & 1.04 & 0.32 & -3.50 & 469 \\
\hline Domain d/s of Iron Gate & 1.37 & 1.12 & 0.34 & 2.91 & 279 \\
\hline
\end{tabular}

Table 13. Conductivity validation \#1 error data

\begin{tabular}{|c|c|c|c|c|c|}
\hline Location & $\begin{array}{c}\text { RMSE } \\
(\mu \mathrm{S} / \mathrm{cm})\end{array}$ & $\begin{array}{c}\text { ABSE } \\
(\mu \mathrm{S} / \mathrm{cm})\end{array}$ & $\begin{array}{c}\text { ME } \\
(\mu \mathrm{S} / \mathrm{cm})\end{array}$ & $\begin{array}{c}\text { MAXE } \\
(\mu \mathrm{S} / \mathrm{cm})\end{array}$ & $\mathbf{n}$ \\
\hline $\mathrm{d} / \mathrm{s}$ of JC Boyle & 35.90 & 24.00 & 20.15 & 117.60 & 277 \\
\hline $\mathrm{d} / \mathrm{s}$ of Copco & 12.99 & 9.79 & -4.52 & 28.9 & 15 \\
\hline $\mathrm{d} / \mathrm{s}$ of Iron Gate & 26.45 & 11.07 & -1.11 & -177.25 & 249 \\
\hline $\mathrm{d} / \mathrm{s}$ of Shasta confluence & 29.29 & 25.76 & -25.76 & -52.5 & 14 \\
\hline $\mathrm{d} / \mathrm{s}$ of Scott confluence & 32.49 & 29.42 & -23.82 & -47.60 & 14 \\
\hline Entire domain & 30.92 & 17.58 & -7.01 & -177.25 & 519 \\
\hline Domain d/s of Iron Gate & 26.81 & 12.31 & -16.90 & -177.25 & 277 \\
\hline
\end{tabular}

RMSE - root mean squared error, ABSE - absolute mean error, ME - mean error, $\overrightarrow{\mathrm{MAXE}}$ - maximum enror, $\mathrm{n}$ - number of data comparisons

Table 14. Model correlation coefficients for validation \#1

\begin{tabular}{|c|c|}
\hline Constituent & $\mathbf{R}^{2}$ \\
\hline Temperature & 0.853 \\
\hline DO & 0.342 \\
\hline Conductivity & 0.287 \\
\hline
\end{tabular}

Validation \#2 Goodness of Fit Results

Goodness of fit methods were applied to the 1998 validation model simulation. The summary statistics appear in Table 15 - Table 18 below. A complete set of plots that describe the comparison between model prediction and measured data can be seen in 
Appendix III. All input data to the water quality model for the validation process can also be found in the Appendix III of this report.

To ease the data manipulation for this validation, only daily average datasonde data were compared to the daily average conditions predicted by the model. This limited both the number of error comparisons and the magnitude of error somewhat, but provided ample data comparisons at both the upstream and downstream ends of the mainstem Klamath River reach. The number of data points compared using only the datasonde data is roughly the same as for DO and conductivity for the calibration and validation \#1.

Table 15. Temperature validation \#2 error data

\begin{tabular}{|c|c|c|c|c|c|}
\hline Location & $\begin{array}{c}\text { RMSE } \\
\left({ }^{\circ} \mathbf{C}\right)\end{array}$ & $\begin{array}{c}\text { ABSE } \\
\left({ }^{\circ} \mathbf{C}\right)\end{array}$ & $\begin{array}{c}\text { ME } \\
\left({ }^{\circ} \mathbf{C}\right)\end{array}$ & $\begin{array}{c}\text { MAXE } \\
\left({ }^{\circ} \mathbf{C}\right)\end{array}$ & $\mathbf{n}$ \\
\hline $\mathrm{d} /$ s of Iron Gate & 1.06 & 0.93 & -0.24 & -3.49 & 262 \\
\hline Seiad & 1.02 & 0.83 & -0.34 & -4.18 & 257 \\
\hline Entire domain & 1.04 & 0.88 & -0.32 & -4.18 & 519 \\
\hline
\end{tabular}

Table 16. DO validation \#2 error data

\begin{tabular}{|c|c|c|c|c|c|}
\hline Location & $\begin{array}{c}\text { RMSE } \\
(\mathbf{m g} / \mathbf{l})\end{array}$ & $\begin{array}{c}\text { ABSE } \\
(\mathbf{m g} / \mathbf{)})\end{array}$ & $\begin{array}{c}\text { ME } \\
(\mathbf{m g} / \mathbf{l})\end{array}$ & $\begin{array}{c}\text { MAXE } \\
(\mathbf{m g} / \mathbf{l})\end{array}$ & $\mathbf{n}$ \\
\hline $\mathrm{d} /$ s of Iron Gate & 1.41 & 1.20 & -0.07 & 3.55 & 262 \\
\hline Seiad & 1.21 & 1.03 & 0.76 & -4.33 & 257 \\
\hline Entire domain & 1.31 & 1.12 & 0.34 & -4.33 & 519 \\
\hline
\end{tabular}

Table 17. Conductivity validation \#2 error data

\begin{tabular}{|c|c|c|c|c|c|}
\hline Location & $\begin{array}{c}\text { RMSE } \\
(\mu \text { S/cm })\end{array}$ & $\begin{array}{c}\text { ABSE } \\
(\mu \text { S/cm })\end{array}$ & $\begin{array}{c}\text { ME } \\
(\mu \text { S/cm })\end{array}$ & $\begin{array}{c}\text { MAXE } \\
(\mu \text { S/cm })\end{array}$ & n \\
\hline $\mathrm{d} /$ s of Iron Gate & 21.98 & 14.57 & 13.07 & 76.9 & 261 \\
\hline Seiad & 29.74 & 23.15 & -19.71 & -72.78 & 248 \\
\hline Entire domain & 26.05 & 18.75 & -2.90 & 76.9 & 509 \\
\hline
\end{tabular}

RMSE - root mean squared error, ABSE - absolute mean error, ME - mean error, MAXE - maxirnum error, $n$ - number of data comparisons

Table 18. Model correlation coefficients for validation \#2

\begin{tabular}{|c|c|}
\hline Constituent & $\widehat{\mathbf{R}}^{\mathbf{2}}$ \\
\hline Temperature & 0.972 \\
\hline DO & 0.468 \\
\hline Conductivity & 0.091 \\
\hline
\end{tabular}




\section{SIAM historic temperature validation goodness of fit results}

The 37 year historic SIAM simulation of water temperatures yielded a very large output dataset. A demonstration of the representative fit of the model prediction to the data for Iron Gate and Seiad are presented in Figure 10. These plots show a 5 to 6 year period during the simulation. Error statistics for comparison of this model output with the measured dataset resulted for Iron Gate Dam and Seiad are presented in Table 19.
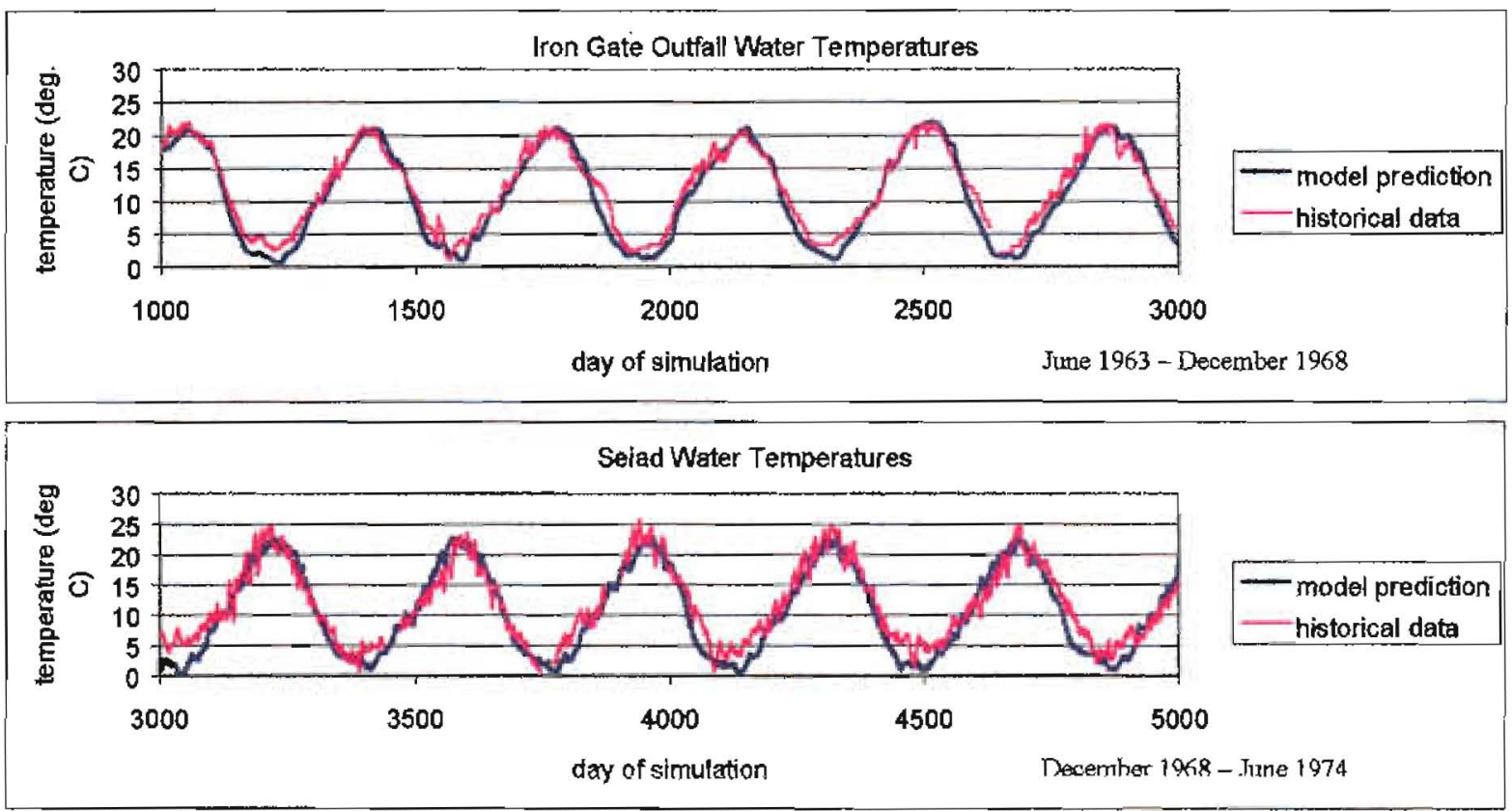

Figure 10. Representative output for Iron Gate and Seiad from the SIAM historical validation

Table 19. Error statistics for SIAM historical temperature validation

\begin{tabular}{|c|c|c|c|}
\hline Error Statistic & Iron Gate Dam & Seiad & All Data \\
\hline $\mathrm{n}$ & 6495 & 5320 & 11815 \\
\hline $\operatorname{RMSE}\left({ }^{\circ} \mathrm{C}\right)$ & 1.9 & 2.8 & 2.3 \\
\hline $\mathrm{ABSE}\left({ }^{\circ} \mathrm{C}\right)$ & 1.5 & 2.3 & $\mathbf{1 . 8}$ \\
\hline $\mathrm{ME}\left({ }^{\circ} \mathrm{C}\right)$ & -0.9 & -1.3 & -1.1 \\
\hline $\mathrm{MAXE}\left({ }^{\circ} \mathrm{C}\right)$ & -6.4 & 8.1 & $\mathbf{8 . 1}$ \\
\hline $\mathrm{R}^{2}$ & 0.95 & 0.88 & 0.92 \\
\hline
\end{tabular}

RMSE - root mean squared exkor, ABSE - absolute mean error, ME - mean exror, MAXE - maximum error, n - number of data comparisons

The SIAM temperature prediction is within an absolute error of $1.8^{\circ} \mathrm{C}$. For calibration and validation, the model prediction was within an absolute exror of $1^{\circ} \mathrm{C}$. These error statistics are for a large population, a much larger set than the one year calibration and validation simulations. 


\section{Discussion}

This report discusses the model development, calibration and validation of the water quality model within SIAM. The calibration and validation have been performed apart from SIAM and therefore the estimates of model prediction are for the water quality model only. A validation of the water temperature prediction of SIAM as a whole for a long historical simulation was also presented.

The water temperature predictions computed by the calibrated model are within an absolute error of $1^{\circ} \mathrm{C}$, as compared to measured data. This is considered a very good temperature calibration based on daily average computations. Previous applications of HEC5Q have found that calibration within $1^{\circ} \mathrm{C}$ is considered the accuracy potential of the HEC5Q model for temperature USACOE (1993). HEC5Q temperature prediction is the most trusted of all the constituents simulated. The most complete set of required temperature data was available for the calibration period and the largest set of model tuning parameters also exists for temperature calibration.

The dissolved oxygen calibration is satisfactory to identify general annual trends. The simplified dissolved oxygen system used in HEC5Q is difficult to calibrate correctly. Without simulating plant growth and the associated nutrients, the model prediction of DO is not chemically complete and predicted annual changes in DO do not reflect all the influences present in the basin. However general trends in DO are in fact predicted and are within an absolute error of $1-2 \mathrm{mg} / \mathrm{D} \mathrm{DO}$ for the mainstem Klamath.

The calibration for conductivity points out the need for a complete data set. Conductivity data for the Shasta and Scott Rivers were unavailable for the calibration period. This is seen in a poor comparison of model prediction with measured data at Seiad. However general trends within an absolute error of $30 \mu \mathrm{S} / \mathrm{cm}$ are predicted.

The model validation exercises demonstrate the water quality model's ability to predict water quality to the level of confidence demonstrated in calibration. The calendar year 1998 validation resulted in the best error statistics. The model predictive ability reflects the level of detail of the input data. Continuous daily average of tributary water quality available for 1998 was used for model input. This high-quality input data drives the model to some degree and results in higher quality predictions. Comparison of the model prediction to continuous daily average datasonde data provides a direct comparison between measured and simulated values and actively reflects the quality of model performance.

The performance of SIAM as a whole to predict water temperatures for many years is not as accurate as the one-year HEC5Q simulations. The absolute error for SIAM's temperature prediction is within $1.8^{\circ} \mathrm{C}$, compared to within $1{ }^{\circ} \mathrm{C}$ when the water quality model is run standalone for one year. The increase in error of the prediction for this historical simulation is as a result of the large quantities of data that were estimated for this 37 year simulation. The flows were provided by the calibrated MODSIM model for the basin that is known to have up to a $10 \%$ error on a monthly basis. A different meteorological data source was used and adjustments made to fit this data to the basin location. The variation in inflow water quality from year to year is not represented. One year of Keno data (1996) was used for the tributaries for every year in the simulation. Even with these limitations, for long historical simulations, the water quality model seems to simulate temperature fairly well, although an overall under-prediction bias is 
apparent (i.e., negative value for mean error, ME). Both the temporal and spatial variability in the observed data seems to be preserved in the output from model simulations.

Analysis of the error computations for calibration and validation describe quantitatively the ability of the model to predict the different water quality constituents throughout the Klamath Basin. The ability of the model to predict any individual daily constituent value is best described by the Absolute Mean Error (ABSE) measurement for the entire domain. The overall model prediction for any constituent over the entire simulation period and domain is best described by the Mean Error (ME) measurement. This error measurement will yield a measure of over or underprediction of the model for the simulation. The largest $\mathrm{ABSE}$ and $\mathrm{ME}$ error values that were found during calibration or validation are presented in Table 20 below. These values describe the upper bound of the model error that was found during model development.

Table 20. Water quality model predictive estimates

\begin{tabular}{|c|c|c|}
\hline Constituent & Individual prediction & Overall prediction \\
\hline Temperature & within $1.02^{\circ} \mathrm{C}$ & underestimated by $0.32^{\circ} \mathrm{C}$ \\
\hline Dissolved Oxygen & within $1.12 \mathrm{mg} / 1$ & underestimated by $0.55 \mathrm{mg} / 1$ \\
\hline Conductivity & within $19 \mu \mathrm{S} / \mathrm{cm}$ & overestimated by $9 \mu \mathrm{S} / \mathrm{cm}$ \\
\hline
\end{tabular}

The range of ABSE values are similar for calibration and validation for all constituents. This indicates that the calibrated model is able to predict water quality reasonably well for an independent input data set. Overall, the model ${ }^{9} \mathrm{~s}$ ability to predict water quality below Iron Gate dam was not significantly improved over the prediction for the entire domain. The general overprediction or underprediction of constituents was inconsistent between calibration and validation runs, so a determination of general overor underprediction can not be made. The error computations for calendar year 1998 validation are also slightly better than those computed for model calibration or water year 1997 validation. This may reflect the need for high quality Shasta and Scott River input water quality data in order to provide the best possible model prediction. Data from Keno were used to represent Shasta and Scott River water quality within SIAM during altemative simulations. The use of this representative data may introduce errors in water quality prediction for the alternative under study. These errors would, however, be consistent among SIAM simulations because representative data is used consistently for all alternative simulations.

The magnitudes of $\mathrm{R}^{2}$ values are fairly consistent between model calibration and validation as described in Table 10, Table 14 and Table 18. The model's predictive ability for each constituent can be evaluated directly by the $\mathrm{R}^{2}$ values and expressed as a percent of the overall variations in the measured data that are described by the model. These values are presented in Table 21.

Table 21. Model predictive ability for each constituent

\begin{tabular}{|c|c|}
\hline Constituent & Variation Described by The Model \\
\hline Temperature & $85-97 \%$ \\
\hline Dissolved Oxygen & $34-47 \%$ \\
\hline Conductivity & $9-2 \overline{9} \%$ \\
\hline
\end{tabular}


More than $85 \%$ of the water temperature variations over a year throughout the Klamath Basin were predicted by the model. This accurate prediction of temperature is consistent with the level of detail in the HEC5Q model. The model simulates most of the physical processes that change water temperature in the river. The driving forces of meteorology and mixing as well as the geometry of the basin are well represented in the model and provide adequate information to compute the changes in water temperature throughout the Klamath Basin.

The confidence in the DO prediction is lower than that of temperature; less than $50 \%$ of the measured variations are predicted by the model. Changes in DO are a result of a suite of chemical reactions, only a few of these, namely reaeration and simplified BOD, are estimated within the model. The water quality model for the Klamath Basin does not currently simulate nutrients and algal growth. Algae produce oxygen during photosynthesis and use oxygen during respiration. Furthermore, the oxidation of nutrients and the decay biomass results in oxygen depletion in the river. These chemical interactions are not simulated within the model. Instead they are estimated by constant values of $B O D$. The DO saturation of the water is a function of temperature. Thus, errors in temperature predictions could result in errors in DO values. A large number of factors influence the $\mathrm{DO}$ of the water in the Klamath basin. Only a small subset of these are estimated by the model. Observed errors in prediction of DO are at least partially attributable to model limitations.

Confidence in the model prediction of conductivity is the lowest of all constituents simulated. Conductivity is a conservative tracer, i.e., this constituent does not decay via chemical reactions. The mixing of waters of different conductivity is the only process that changes the in-river conductivity in the model. The large errors and the low $\mathrm{R}^{2}$ value, demonstrates that the conductivity (and hence water quality) of all inflow water is not well represented. If the quantity and conductivity of all water in the basin were known, through mass balance computations performed by the model, the in-river conductivity would be better predicted. The poor prediction of the conservative conductivity constituent demonstrates that estimates of the water quality of the inflow and accretion water to the Klamath River and its reservoirs may not be highly accurate.

The ability of the water quality model within SIAM to compute daily average water quality based on monthly flows is within reasonable ranges. The errors within daily average predictions of temperature and DO are most definitely within the diurnal ranges of water quality seen in the Klamath River.

It should be reiterated that the water quality model for the Klamath Basin is a onedimensional representation of the reservoirs and river reaches within the Klamath, where only the major physical processes that affect changes in water quality are represented in the model computations. Within SIAM, the water quality model is very effective at describing water quality throughout the basin as a result of water management changes. The basin water management is provided by the MODSIM model using a monthly timestep. The water quality of the ungaged inflow water to the basin's reservoirs and river reaches is characterized using representative and estimated data. The meteorological data for a simulation is selected from a small group of historical datasets. The water quality model predictions based on these conditions are displayed numerically and graphically. Given the relatively small known errors, this relatively simple 
mathematical model, used to predict the daily average water quality throughout a complex basin for one-year time periods, is a very valuable predictive tool.

The ability to exactly predict all water quality constituents is not the goal of this modeling exercise. This tool will be used as a 'laboratory apparatus' to make qualitative and quantitative predictions about how the water quality is changed as a result of a variety of water nanagement options. This was the goal of the System Management Flexibility study (Hanna et al., 1999) where extremes of water management were simulated and the resulting water quality changes quantified.

\section{Future Work}

The water quality model within SIAM is still under development. Future work includes extension of the model domain both upstream to include Upper Klamath Lake and downstream to include the influence of the Salmon and Trinity Rivers and simulation of the mainstem to the River's mouth at the Pacific Ocean. Characterization of the inflow water quality for each individual tributary is a high priority task. This will include the development of regression models for the creation of complete historical data sets for each tributary. Recalibration to minimize model error may be required for this extended model domain. Calibration simulations will be performed for multiple years using SIAM as a whole. With the increased size of the water quality model domain a second meteorological zone, characterizing the coastal area, will be added and representative meteorological data will be used. This development will make the water quality model application for the Klamath Basin more complete and the Klamath Systems Impact Assessment model more informative for its users. 


\section{References}

American Public Health Association(APHA). 1992. Standard Methods for the Examination of Water and Wastewater; $18 \mathrm{ed}$, Washington, DC.

Bartholow, J., J. Sandelin, B.A.K. Coughlin, J. Laake, and A. Moos. 1997. SALMOD: A Population Model for Salmonids: User's Manual. Version 2.0. USGS/MESC Internal publication. $89 \mathrm{pp}$.

Bartholow, J. 1998. SIAM - A System Impact Assessment Model for Riverine Ecosystems. Chronicle of Instream Flow Activities; USGS, Ft. Collins, CO. Vol 2(2) online at http://www.mesc.usgs.gov/rsm/ifim-chron/2-2Chronicle/siam.htm

Chapra, S. C. and R. P. Canale. Numerical Methods for Engineers, New York: McgrawHill Inc. 2nd Edition. 1988.

Chapra, Steven C., Surface Water-Quality Modeling, New York: McGraw-Hill Companies, Inc. 1997.

Chaudry, M. H. Open-Channel Flow. Englewood Cliffs: Prentice-HaIl, Inc. 1993.

Deas, Michael, 1997, Personal Communication, Doctoral Student, Water Resources and Modeling Group, Civil and Environmental Engineering, University of California, Davis, CA.

Earthinfo, Inc. 1996a. Database Guide for Earthinfo $\mathrm{CD}^{2}$ NCDC Surface

Airways. Boulder, Colorado. $3 \mathrm{~cd}$ 's, one install diskette, one documentation manual.

Earthinfo, Inc. 1996b. NCDC Summary of the Day. Boulder, Colorado. $2 \mathrm{~cd}^{\text {s }}$, two install diskettes, one documentation manual.

Earthinfo, Inc. 1996c. USGS Quality of Water. Boulder, Colorado. 2 cd's, one install diskette, one documentation manual.

Flug, M. and J. F. Scott. 1998. Modeling and Management of Water in the Klamath River Basin: Overcoming Politics and Conflicts. In: ASCE 1998 International Water Resources Engineering Conference Proceedings, Water Resources Engineering 98", Abt, S. R., et. Al., (Editors), American Society of Civil Engineers, VA, Vol. 1, 938-943.

Flug, M and J.F Scott, June, 1996 - August, 1997. 11 Task Reports to Klamath River Fisheries Task Force.

Haber, A. and R. P. Runyon, General Statistics, Menlo Park: Addison-Wesley Publishing Company, 1969. 
Hanna, R. B. 1997. Water Quality Modeling in the System Impact Assessment Model, Case Study: Klamath Basin, Prototype Final Report.

Hanna, R. B., 1998. Water Quality Modeling in the System Impact Assessment Model, Case Study: Klamath Basin, Addendum to Prototype Final Report.

Hanna, R.B., S. Campbell, M. Flug and J. Scott. 1999. Using Models to Evaluate System Management Flexibility on Water Quantity and Quality: Klamath River., Manuscript: submitted to ASCE Journal of Water Resources Planning and Management July, 1999 ,

Hanna, R.B., S. Campbell and J. Bartholow. 2000. Water Quality Modeling (HEC5Q) and Systems Impact Assessment Modeling (SIAM) for U.S. Bureau of Reclamation, Klamath Project Operations in FY2000。 USGS/BRD. Final Contract Completion Report for Interagency Agreement Number 00-AA-20-0027. Version 2.0. January, 2000.

Henriksen, $\mathrm{J}$ and T. Shaw, Mesohabitat Study Segment Data, Unpublished data provided by USGS/BRD and US Fish and Wildlife Service.

Hydrolab Corporation, May 1995, Recorder TM Water Quality Multiprobe LoggerOperating Manual.

Labadie, J.W. 1988. Program MODSIM: River basin network flow model for the microcomputer. Department of Civil Engineering, Colorado State University, Ft. Collins, Colorado.

PacifiCorp, 1995, Klamath River Hydrodevelopment Information, (unpublished data)

OSSA, Oregon State Sanitary Authority. 1964. Final report on the quality of Klamath Basin water in Oregon. July 1959 to December 1963.

Scott, J. F. and M. Flug. 1998. Modeling With MODSIM: Klamath River Basin Water Quantity for Protecting Fish and Other Resource Values. In: First Federal Interagency Hydrologic Modeling Conference Proceedings, Subcommittee on Hydrology of the Interagency Advisory Committee on Water Data, Las Vegas, Nevada. April 19-23, 1998; Vol 2, 8-103-8-110.

US Army Corps of Engineers. 1986. HEC-5 Simulation of Flood Control and Conservation Systems, Appendix on Water Quality Analysis, 220pp.

US Army Corps of Engineers, 1993. McKenzie River Water Temperature Study Project Report.

USGS/BRD. 1995. Compilation of Phase I Reports for the Klamath Basin. River Systems Management Section, NBS-Midcontinent Ecological Sciences Center, Fort Collins, CO. 
USGS California Hydrologic Data Report for water year 1996.

USGS California Hydrologic Data Report for water year 1997.

Zison, S. W., Mills, W. B., Diemer, D., and Chen, C. W. 1978. Rates, Constants, and Kinetic Formulations in Surface Water Quality Modeling, U.S. EPA, ORD, Athens, GA. ERL, EPA/600/3-78-105.

\section{Acknowledgments}

Thanks to John Bartholow, Zack Bowen, Michael Deas, Marshall Flug, Jim Henriksen and Ken Mangelson for providing comments on drafts of this report. 


\section{Appendix I \\ Calendar Year 1996 Calibration Plots}

\section{Input Flow Data}

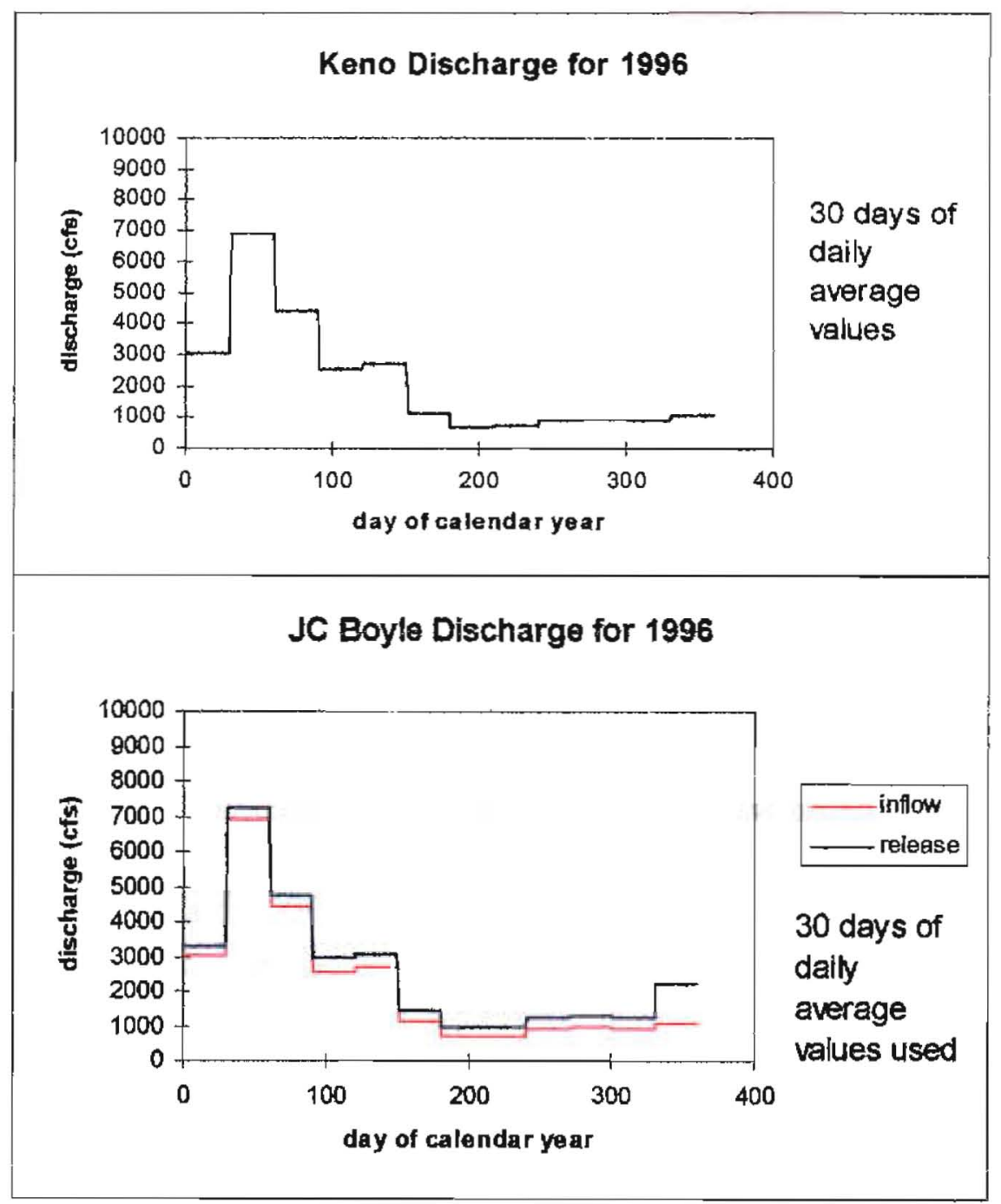




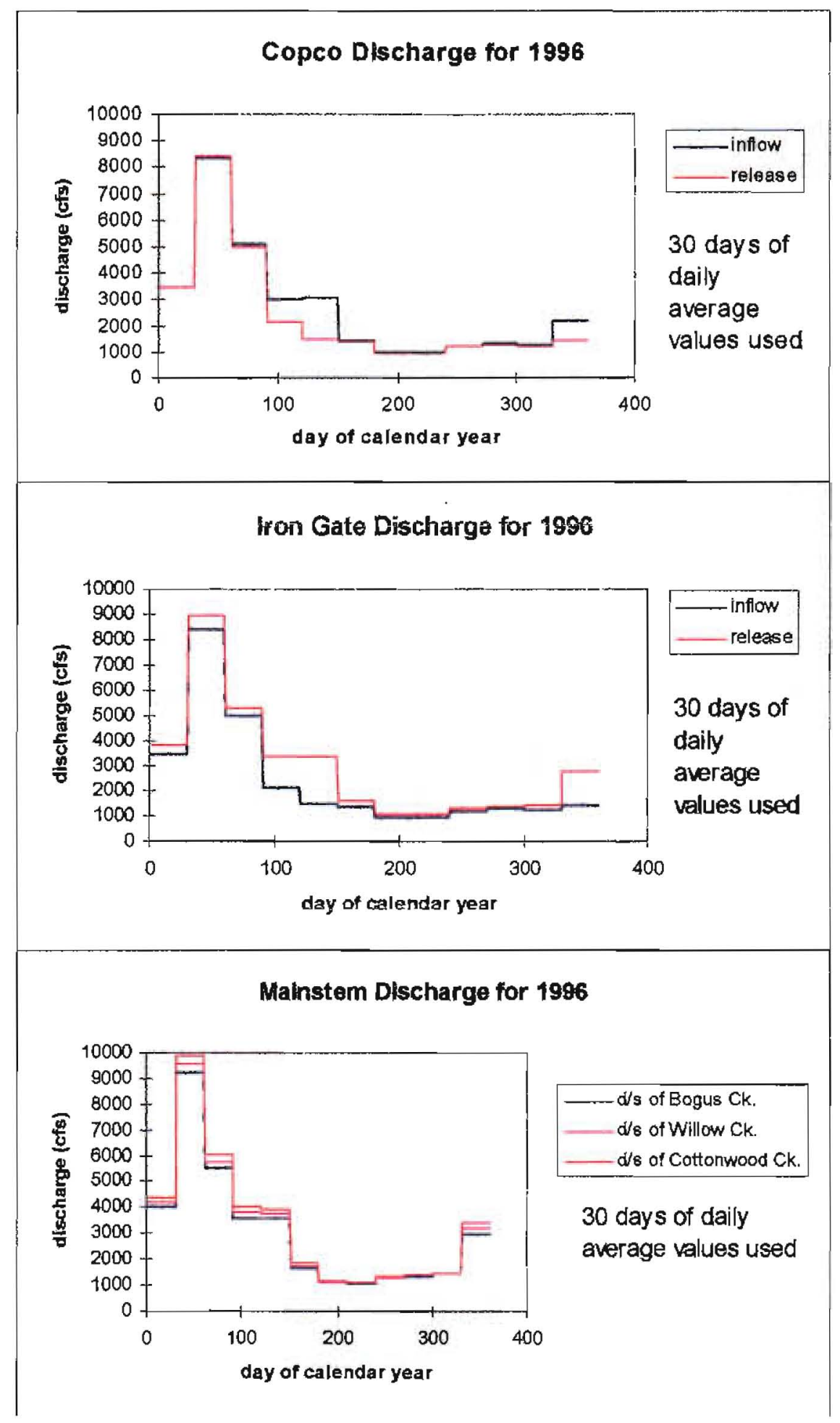

Mainstem Discharge for 1996

30 days of daily average values used 


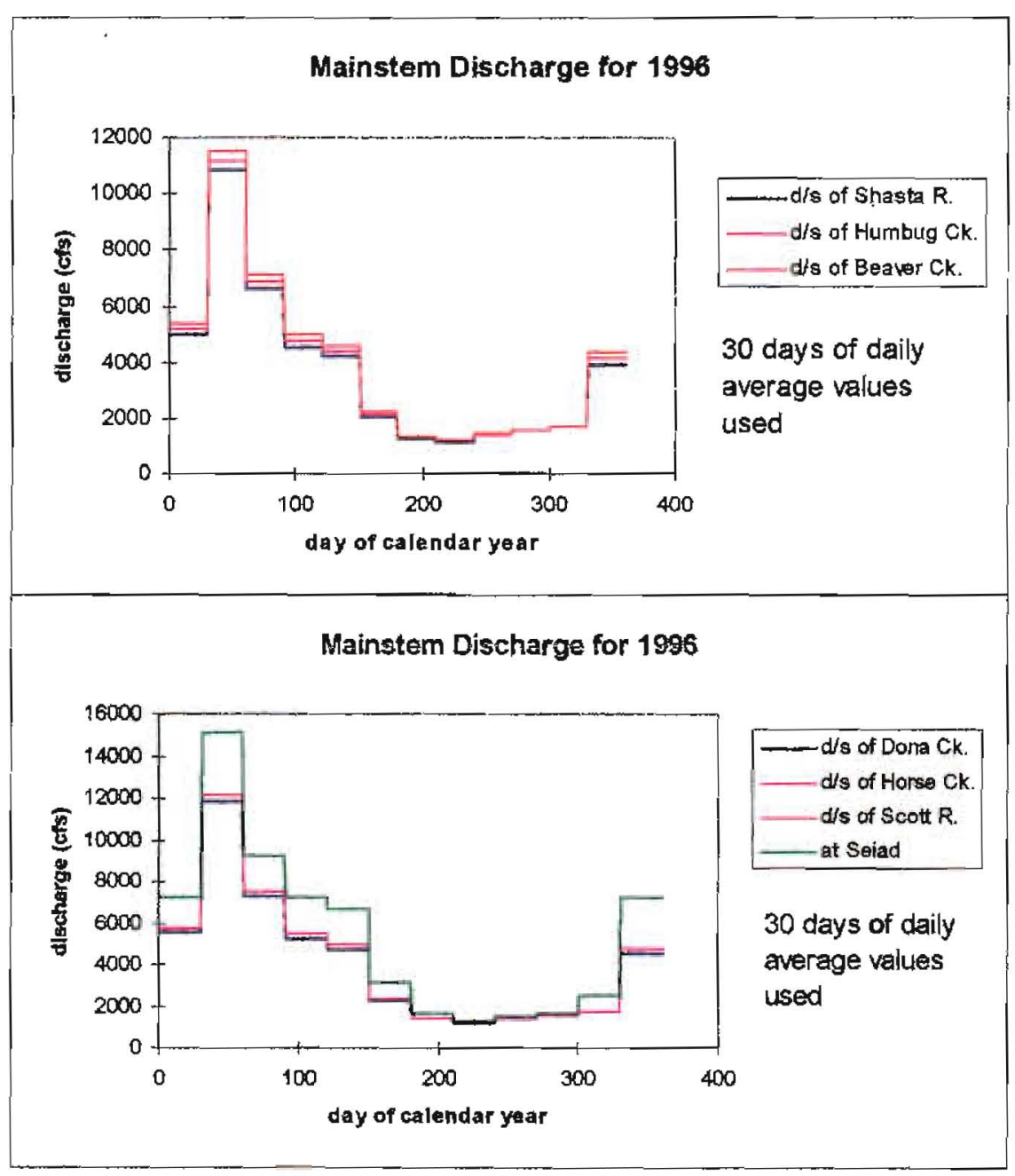


Input Meteorological Data

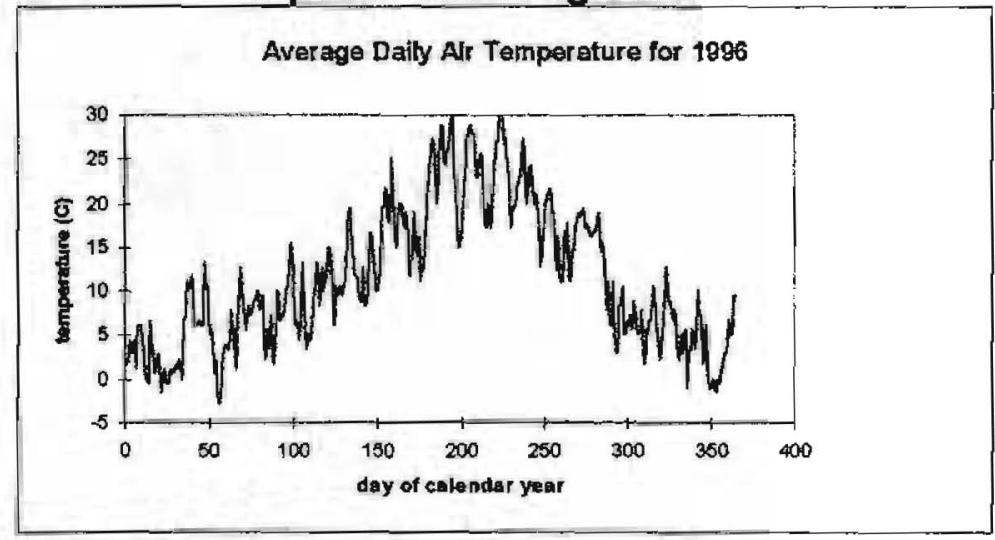

Average Daily Dew Polnt Temperature for 1996

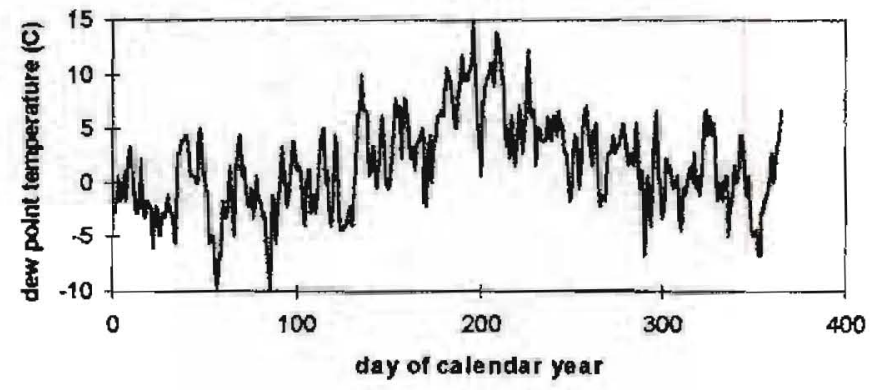

Average Daily Wind Speed for 1996

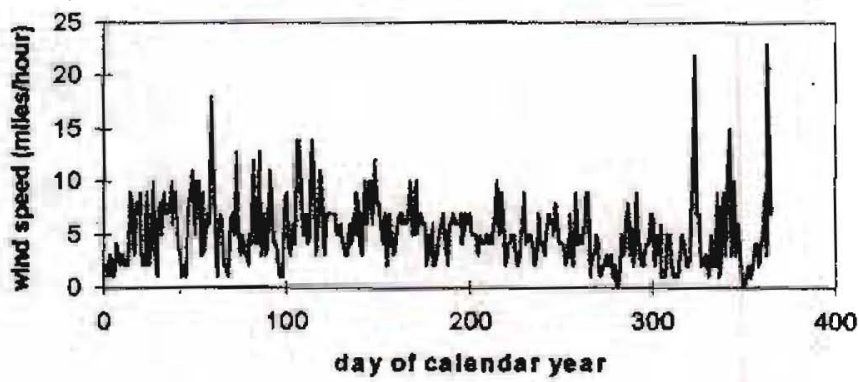

Dally Average Cloud Cover for 1996

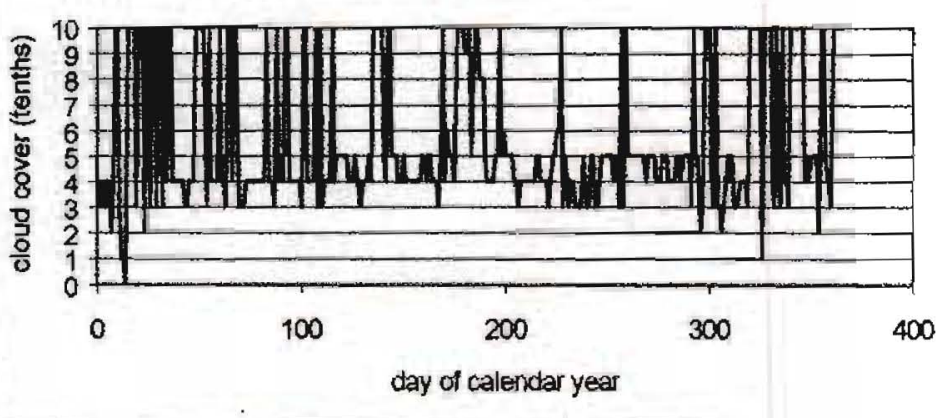


Input Water Quality Data

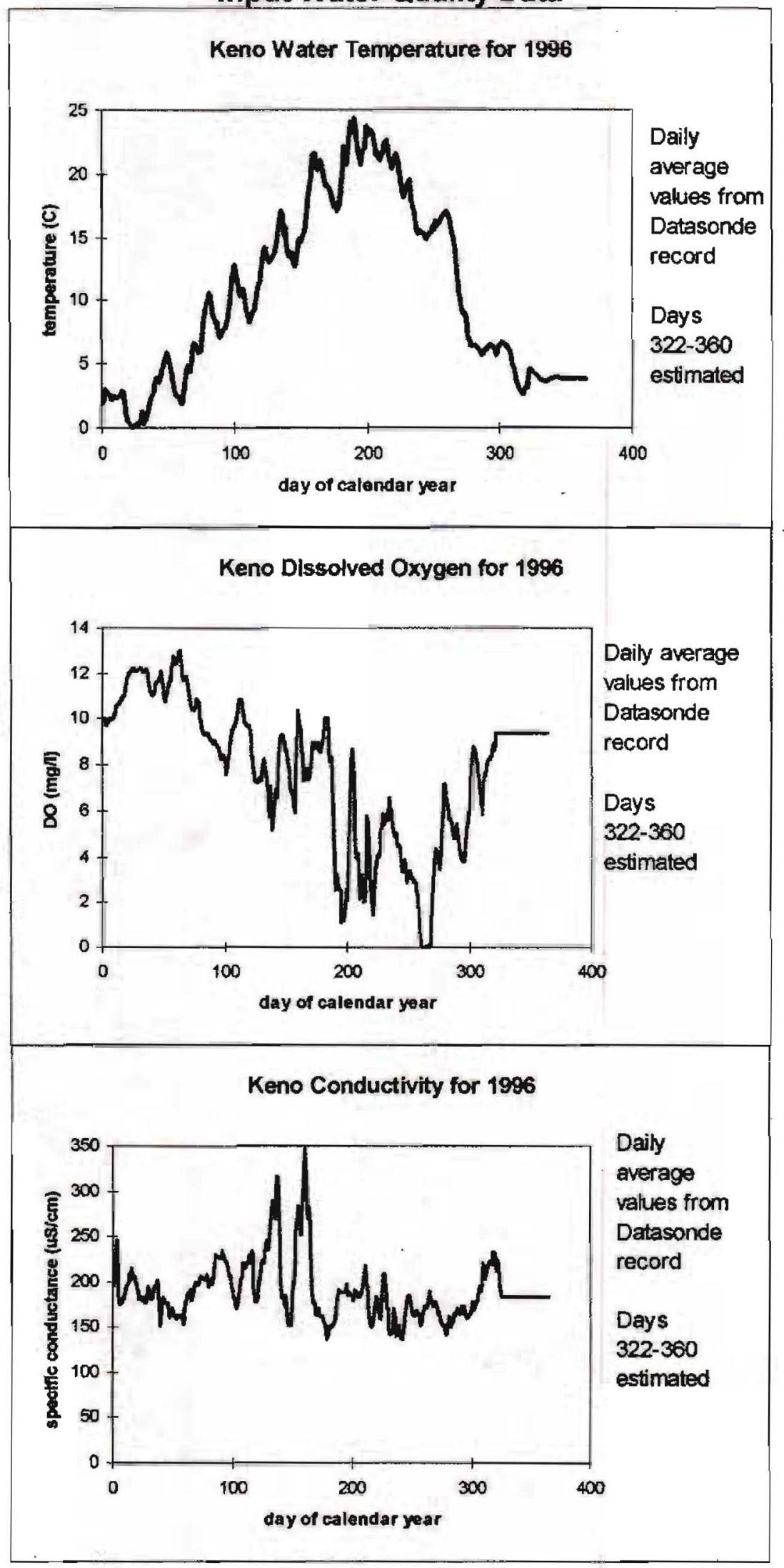


Input Tributary Temperature Data

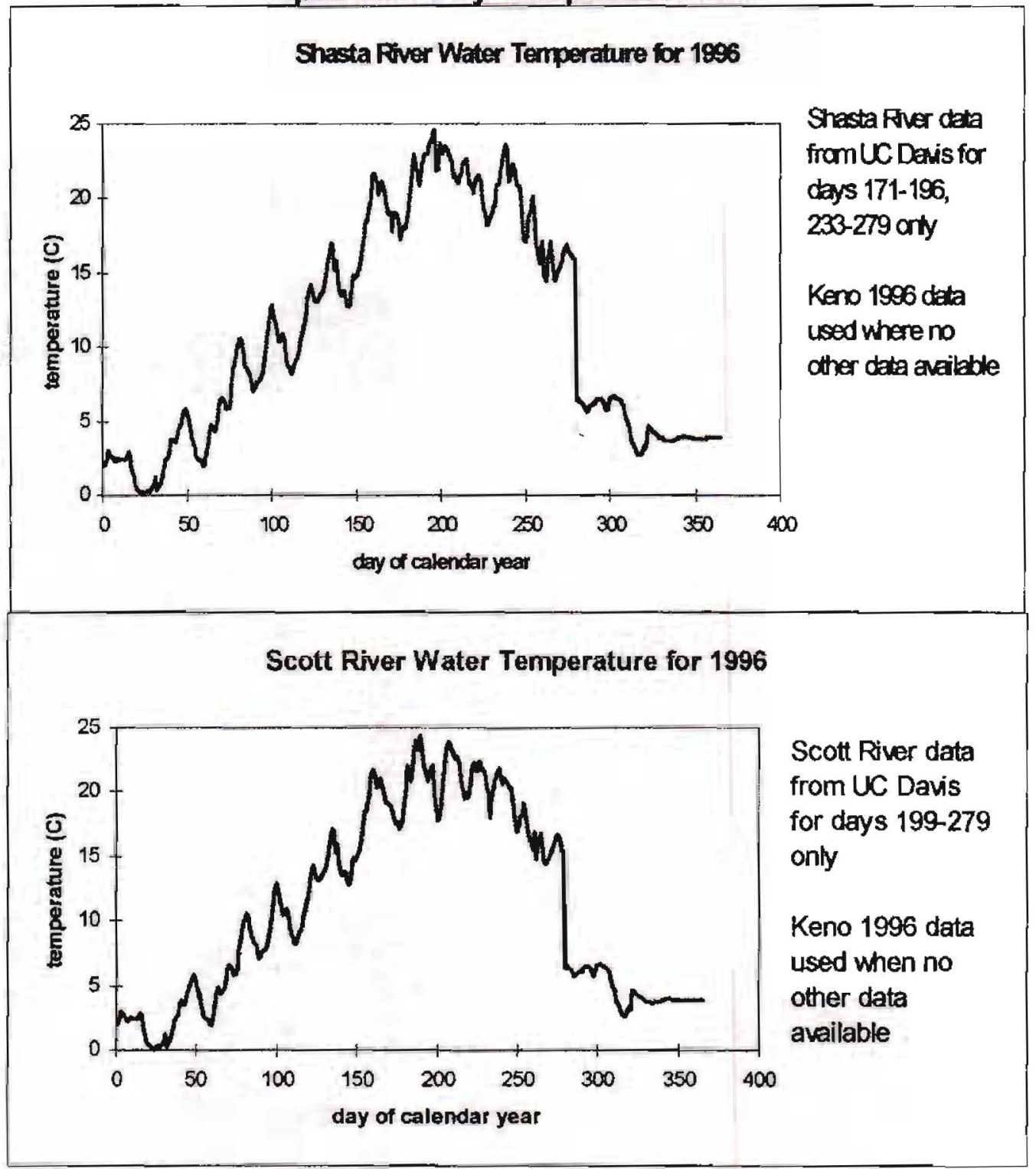




\section{Reservoir Model Results - Water Temperature Profiles Copco Reservoir}

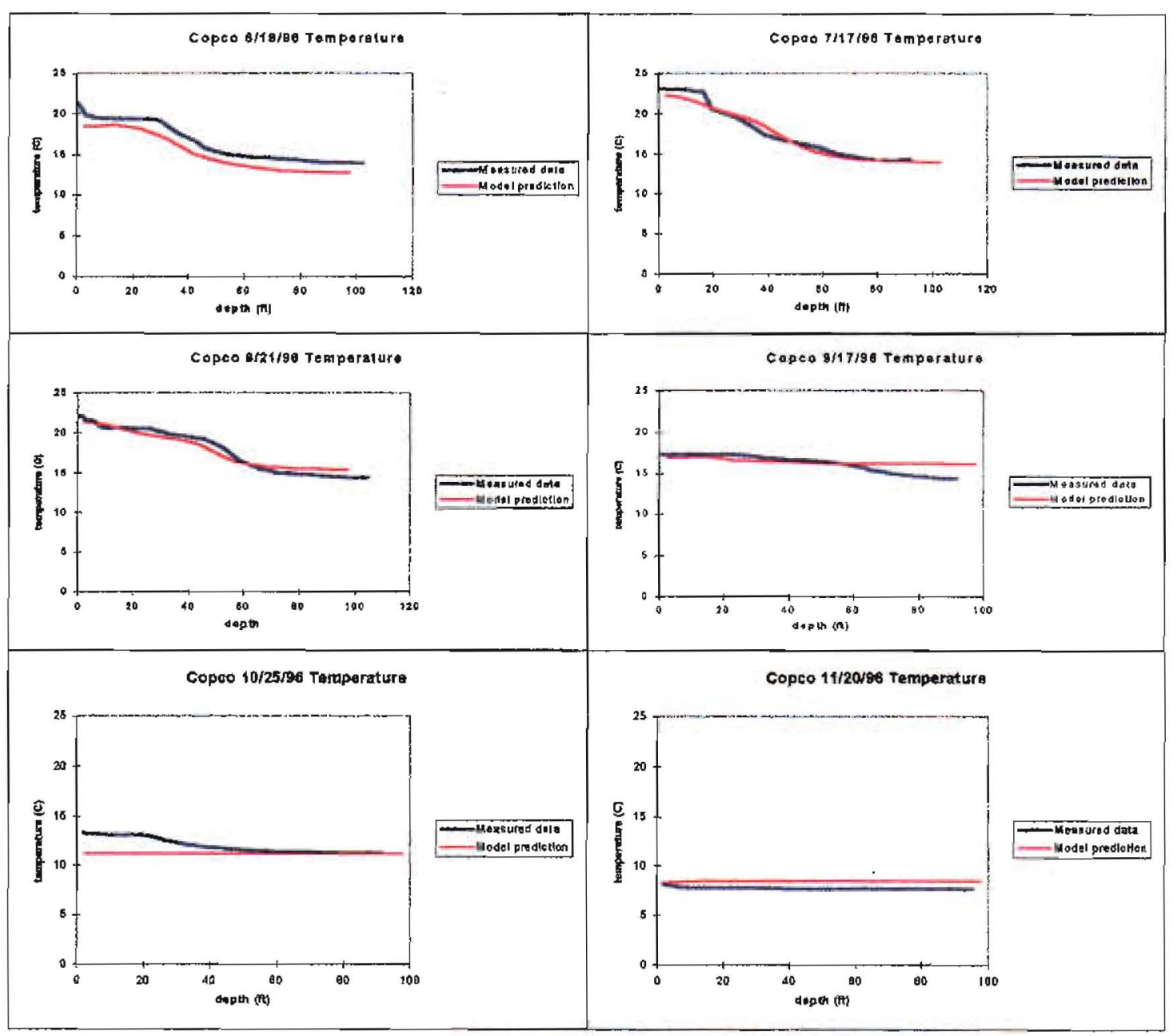


Reservoir Model Results - Water Temperature Profiles Iron Gate Reservoir

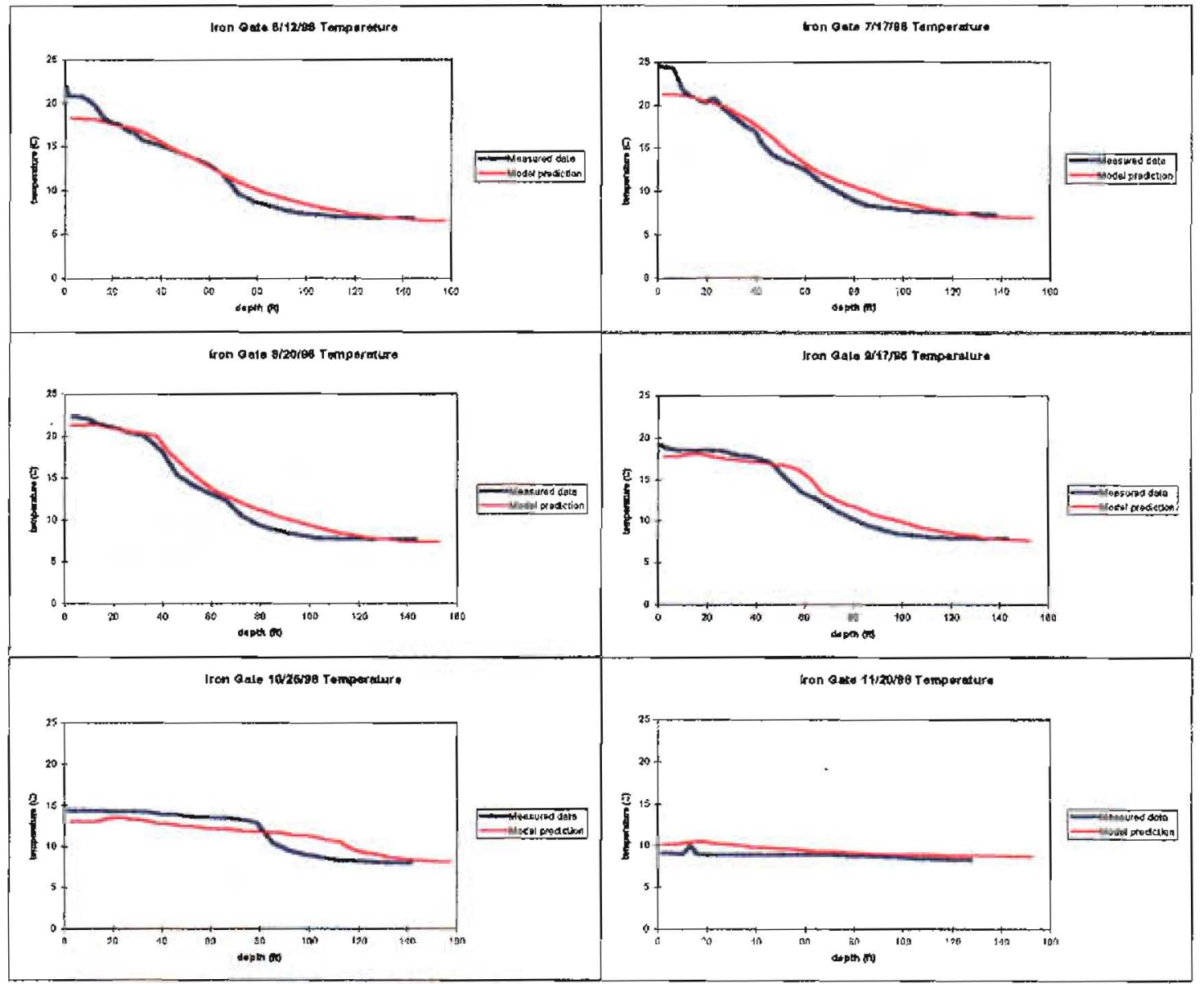




\section{Reservoir Model Results - Dissolved Oxygen Profiles}

Copco Reservoir

(10)



Reservoir Model Results - Dissolved Oxygen Profiles
Iron Gate Reservoir

(10)




\section{Reservoir Model Results - Conductívity Profiles}

Copco Reservoir

(10)




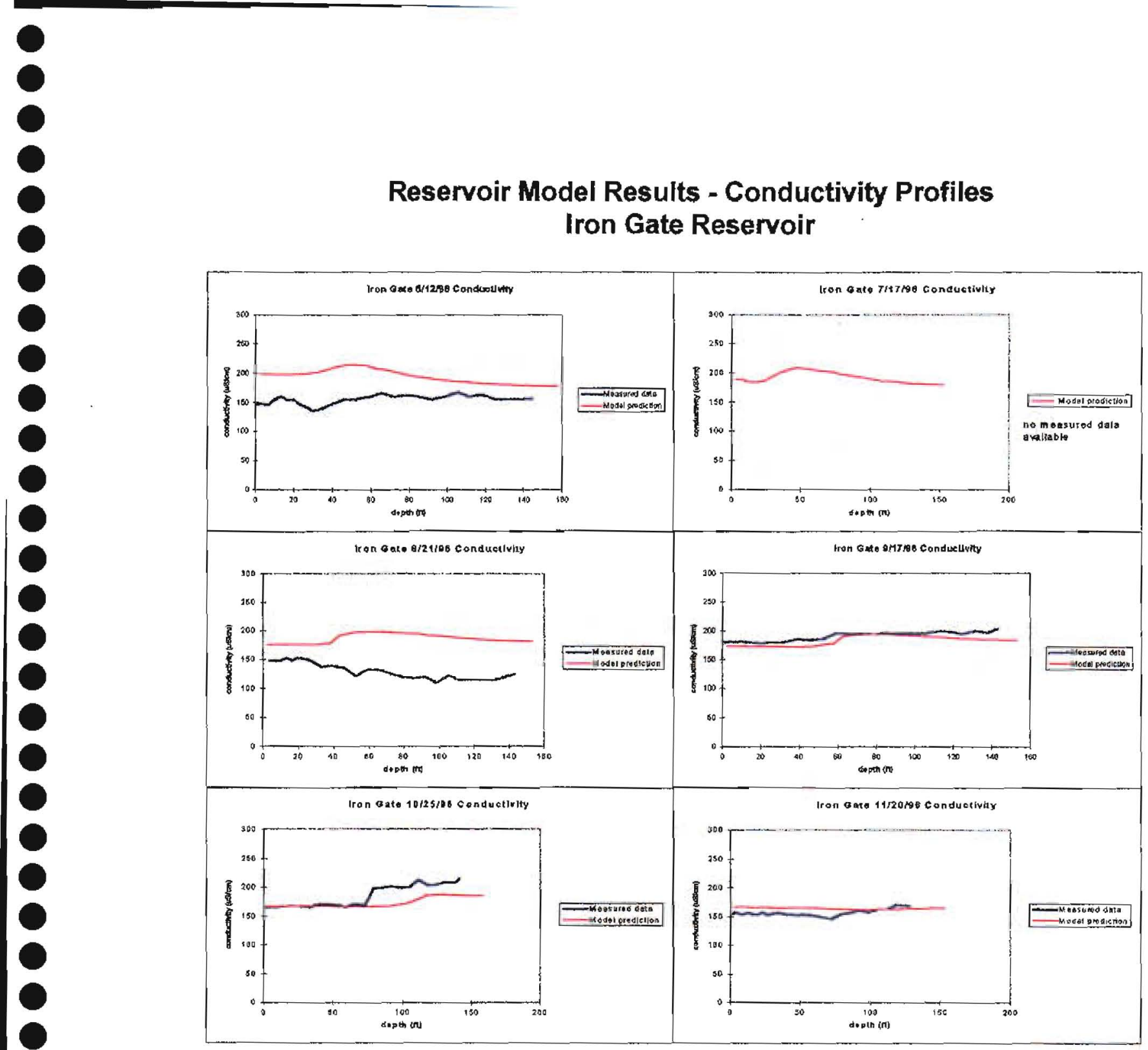


River Model Results - Comparison of Model Temperature, DO and Conductivity Predictions With Measured Data

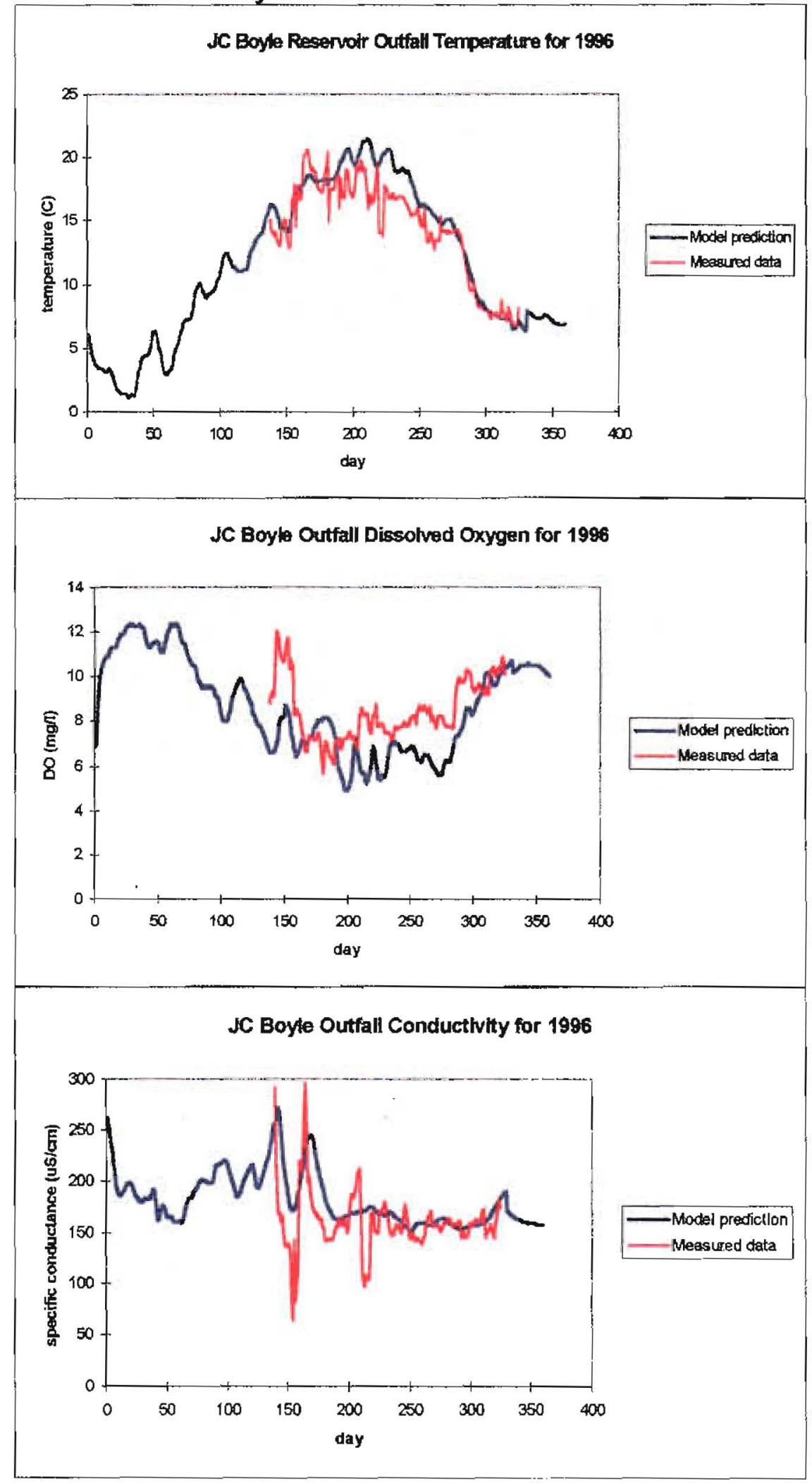




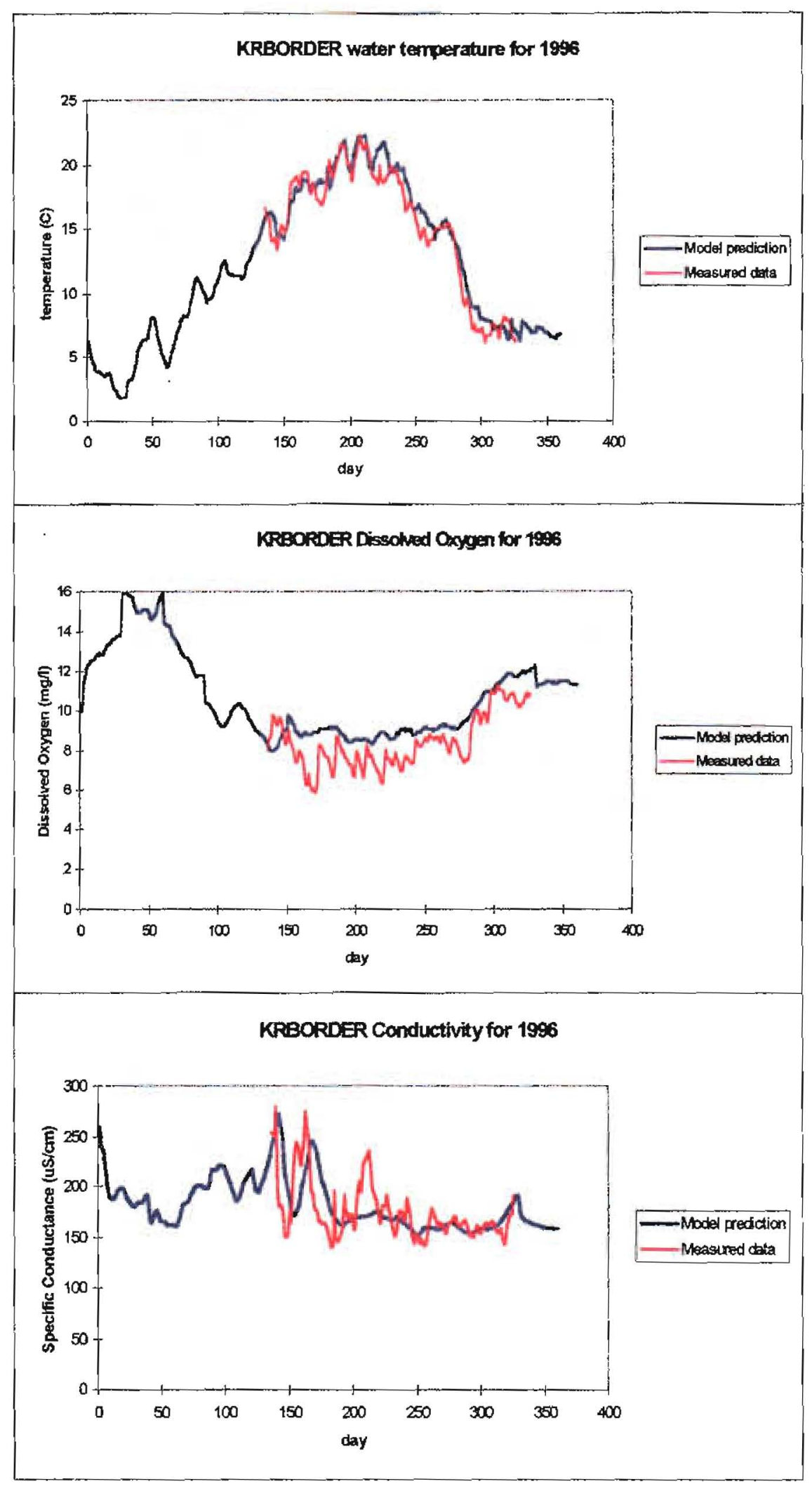




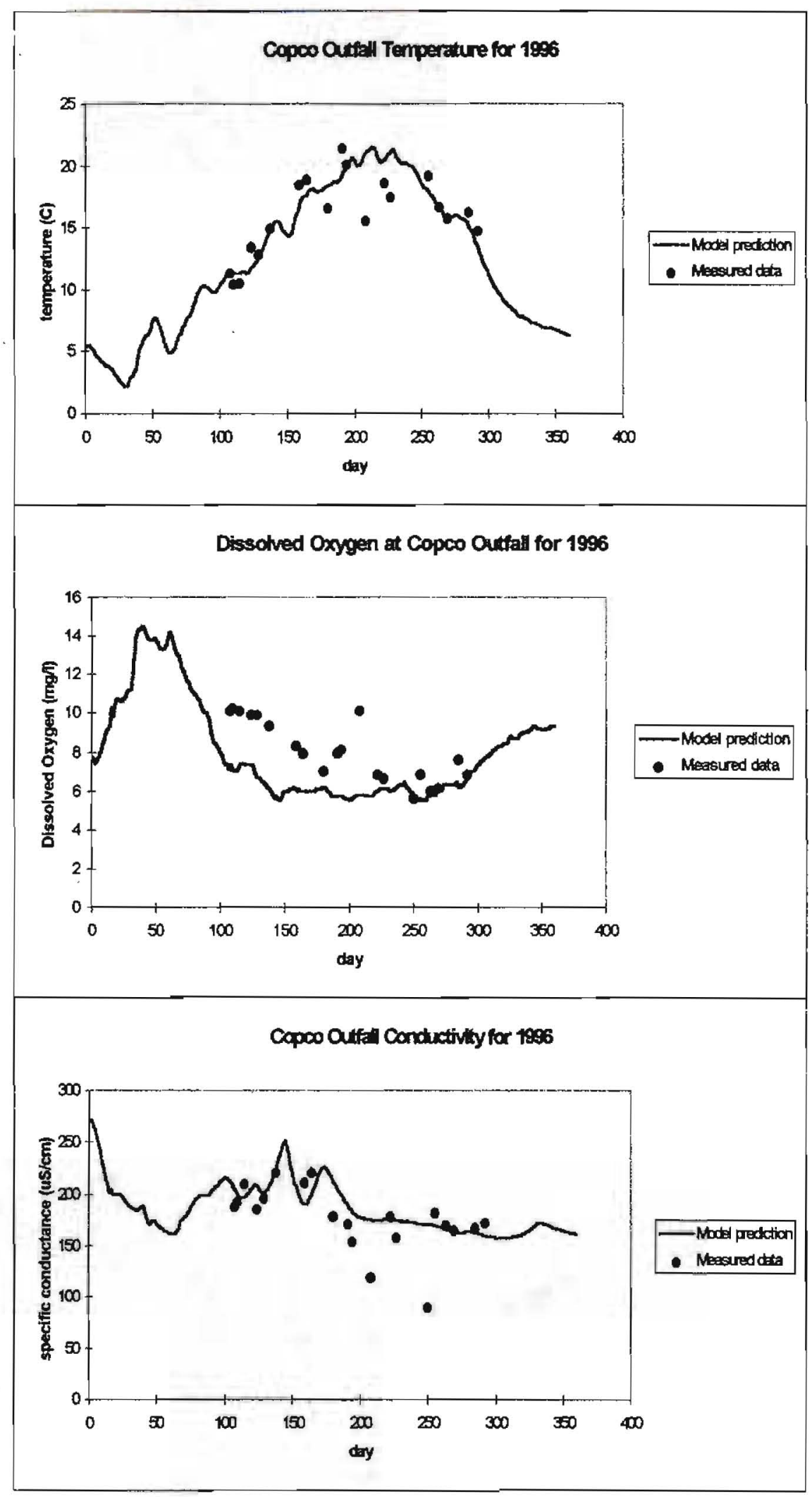




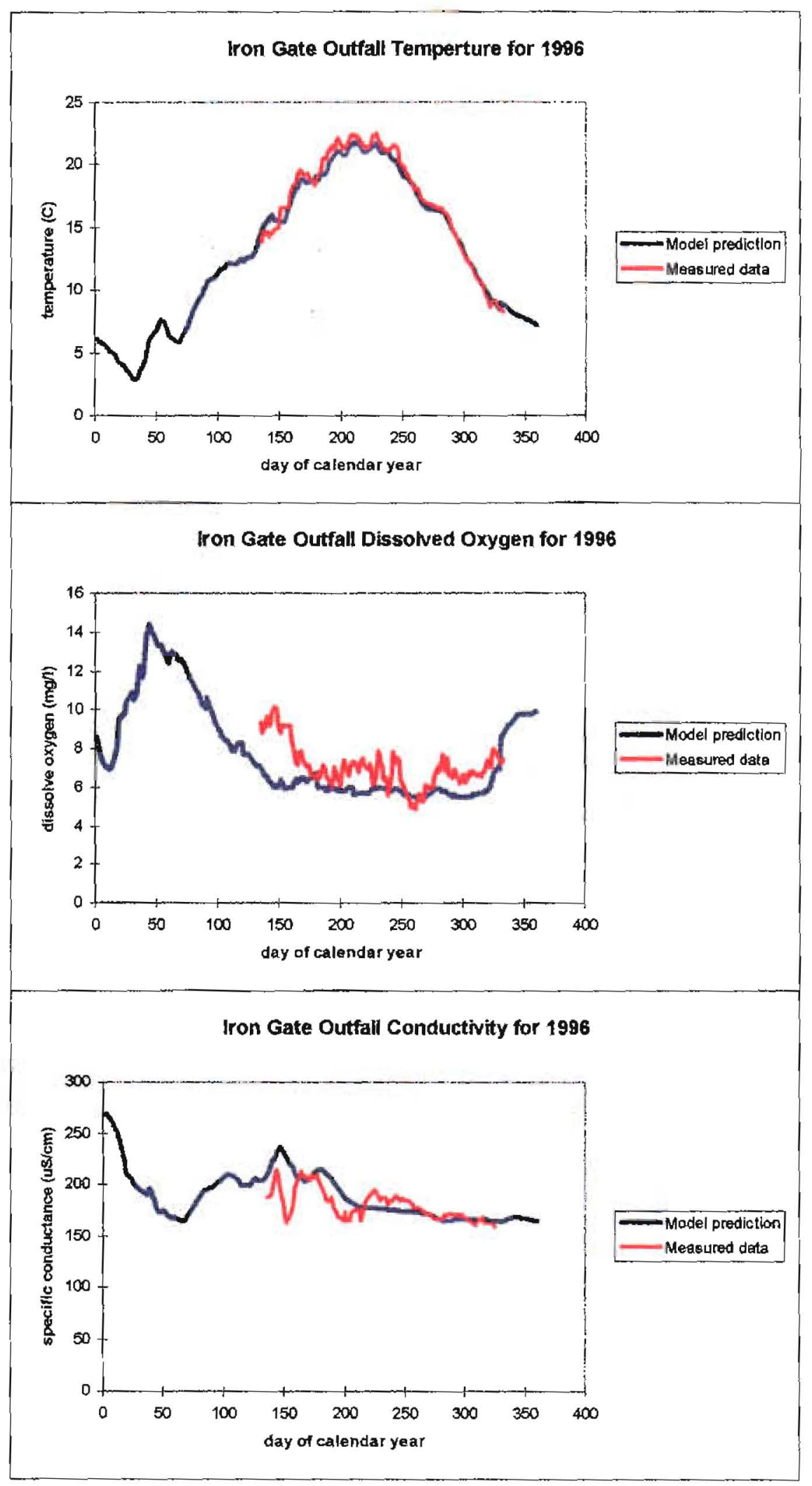




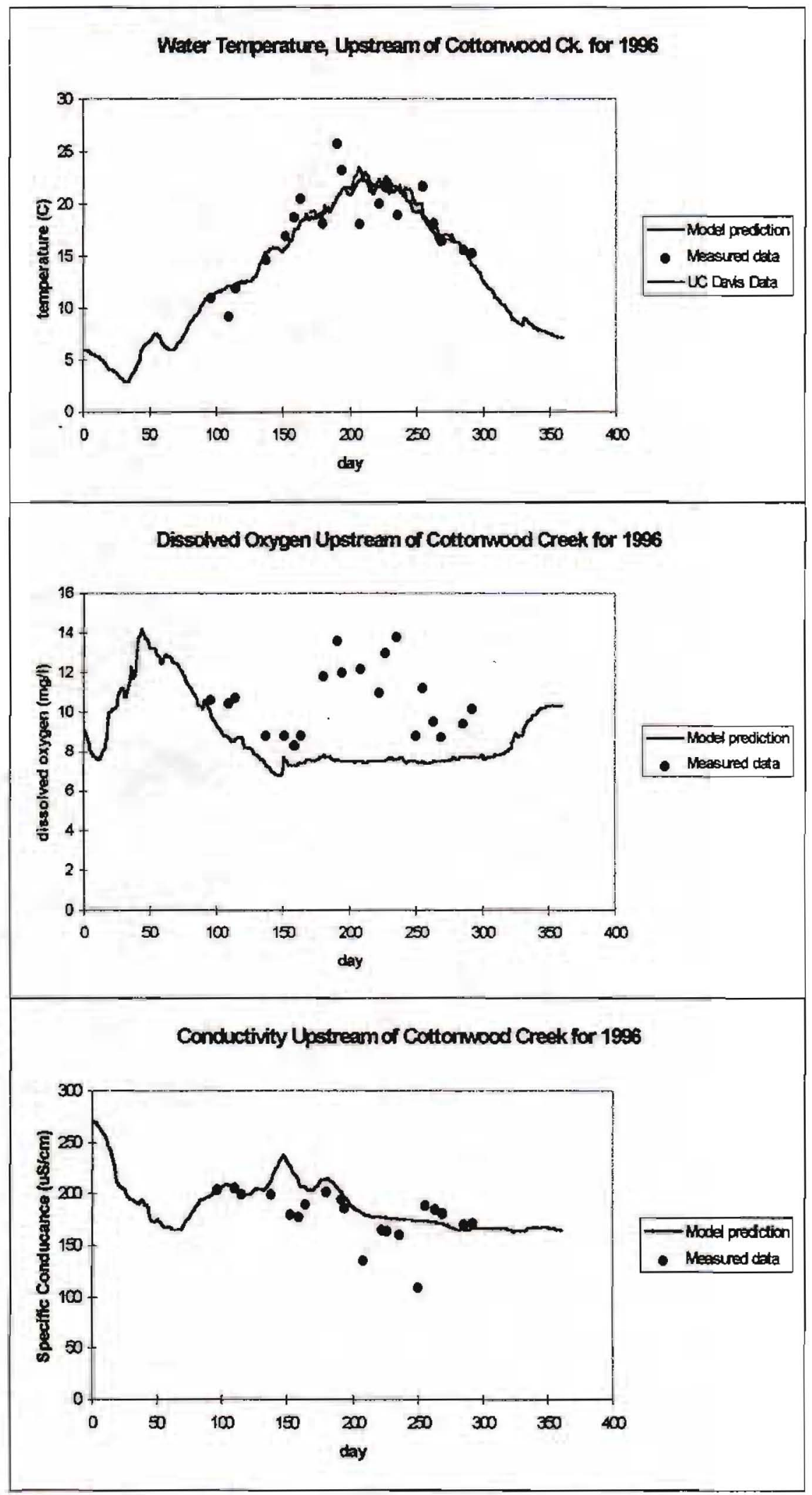




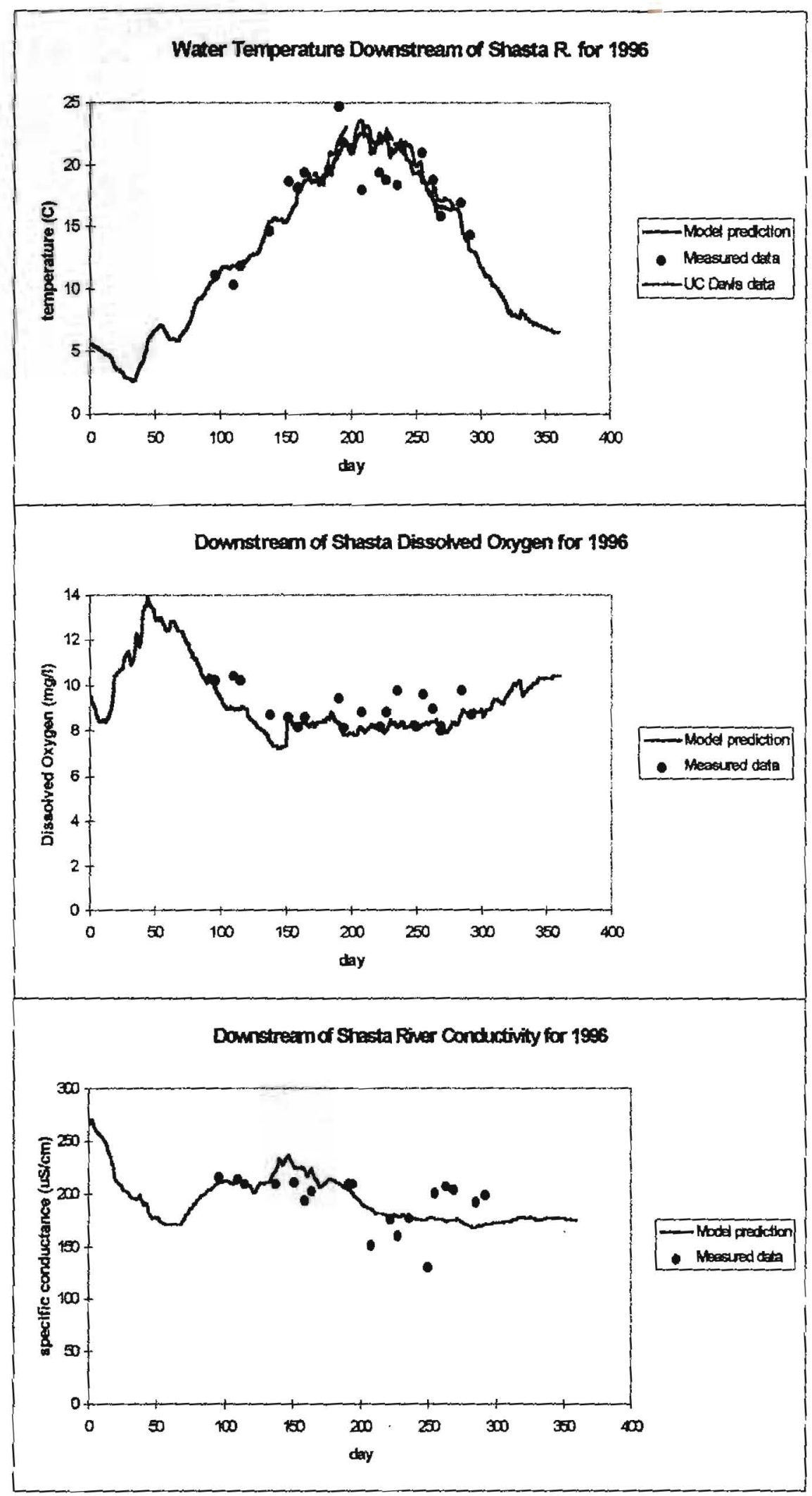




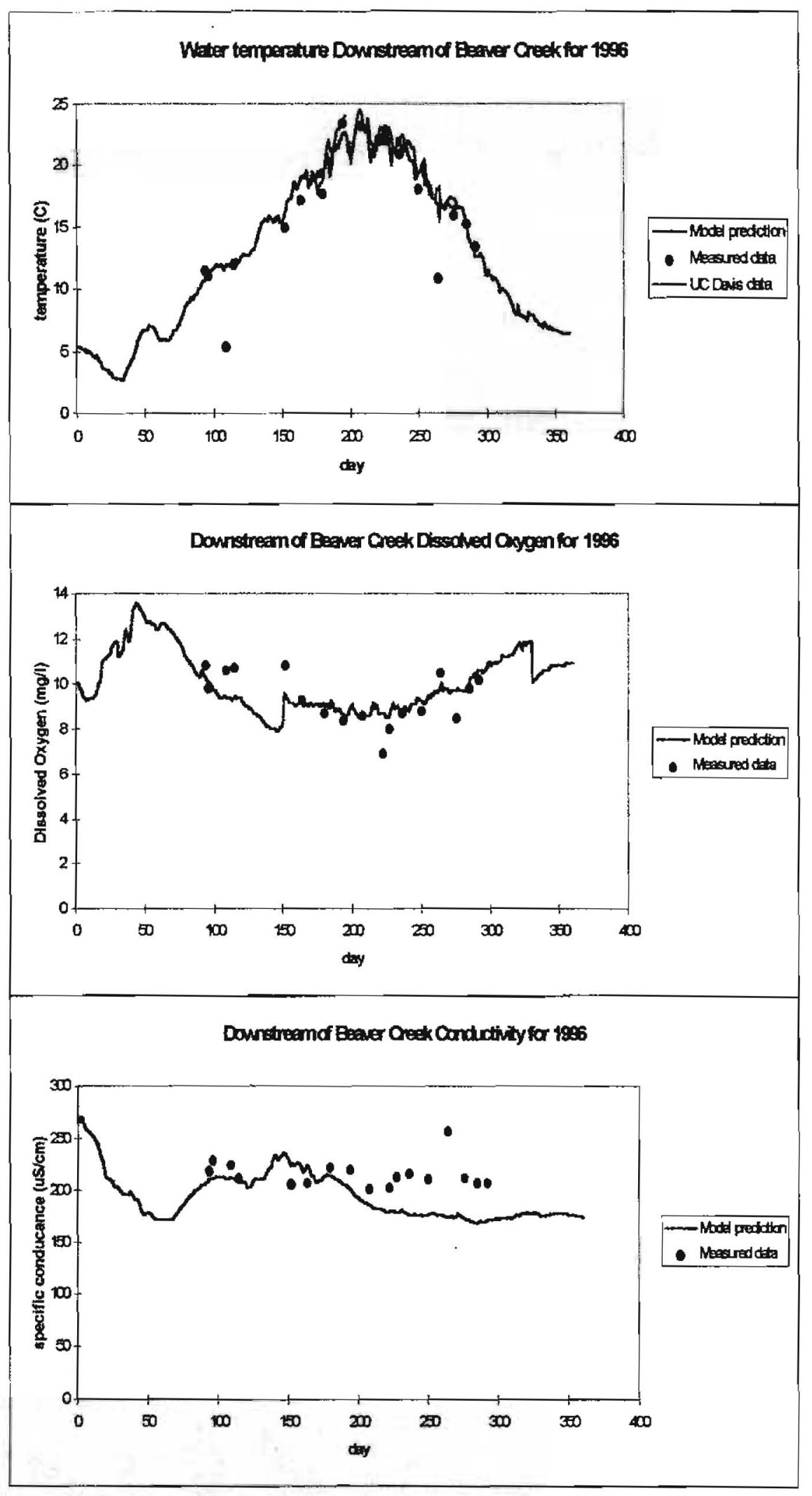




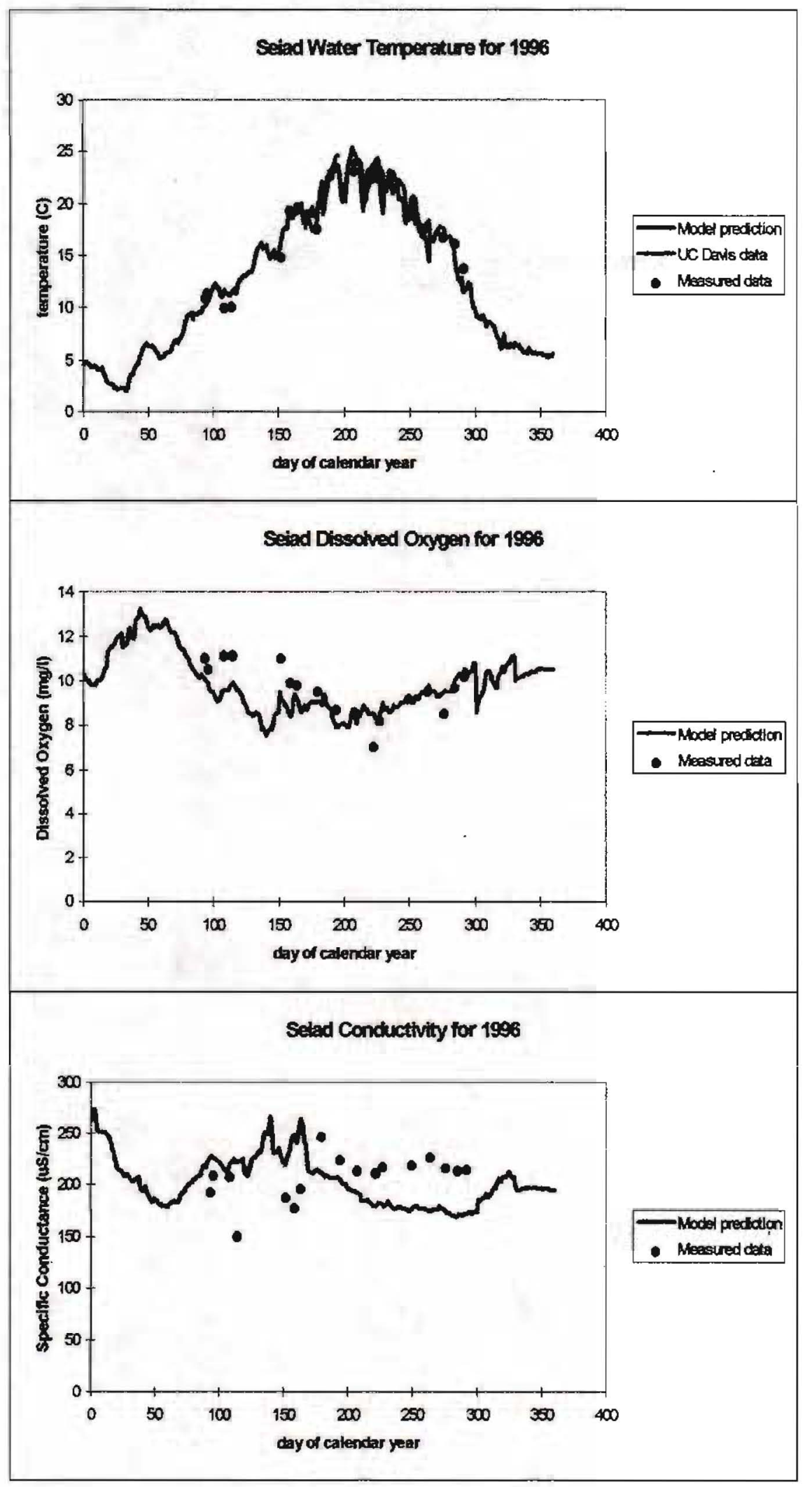


Appendix II

Water Year 1997 Validation Plots

Table 1. Date and day of simulation for water years and calendar years, using 30-day months.

\begin{tabular}{|c|c|c|}
\hline Date & Day of Water Year & Day of Calendar Year \\
\hline October 1 & 1 & 271 \\
\hline November 1 & 31 & 301 \\
\hline December 1 & 61 & 331 \\
\hline January 1 & 91 & 1 \\
\hline February 1 & 121 & 31 \\
\hline March 1 & 151 & 61 \\
\hline April 1 & 181 & 91 \\
\hline May 1 & 211 & 121 \\
\hline June 1 & 241 & 151 \\
\hline July 1 & 271 & 181 \\
\hline August 1 & 301 & 211 \\
\hline September 1 & 361 & 241 \\
\hline
\end{tabular}

Input Flow Data
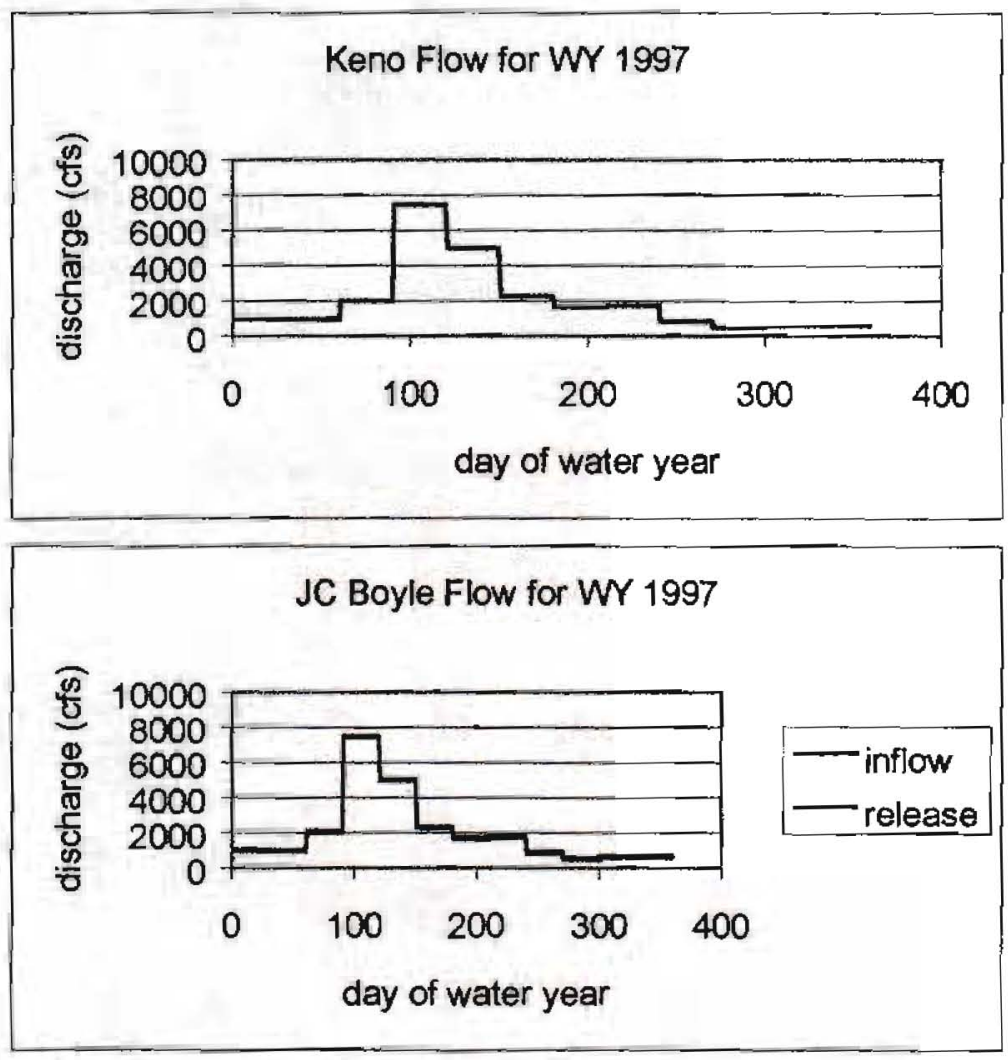

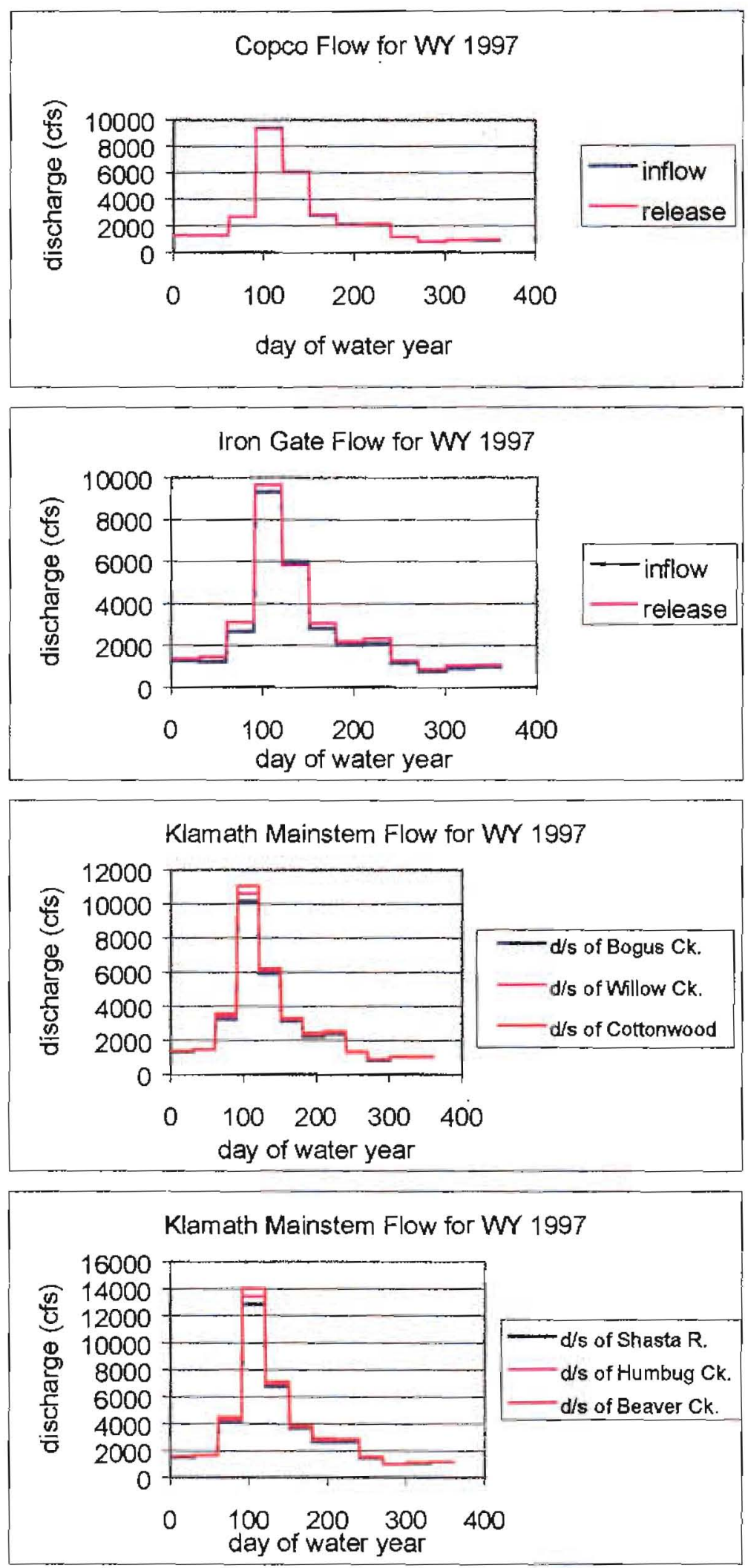


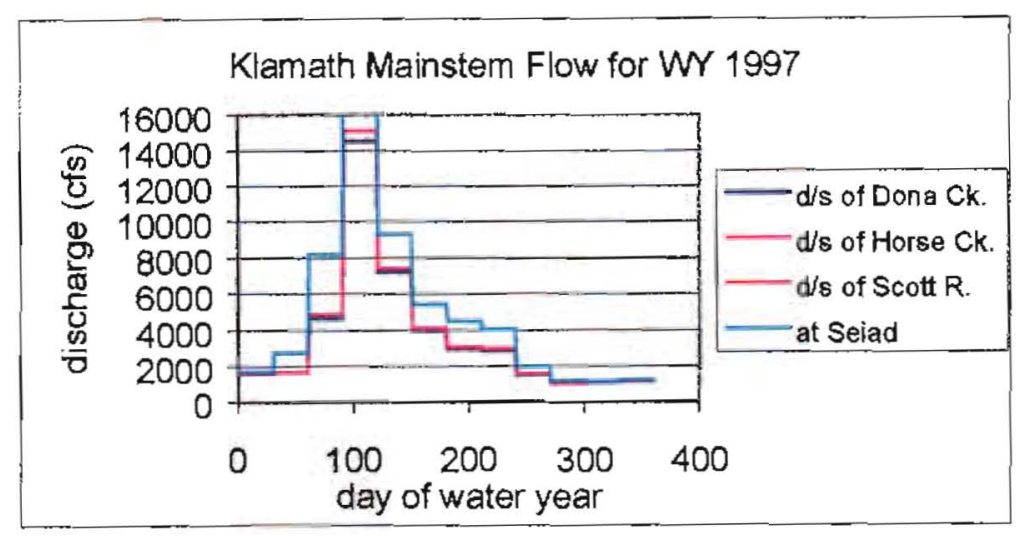


Input Meteorological Conditions
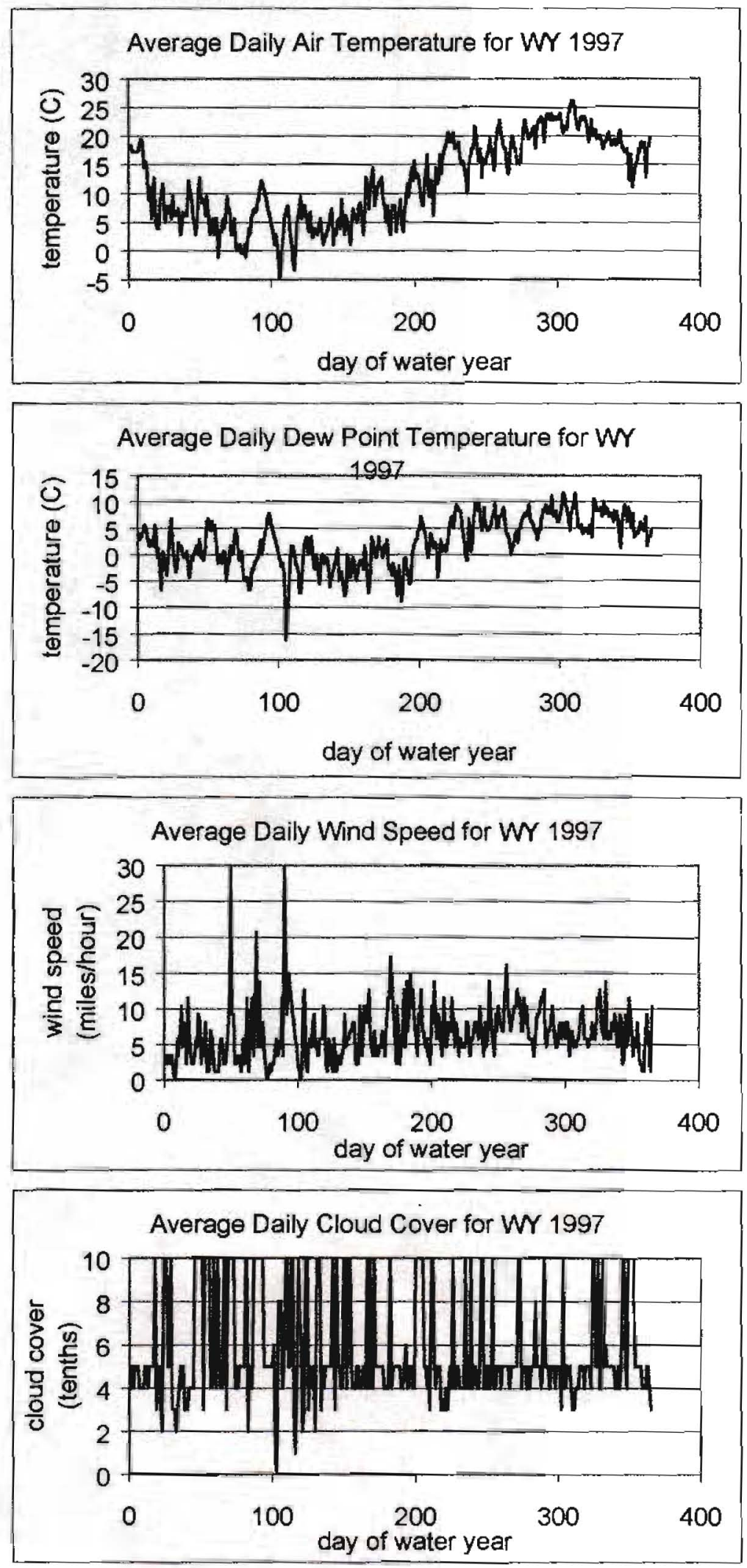
Input Water Quality Data
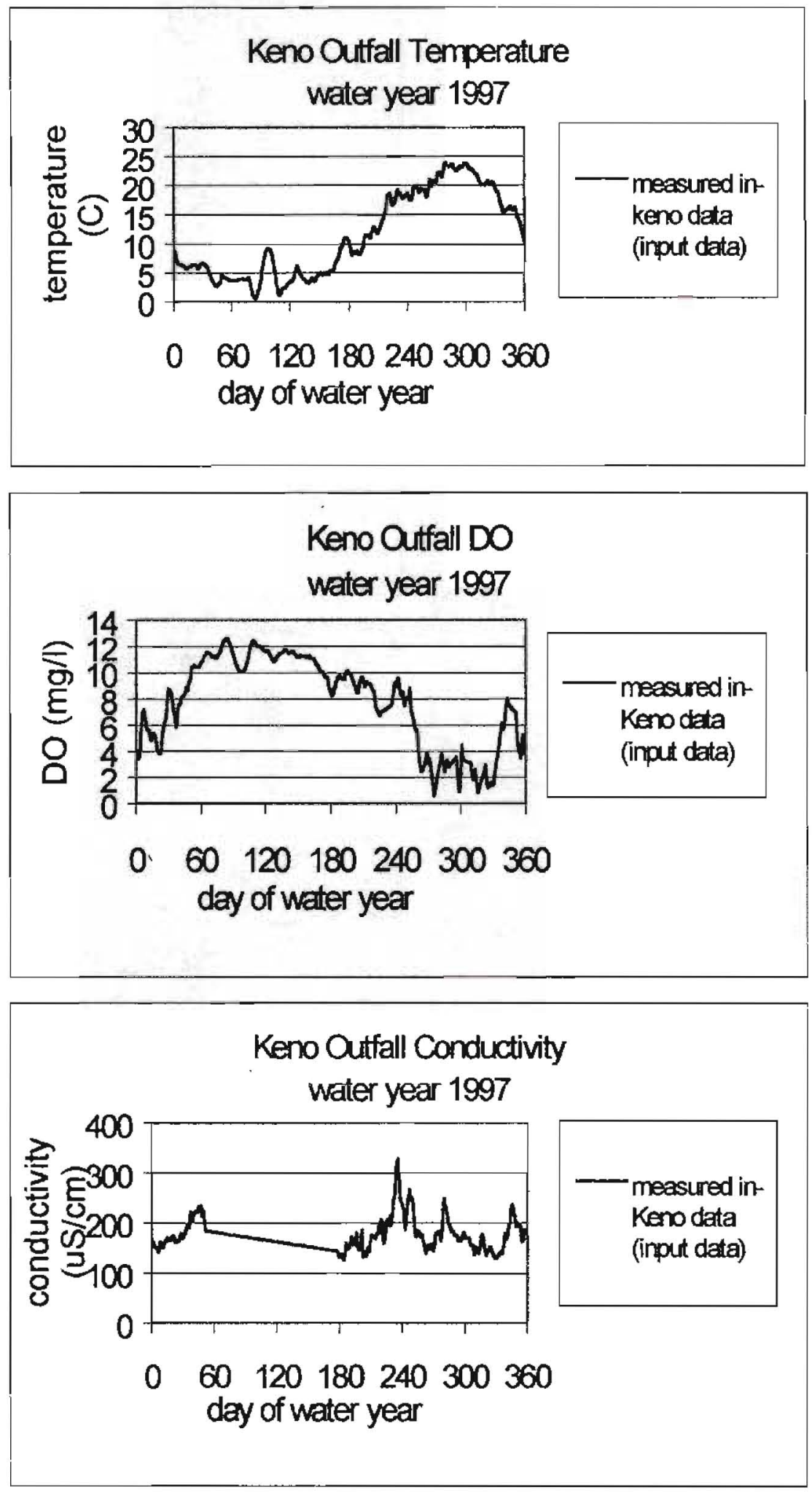

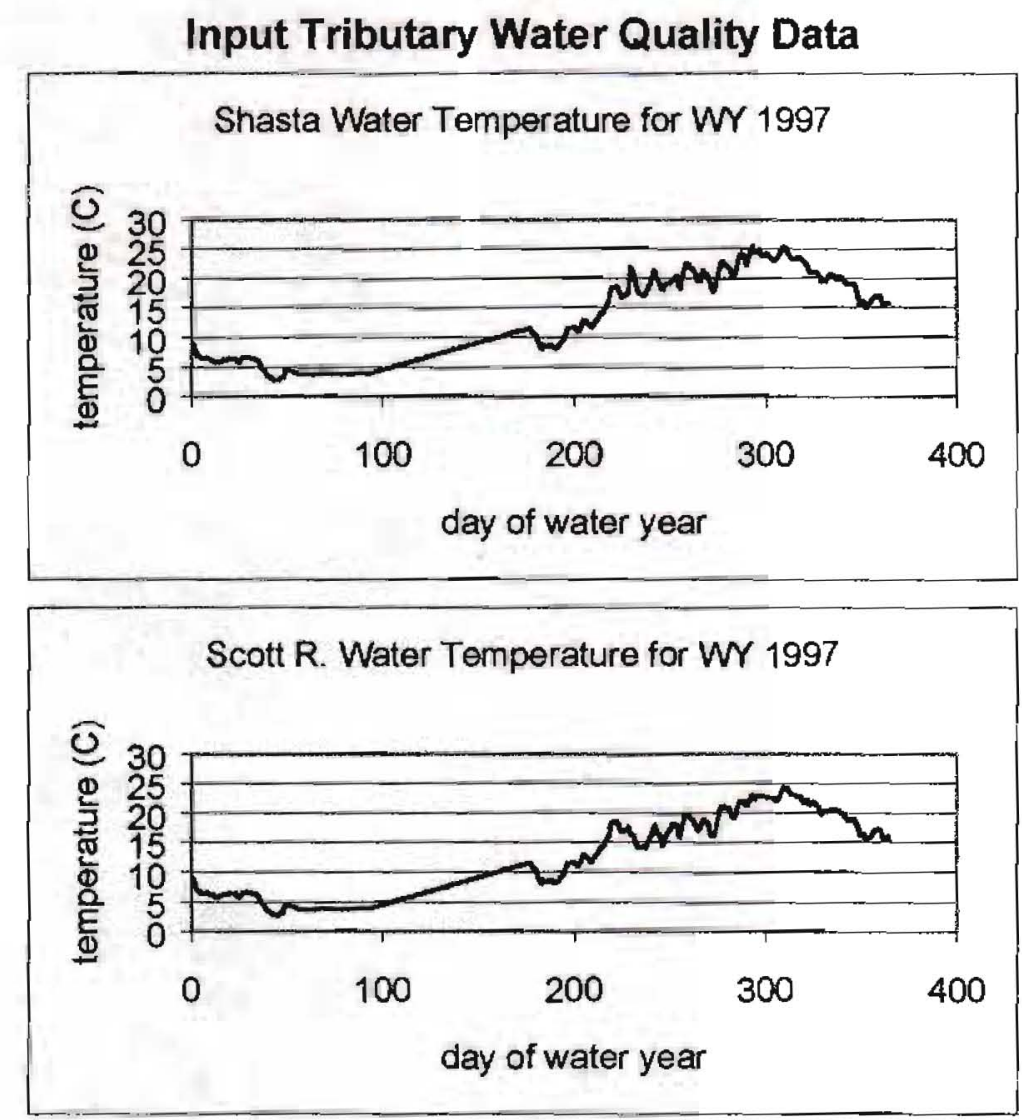


\section{Comparison of Model Output With Measured Data}
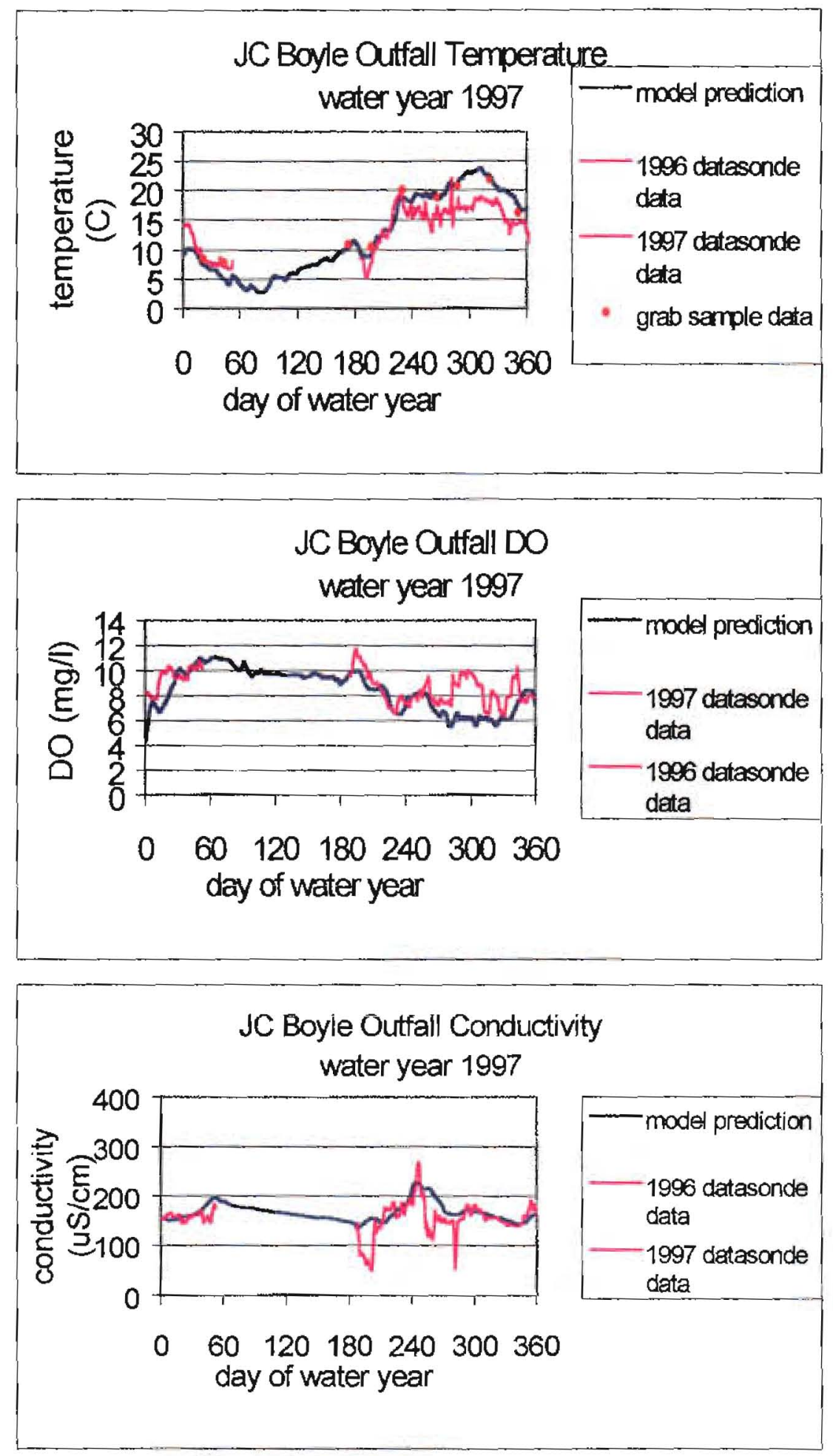

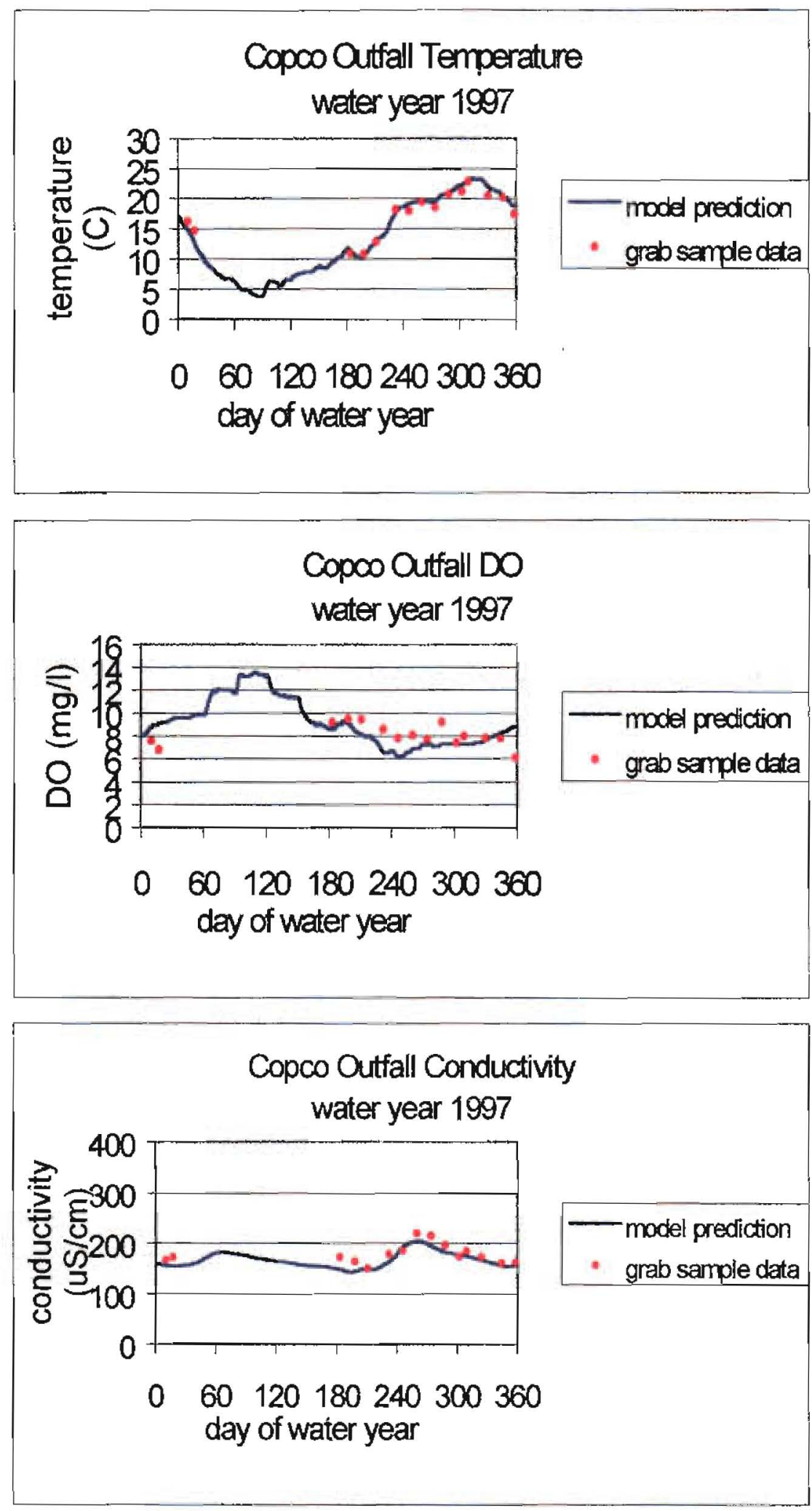

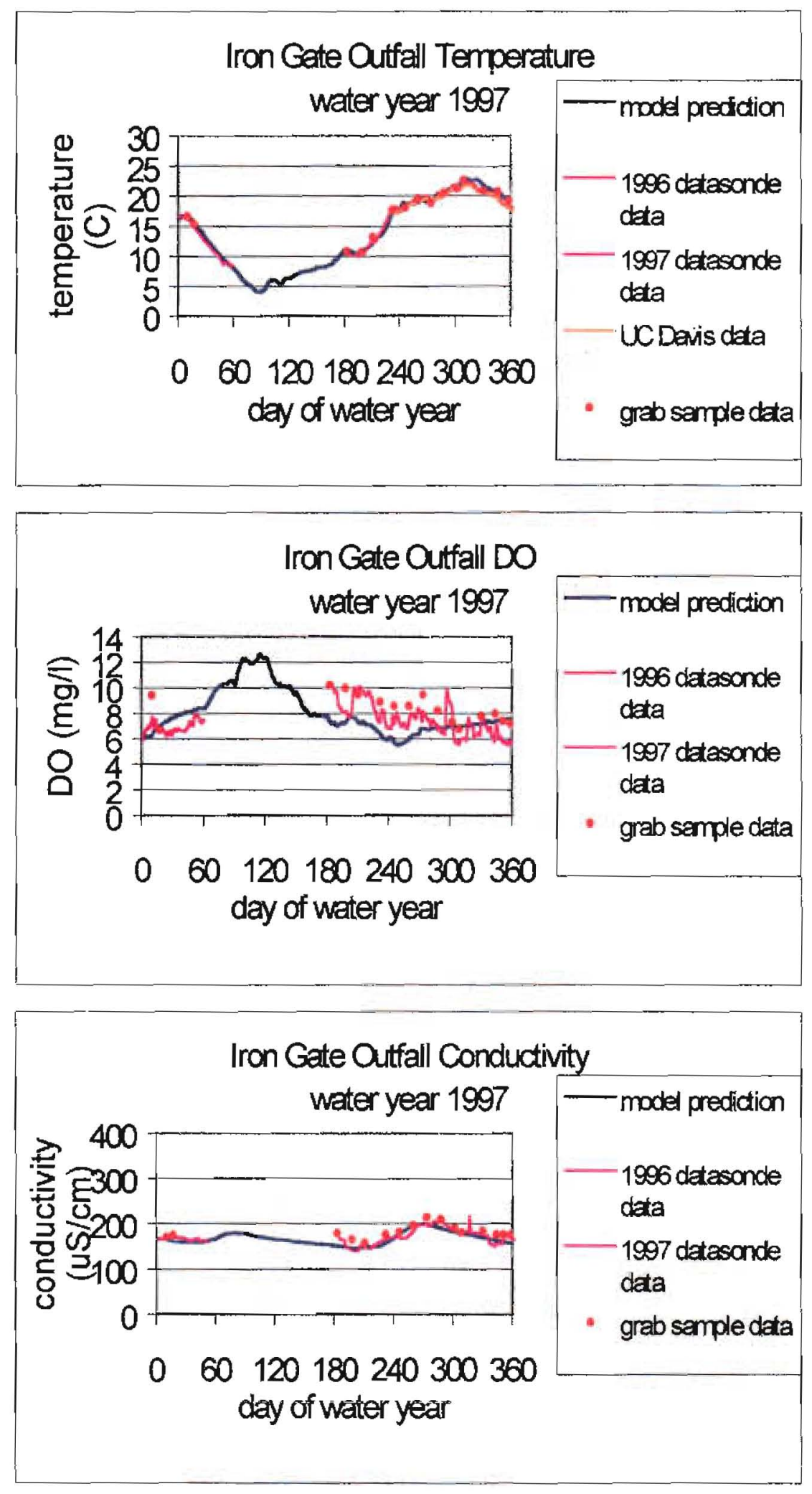

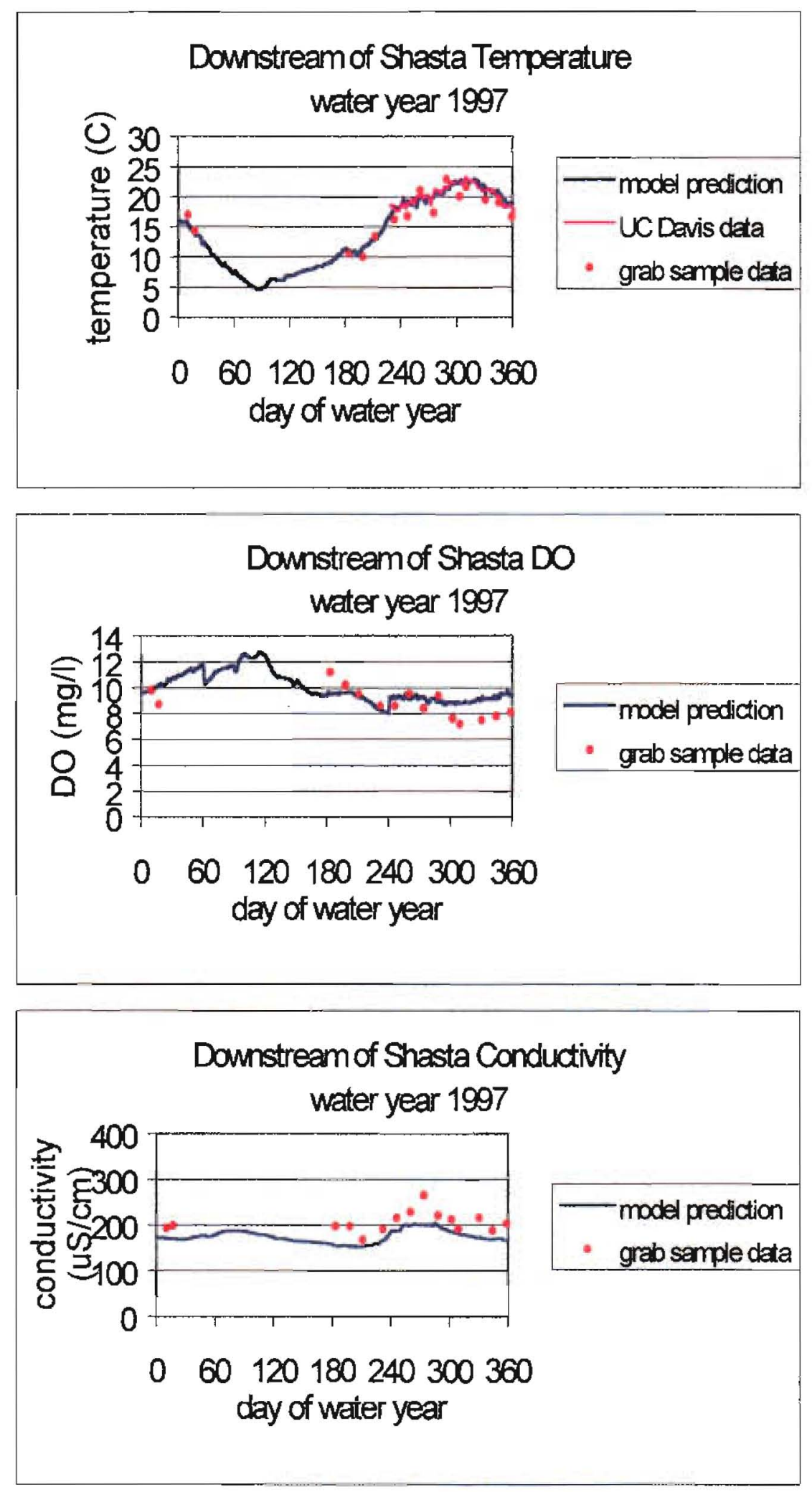

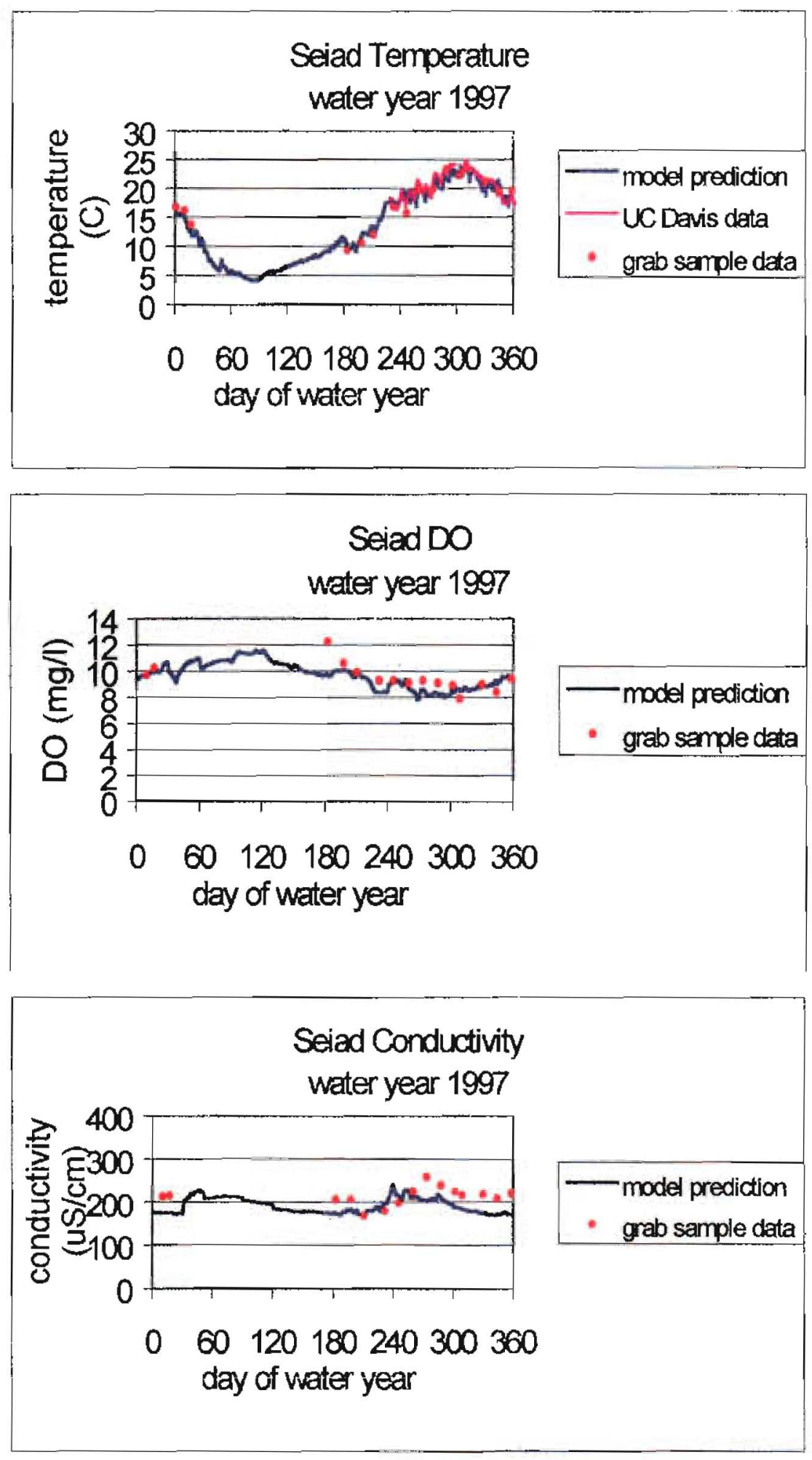

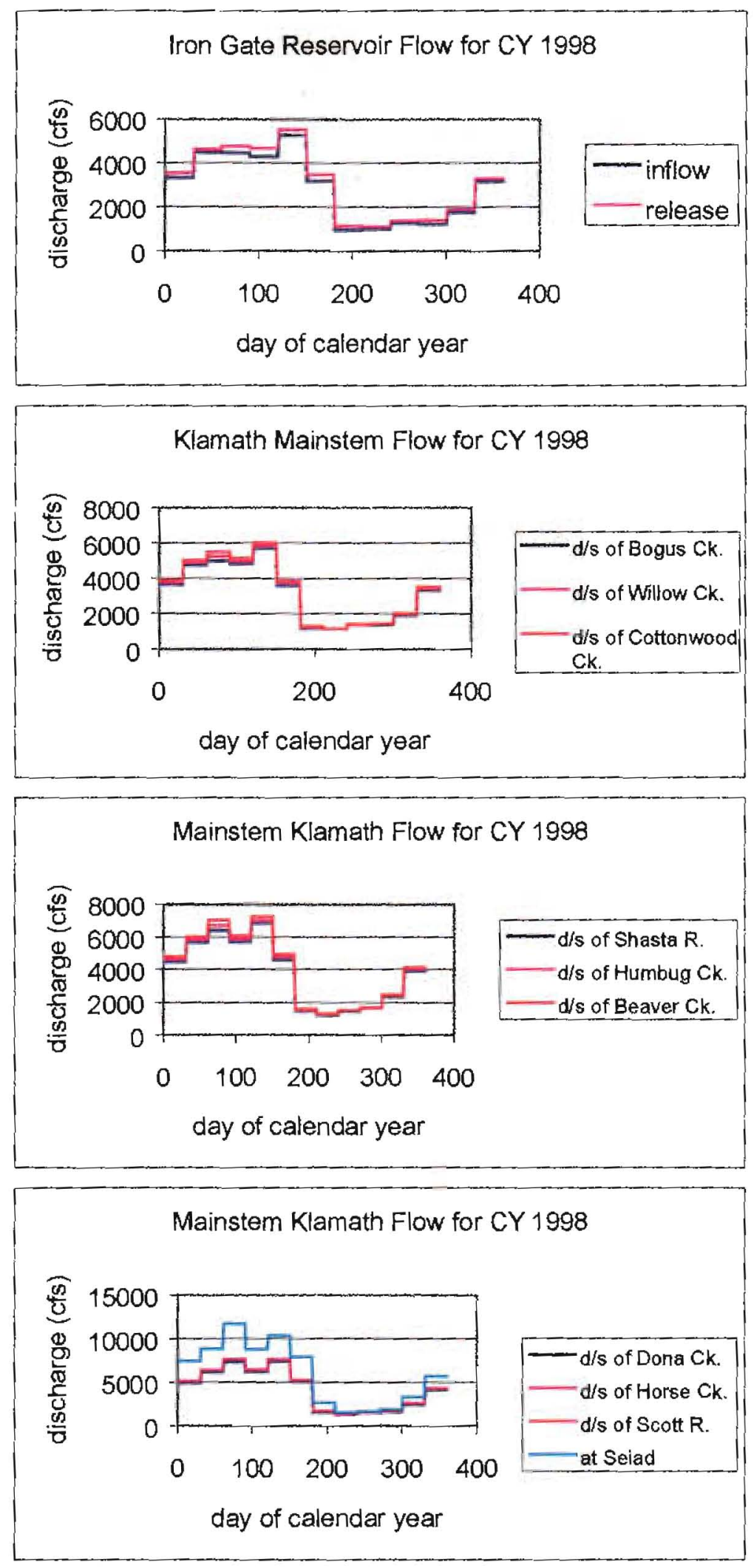
Input Meteorological Conditions
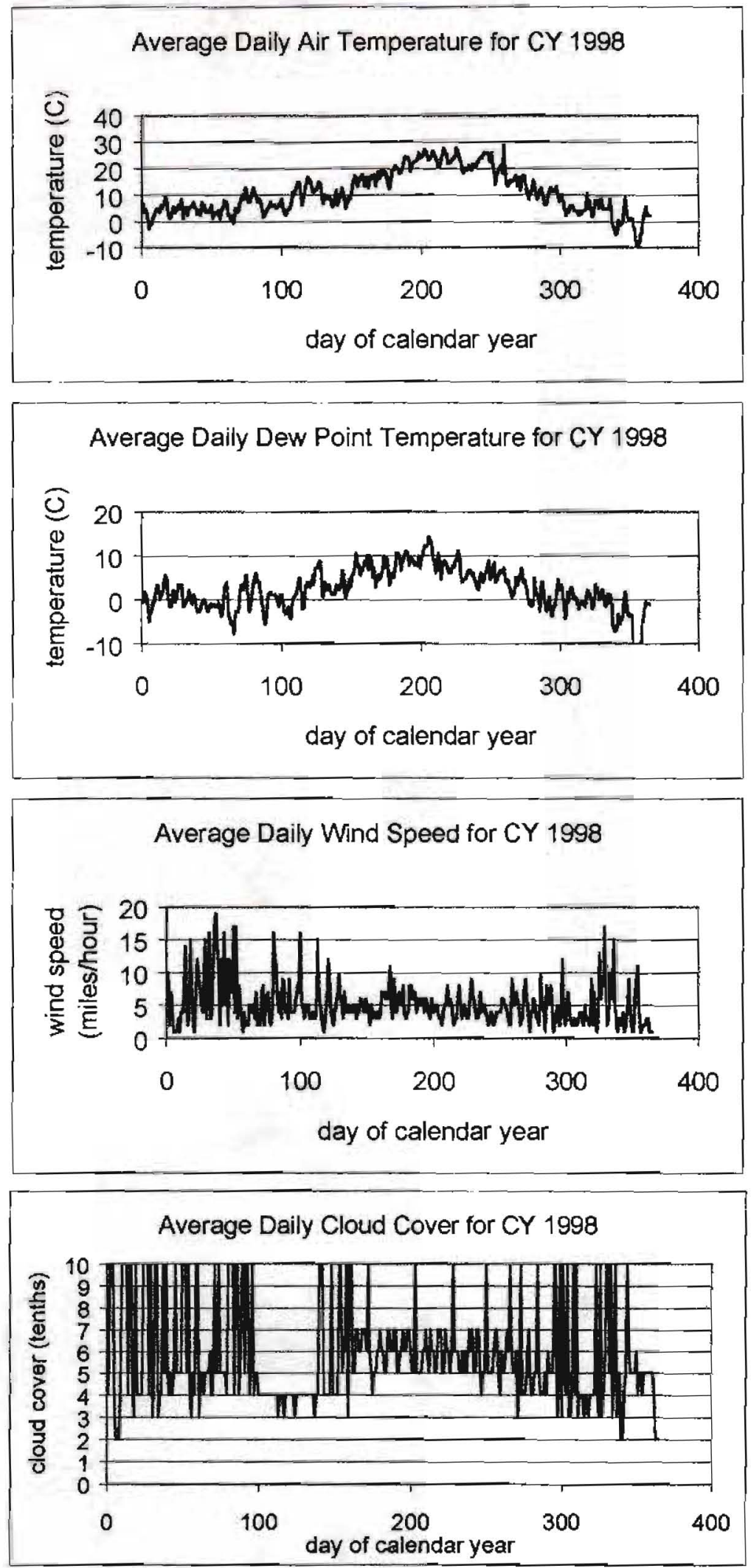
Input Water Quality Data
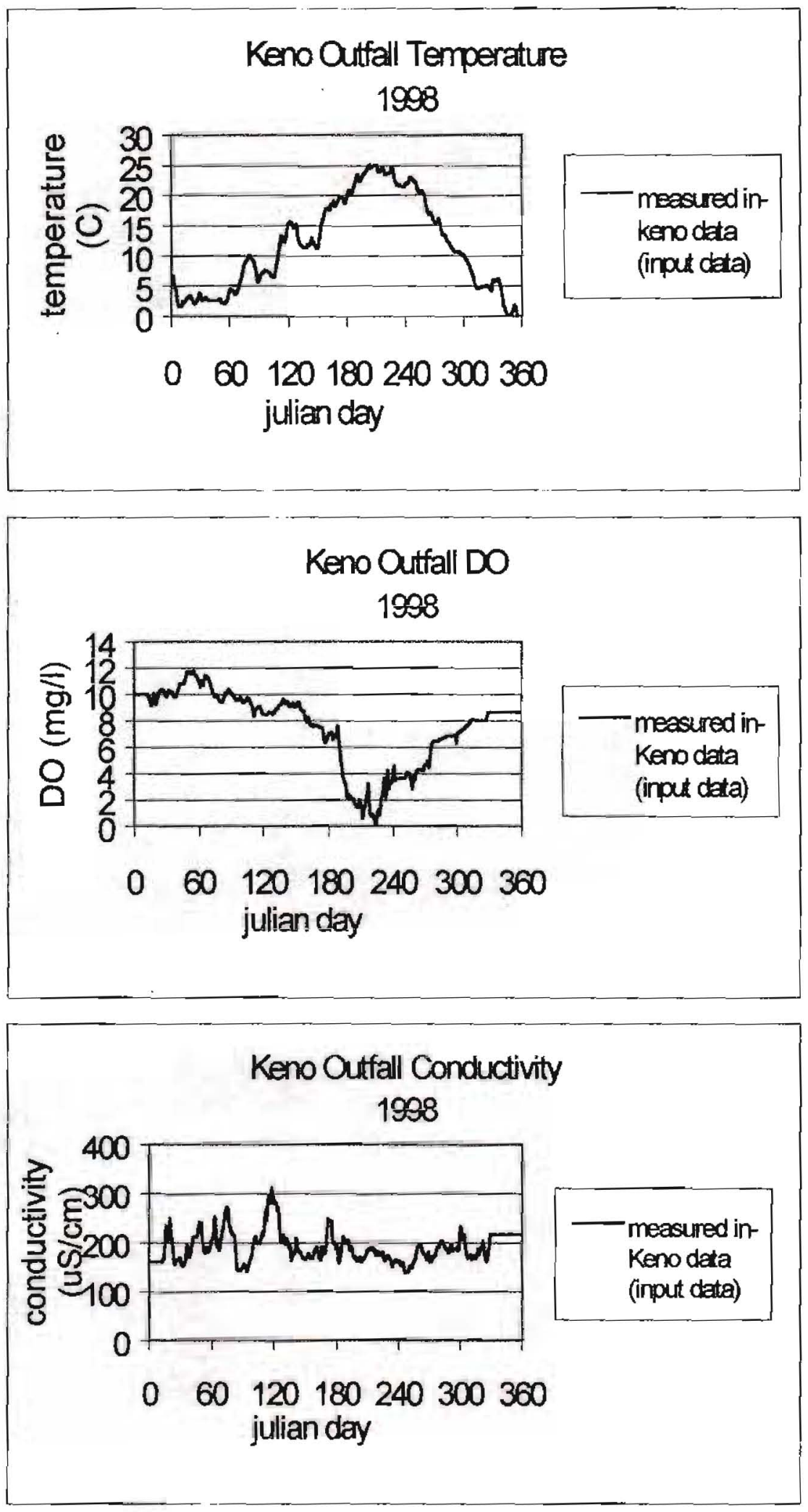
Input Shasta River Inflow Water Quality

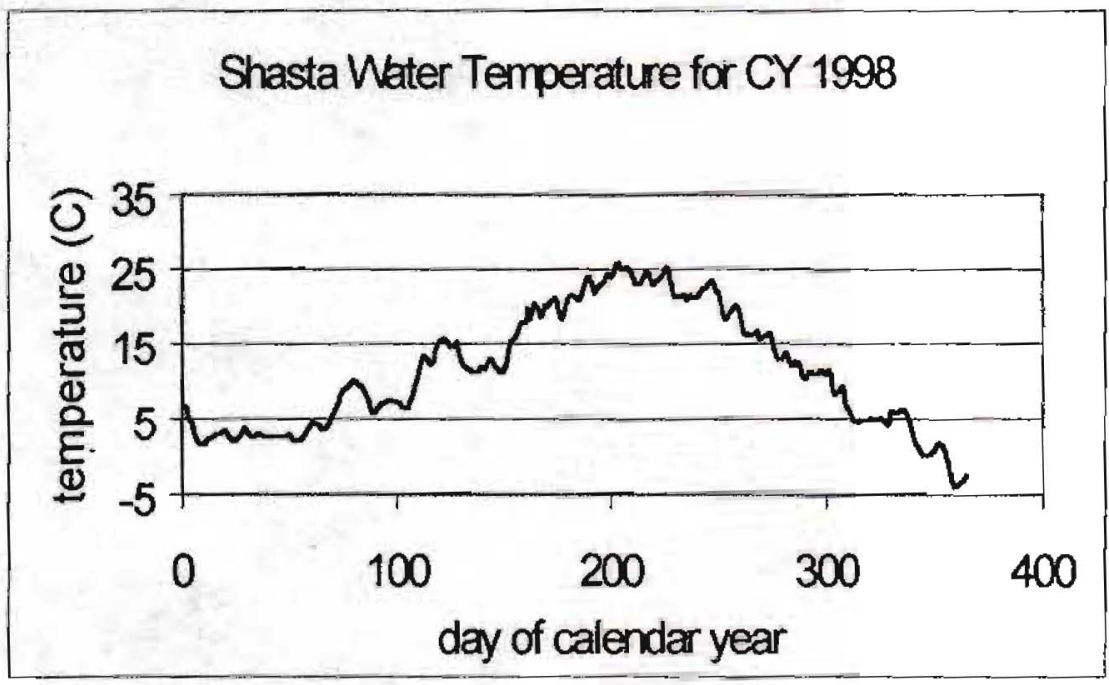

Shasta DO for CY 1998

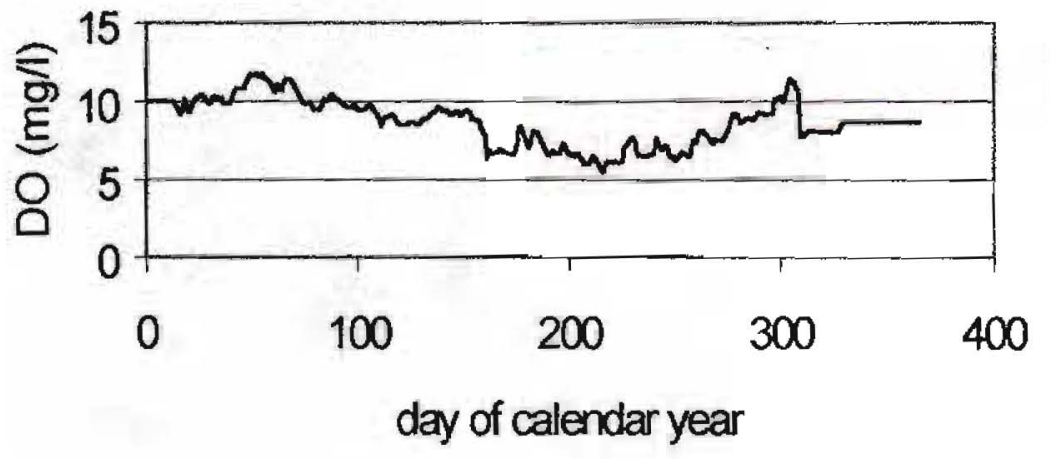

\section{Shasta Conductivity for CY 1998}

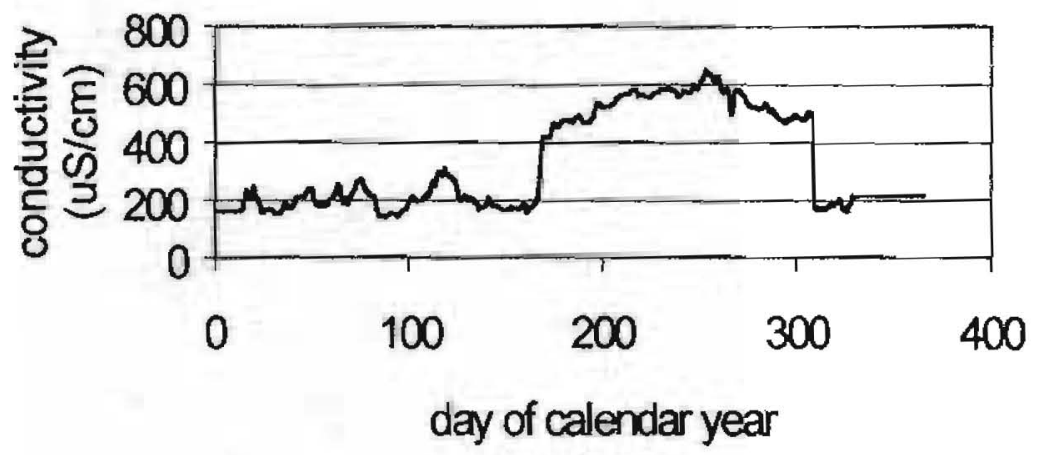


Input Scott River Inflow Water Quality
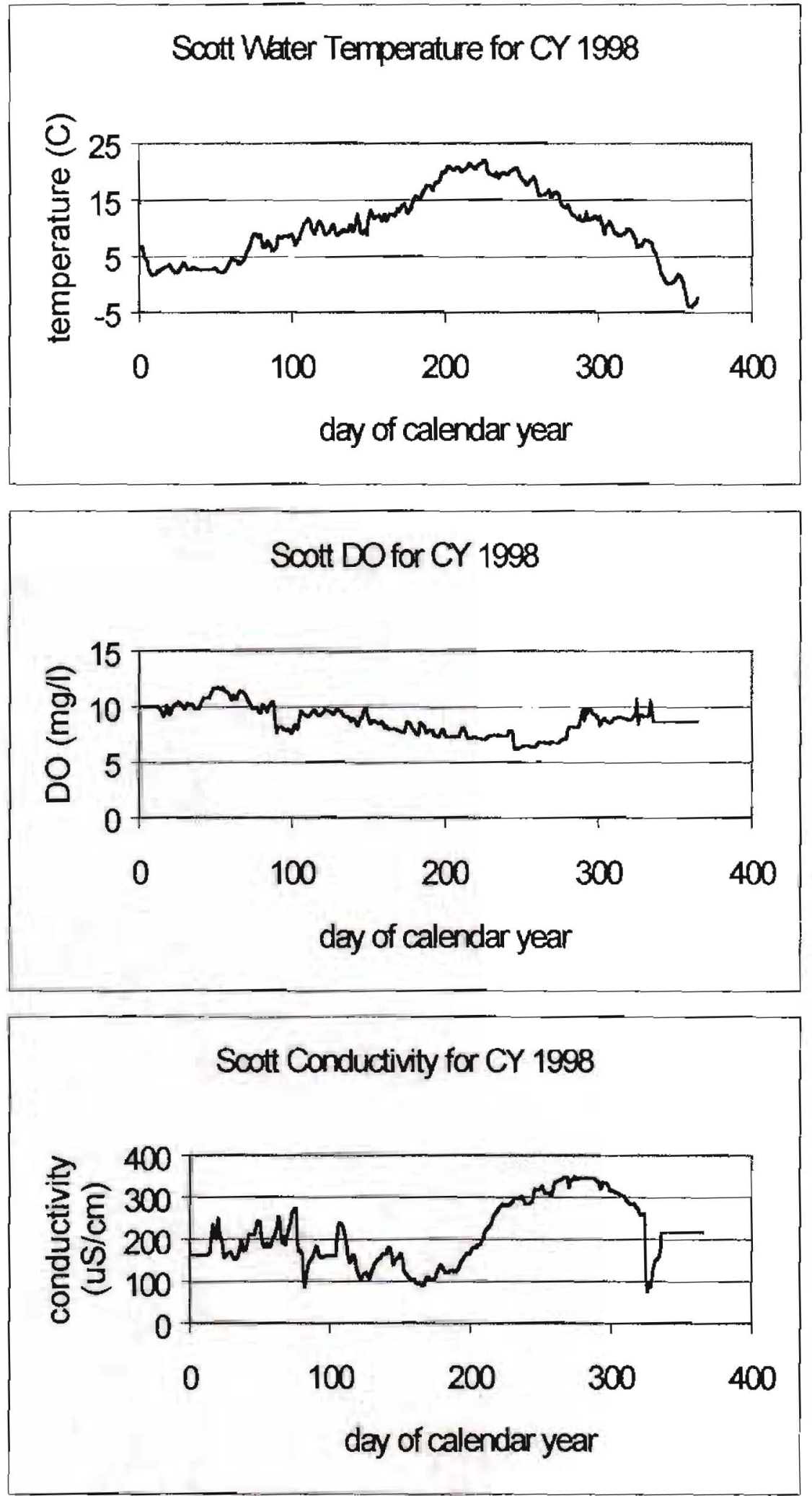
Comparison of Model Predictions With Measured Data
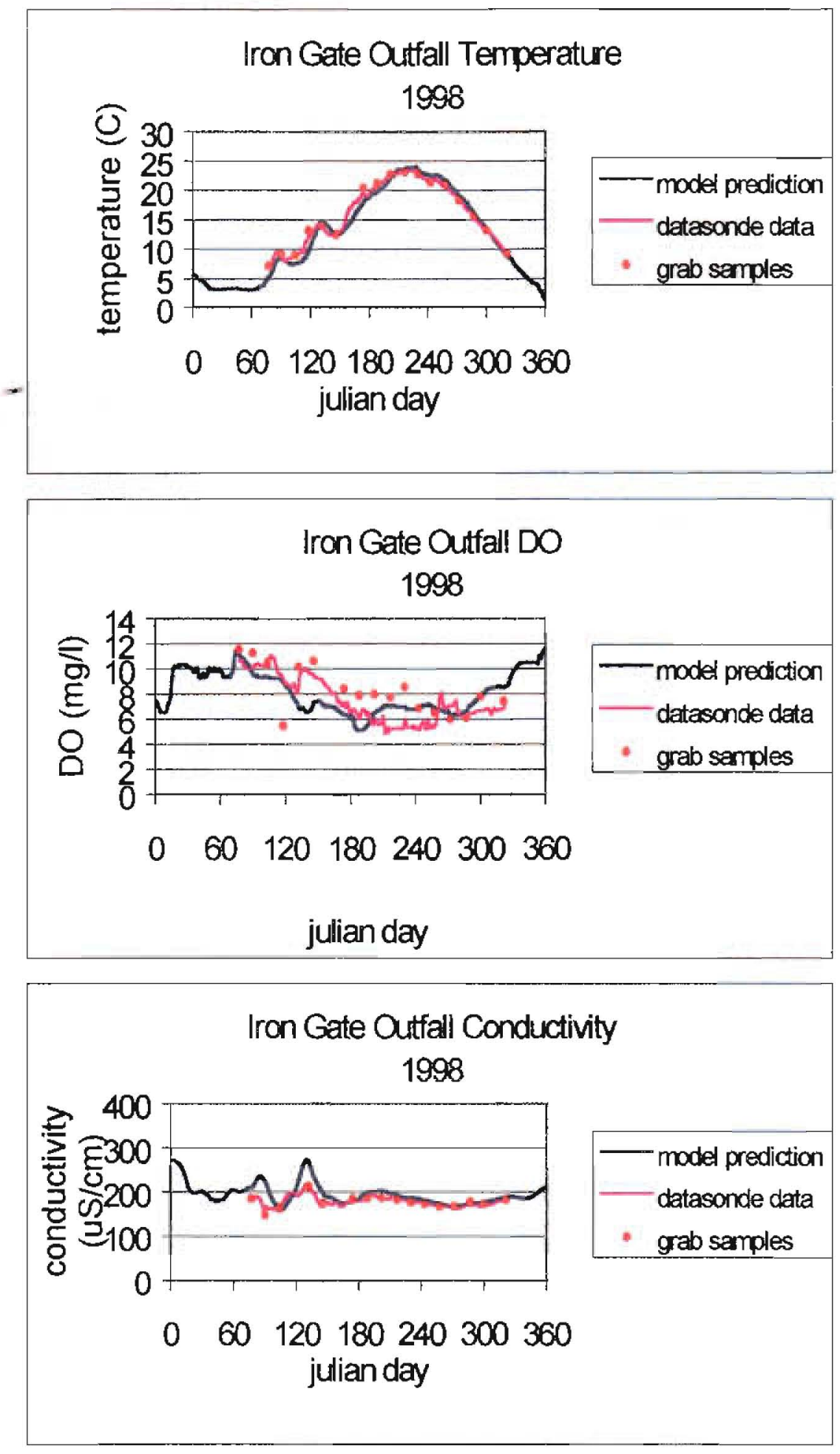

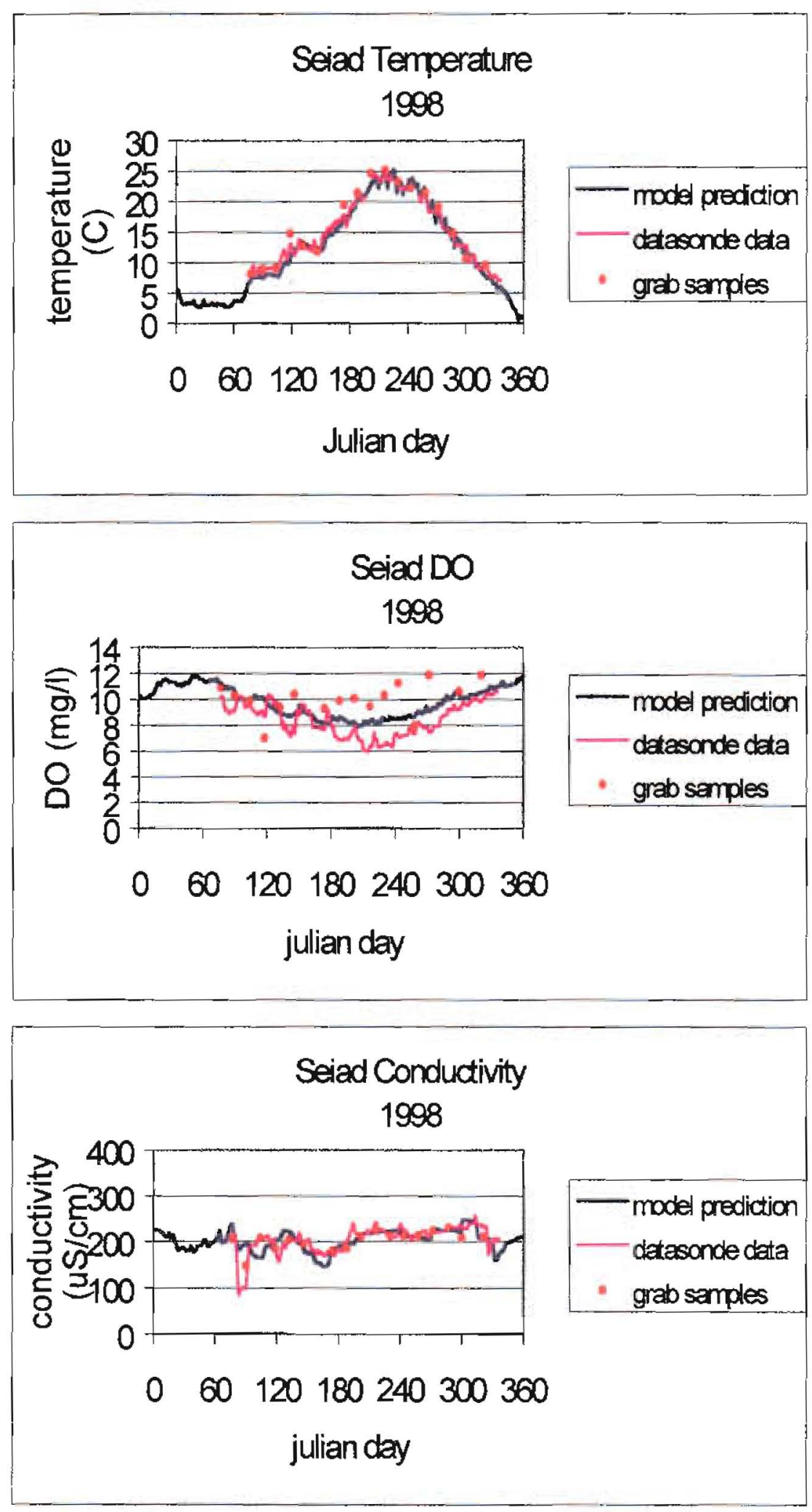
. 